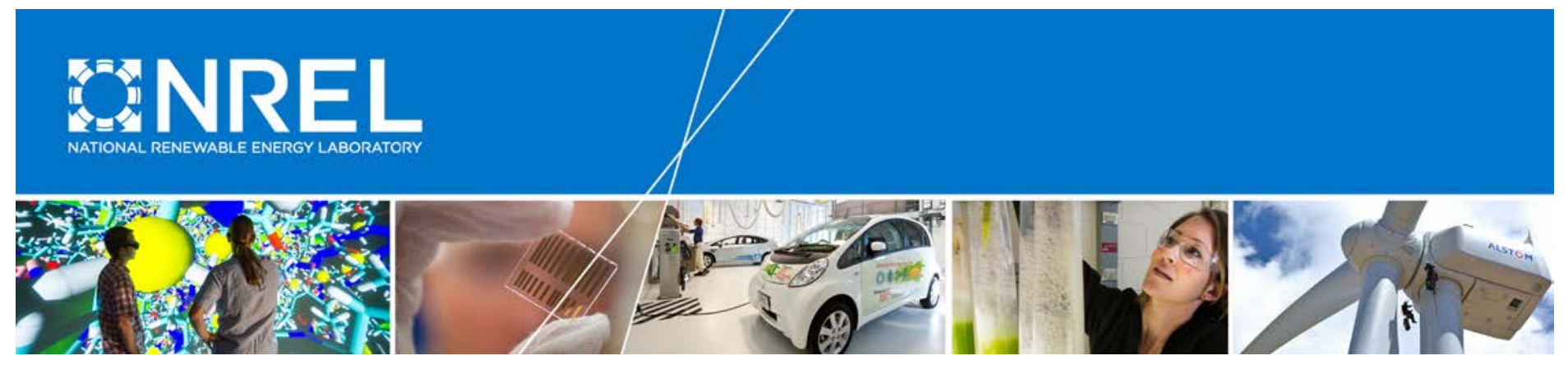

\title{
2017 Standard Scenarios Report: A U.S. Electricity Sector Outlook
}

Wesley Cole, Trieu Mai, James Richards, and Paritosh Das

National Renewable Energy Laboratory

Paul Donohoo-Vallett

U.S. Department of Energy

NREL is a national laboratory of the U.S. Department of Energy Office of Energy Efficiency \& Renewable Energy Operated by the Alliance for Sustainable Energy, LLC

This report is available at no cost from the National Renewable Energy Laboratory (NREL) at www.nrel.gov/publications.

Technical Report

NREL/TP-6A20-68548

October 2017

Contract No. DE-AC36-08G028308 


\section{Standard Scenarios Report: A U.S. Electricity Sector Outlook}

Wesley Cole, Trieu Mai, James Richards, and Paritosh Das

National Renewable Energy Laboratory

Paul Donohoo-Vallett

U.S. Department of Energy

Prepared under Task No. OOSP.10291.17.02.27

NREL is a national laboratory of the U.S. Department of Energy Office of Energy Efficiency \& Renewable Energy Operated by the Alliance for Sustainable Energy, LLC

This report is available at no cost from the National Renewable Energy Laboratory (NREL) at www.nrel.gov/publications.

National Renewable Energy Laboratory 15013 Denver West Parkway Golden, CO 80401

303-275-3000 • www.nrel.gov

\section{Technical Report}

NREL/TP-6A20-68548

October 2017

Contract No. DE-AC36-08GO28308 


\section{NOTICE}

This report was prepared as an account of work sponsored by an agency of the United States government. Neither the United States government nor any agency thereof, nor any of their employees, makes any warranty, express or implied, or assumes any legal liability or responsibility for the accuracy, completeness, or usefulness of any information, apparatus, product, or process disclosed, or represents that its use would not infringe privately owned rights. Reference herein to any specific commercial product, process, or service by trade name, trademark, manufacturer, or otherwise does not necessarily constitute or imply its endorsement, recommendation, or favoring by the United States government or any agency thereof. The views and opinions of authors expressed herein do not necessarily state or reflect those of the United States government or any agency thereof.

This report is available at no cost from the National Renewable Energy Laboratory (NREL) at www.nrel.gov/publications.

Available electronically at SciTech Connect http:/www.osti.gov/scitech

Available for a processing fee to U.S. Department of Energy and its contractors, in paper, from:

U.S. Department of Energy

Office of Scientific and Technical Information

P.O. Box 62

Oak Ridge, TN 37831-0062

OSTI http://www.osti.gov

Phone: 865.576.8401

Fax: 865.576.5728

Email: reports@osti.gov

Available for sale to the public, in paper, from:

U.S. Department of Commerce

National Technical Information Service

5301 Shawnee Road

Alexandria, VA 22312

NTIS http://www.ntis.gov

Phone: 800.553 .6847 or 703.605 .6000

Fax: 703.605.6900

Email: orders@ntis.gov 


\section{Preface}

This report is one of a suite of National Renewable Energy Laboratory (NREL) products aiming to (1) provide a consistent and timely set of technology cost and performance data and (2) define a scenario framework that can be used in forward-looking electricity analyses by NREL and others. The long-term objective of this effort is to identify a range of possible futures for the U.S. electricity sector that illuminate specific energy system issues by (1) defining a set of prospective scenarios that bound ranges of technology, market, and policy assumptions and (2) assessing these scenarios in NREL's market models to understand the range of resulting outcomes, including energy technology deployment and production, energy prices, and emissions.

This effort, supported by the U.S. Department of Energy's (DOE) Office of Energy Efficiency and Renewable Energy (EERE) focuses on the electric sector by creating a technology cost and performance database, defining scenarios, documenting associated assumptions, and generating results using NREL's Regional Energy Deployment System (ReEDS) and dGen models. The work leverages significant activity already funded by EERE to better understand individual technologies, their roles in the larger energy system, and other market and policy issues that can impact the evolution of the electricity sector.

Specific products from this effort include:

- An Annual Technology Baseline (ATB) workbook documenting detailed cost and performance data (both current and projected) for both renewable and conventional technologies

- An ATB summary website describing each of the technologies and providing additional context for their treatment in the workbook

- This 2017 Standard Scenarios report describing U.S. power sector futures using the Standard Scenarios modeling results.

These products can be accessed at https://www.nrel.gov/analysis/data-tech-baseline.html.

NREL intends to consistently apply these products in its ongoing electric sector scenarios analyses to ensure that the analyses incorporate a transparent, realistic, and timely set of input assumptions and that they consider a diverse set of potential futures. The application of standard scenarios, clear documentation of underlying assumptions, and model versioning is expected to result in:

- Improved transparency of modeling input assumptions and methodologies

- Improved comparability of results across studies

- Improved consideration of the potential economic and environmental impacts of various electric sector futures

- An enhanced framework for formulating and addressing new analysis questions.

Future analyses under this family of work are expected to build on the assumptions used here and provide increasingly sophisticated views of the future U.S. power system with the potential to expand to other sectors of the U.S. energy economy. 


\section{Acknowledgments}

We gratefully acknowledge the many people whose efforts contributed to this report. The ReEDS and dGen modeling and analysis teams, including David Bielen, Max Brown, Stuart Cohen, Kelly Eurek, Bethany Frew, Pieter Gagnon, Jonathan Ho, Kevin McCabe, Matthew Mowers, Ben Sigrin, and Yinong Sun, were active in participating in the model development and analysis leading to this work. We also thank Billy Roberts for creating the maps used in this work. Numerous NREL colleagues reviewed and improved this report, including Doug Arent, Eric Lantz, Jeff Logan, David Mooney, Robin Newmark, Gian Porro, Mark Ruth, and Daniel Steinberg. We are grateful to Paul Basore (DOE), John Bistline (EPRI), Steve Capanna (DOE), Cara Marcy (EIA), Chris Namovicz (EIA), Cristian Rabiti (INL), and Rich Tusing (Allegheny Science and Technology and Senior Advisor to the DOE Wind Energy Technology Office) for providing feedback on this work. This report was funded by the EERE Office of Strategic Programs under contract number DE-AC36-08GO28308. All errors and omissions are the sole responsibility of the authors. 


\section{List of Acronyms}

$\mathrm{AC}$

AEO

ATB

CAES

CAPEX

$\mathrm{CC}$

CSP

CPP

CT

DC

dGen

DOE

DPV

DUPV

EIA

EIPC

GW

ITC

LCOE

MMBtu

MW

MWh

NG

NEI

NREL

OGS

PEV

PHEV

PPA

PTC

PV

RE

ReEDS

RPS

TPO

TRG

TWh

UPV

VRE

WACC alternating current

Annual Energy Outlook

Annual Technology Baseline

compressed air energy storage

capital expenditure

combined cycle

concentrating solar power

Clean Power Plan

combustion turbine

direct current

Distributed Generation model

Department of Energy

distributed PV

distributed utility PV

Energy Information Administration

Eastern Interconnection Planning Collaborative

gigawatt-hour

investment tax credit

levelized cost of energy

million British thermal units

megawatt

megawatt-hour

natural gas

Nuclear Energy Institute

National Renewable Energy Laboratory

oil-gas-steam

plug-in electric vehicle

plug-in hybrid electric vehicle

power purchase agreement

production tax credit

photovoltaic(s)

renewable energy

Regional Energy Deployment System

renewable portfolio standard

third-party owned

techno-resource group

terawatt-hour

utility PV

variable renewable energy

weighted average cost of capital 


\section{Executive Summary}

This report summarizes the results of 26 forward-looking Standard Scenarios of the U.S. power sector simulated using the Regional Energy Deployment System (ReEDS) and Distributed Generation (dGen) capacity expansion models. The annual Standard Scenarios, which are now in their third year, have been designed to capture a range of possible power system futures considering a variety of factors that impact power sector evolution. The ReEDS and dGen models project utility- and distributed-scale power sector evolution, respectively, for the United States using the Standard Scenarios definitions to specify model inputs. Both models have been designed with special emphasis on capturing the unique traits of renewable energy, including variability and grid integration requirements. Detailed scenario results at the state level have been included as part of this report at en.openei.org/apps/reeds.

Based on the Standard Scenarios results, this report explores four key themes of U.S. power sector evolution:

- The continued predominance of natural gas and renewable energy generators for meeting new capacity and generation needs

- The impacts of competition between wind and PV

- The potential impact of low-cost battery storage on generation expansion and operations

- The future of existing nuclear power plants and their influence on new capacity and generation requirements.

We discuss each of these areas in the context of recent trends and projected changes based on the modeled scenario results. The scenarios include a Mid-case that serves as a reference case (using policies in place as of spring 2017) and 25 side cases that include sensitivities in fuel prices, demand growth, retirements, technology and financing costs, transmission and resource restrictions, and policy considerations. Highlights for each of the areas are discussed below.

New capacity and generation are projected to come primarily from natural gas and renewable energy technologies. From 2005 to 2016, over 99\% of net capacity additions were from natural gas and renewable energy. The projections from the Standard Scenarios show that this trend is likely to continue, with nearly all new capacity and generation growth in most of the scenarios coming from renewable energy and natural gas generators (see Figure ES-1). Growth in natural gas and renewable capacity is found in nearly all states. Future gas prices and renewable technology advancements are found to be the greatest determinants of the long-term relative generation shares for natural gas and renewable energy, but these variables are difficult to accurately predict. A wide uncertainty range is therefore found across the scenarios. Despite the uncertainties, these results suggest that with current policies (as of spring 2017) and a range of expected fuel and technology costs, a future electricity system heavily comprised of natural gas and renewables offers the lowest-cost portfolio while satisfying grid reliability considerations. Most scenarios find capacity growth opportunities for natural gas technologies even if the natural gas generation fraction does not increase, in part to support system reliability. The greater reliance on natural gas and renewables - and the corresponding reduction in coal and nuclear - results in consistent reductions in power sector emissions and water use intensity; 
however, absolute emissions and water use decline more slowly due to increasing electricity demand.
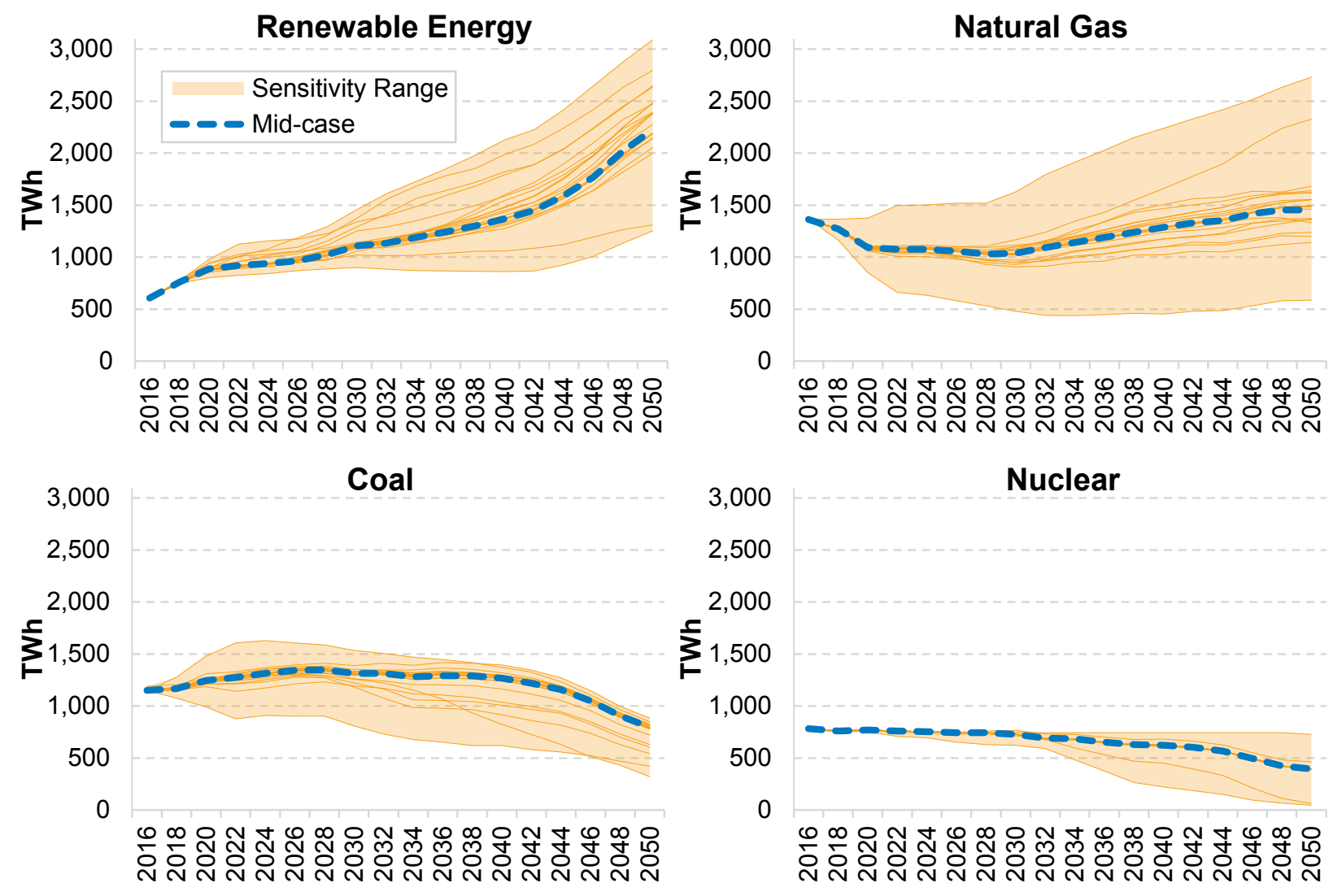

Figure ES-1. Generation projections across 22 non-policy scenarios for renewable energy, natural gas, coal, and nuclear generators. Generation growth, especially over the long-term, comes from renewable energy and natural gas. Non-policy scenarios are those that do not explicitly consider a policy sensitivity beyond the policies and regulations in place as of spring 2017.

As their costs fall, wind and PV begin to compete more directly with one another, but not on a one-to-one basis. Wind and PV technologies - referred to in this report collectively as variable renewable energy (VRE) - have both experienced recent cost declines and are expected to experience continued deployment across the range of Standard Scenarios (see Figure ES-1). In the long term, projected wind and PV costs become more similar, resulting in competition and deployment outcomes that are highly sensitive to their relative costs. While there is competition between the two technologies, lower costs in either technology lead to a net increase in total VRE generation - the increase in one technology more than offsets the decrease in the other (see Figure ES-2). As levelized costs become more similar, differences in system value driven by generation profiles and locations become more important driving factors for deployment results. Moreover, additional non-modeled factors unrelated to direct wind and PV plant cost and performance, such as local economic and siting considerations, are expected to become increasingly important in the future deployment of each of these technologies. 


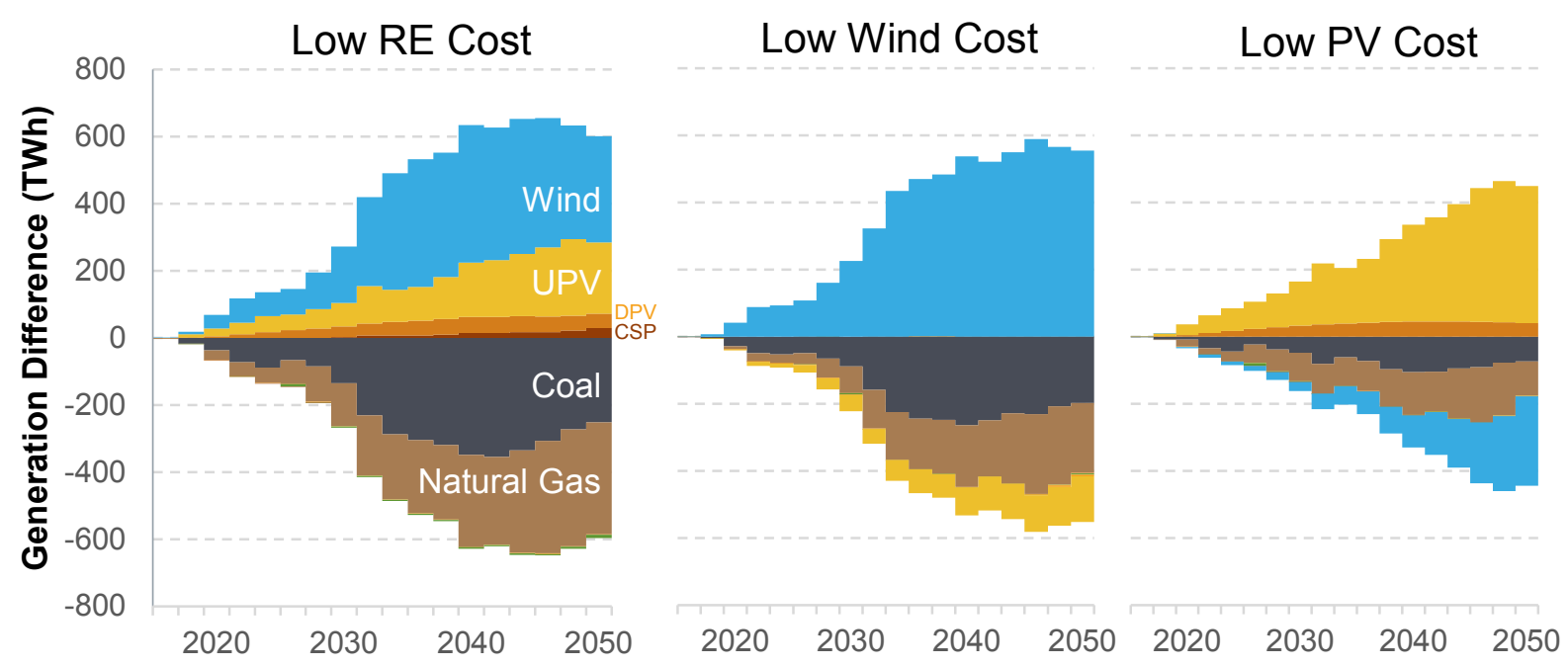

Figure ES-2. Generation difference between the Mid-case scenario and the Low RE Cost (left), Low Wind Cost (middle), and Low PV Cost (right) scenarios. The Low RE Cost scenario sees significant wind and solar deployment that displaces fossil generation. Incremental generation in the Low Wind Cost and Low PV Cost scenarios results in displacement of fossil generation and PV and wind generation respectively, but all scenarios have a net increase in VRE generation.

$\mathrm{CSP}=$ concentrating solar power 
The availability of low-cost battery storage can significantly alter the expected buildout and operation of the grid. All the Standard Scenarios experience some level of new storage deployment, and the level of deployment is strongly correlated with VRE deployment. However, low-cost storage decouples this relationship by making storage economic on its own without relying on VRE to increase its value (see Figure ES-3). Lower-cost storage becomes competitive with gas combustion turbines that are used primarily to provide peaking capacity. And, because storage can recover curtailed renewable energy as well as provide capacity, VRE curtailment is lowest in Low Battery Cost scenario. Low-cost storage also results in increased PV deployment without dampening wind deployment, avoiding the wind-PV offsets discussed above. And because low-cost storage is able to provide both capacity and generation savings, the Low Battery Cost scenario leads to long-term electricity prices that are lower than current day prices.

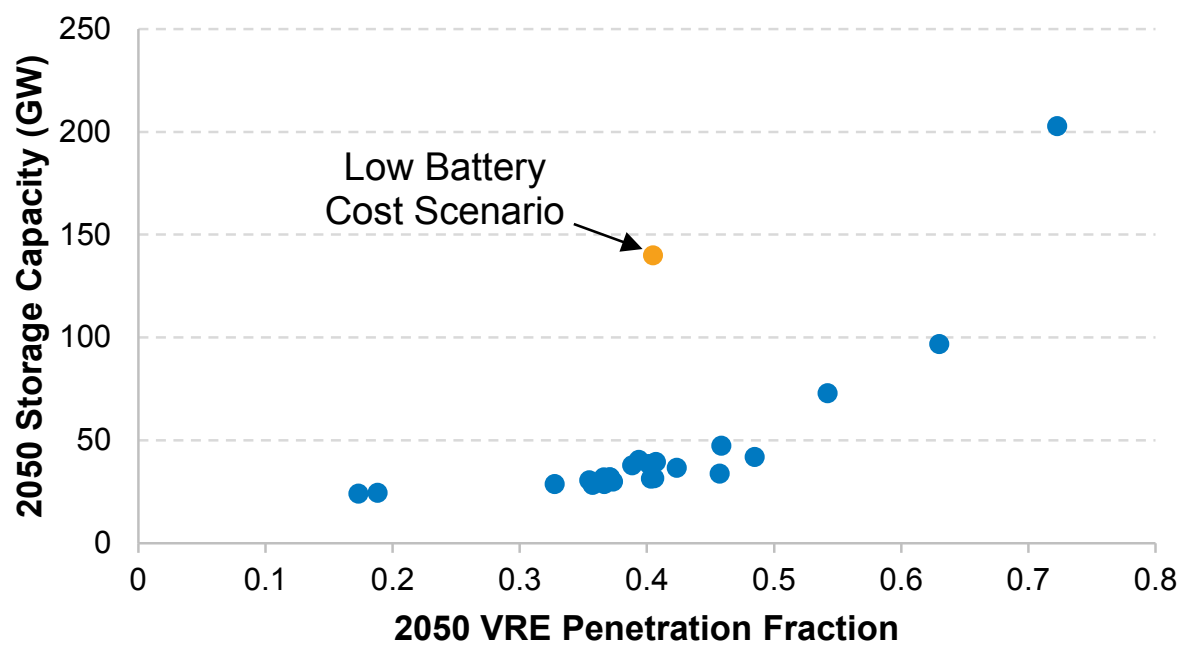

Figure ES-3. Storage capacity in $\mathbf{2 0 5 0}$ versus VRE generation penetration fraction in $\mathbf{2 0 5 0}$ for all the Standard Scenarios. Low battery storage costs result in a decoupling of VRE penetration and storage deployment. 
Uncertainty in the timing of nuclear retirements creates a wide range of future capacity and generation needs. The Standard Scenarios include four nuclear retirement scenarios: (1) an early retirement scenario in which some nuclear plants are retired before they reach a 60 -year life, (2) a 60-year lifetime scenario where all nuclear plants are assumed to receive a single license renewal, (3) the Mid-case scenario which assumes a mix of 60- and 80-year lifetimes, and (4) an 80-year lifetime scenario in which all nuclear plants are assumed to receive a second license renewal. Additional nuclear retirements before 2030 generally lead to more gas and coal generation (see Figure ES-4). Nuclear retirements occurring between 2030 and 2050 are primarily replaced by a mix of natural gas, wind, and PV generation and capacity. Scenarios with longer nuclear lifetimes showed lower carbon dioxide $\left(\mathrm{CO}_{2}\right)$ emissions and fewer transmission builds but higher water usage and renewable energy curtailment rates.
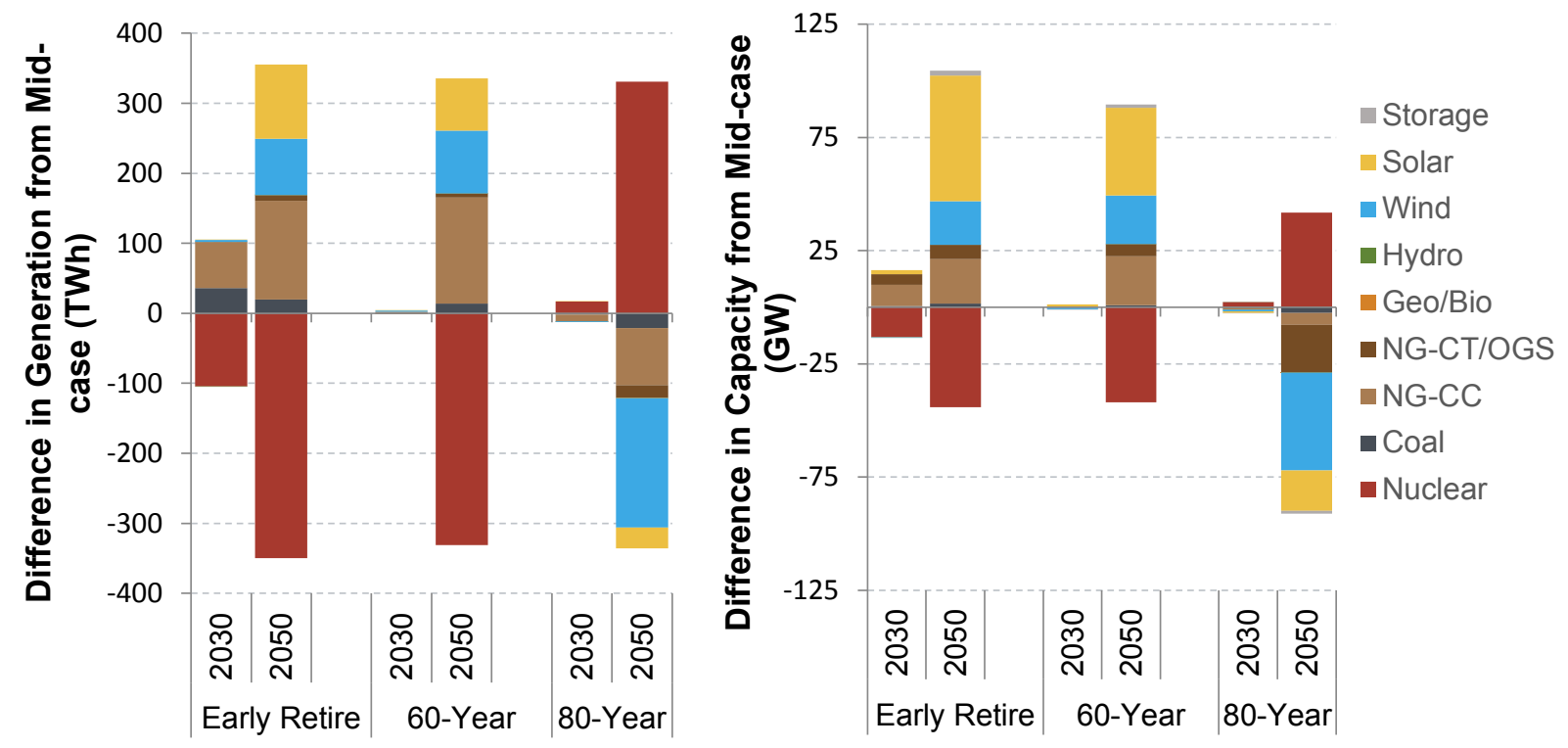

Figure ES-4. Generation and capacity differences by technology relative to the Mid-case scenario for 2030 and $\mathbf{2 0 5 0}$ for three different nuclear retirement scenarios. NG-CC is natural gas combined cycle, NG-CT is natural gas combustion turbine, OGS is oil-gas-steam, and Geo/Bio is geothermal and biopower.

Taken together, the four areas highlighted above point to continued rapid change in the U.S. power sector. The rapid advances in technology development, from PV modules to battery packs to natural gas drilling techniques, create a wide range of uncertainty in expected long-term power sector outcomes. As such, we anticipate that the Standard Scenarios and this associated report will provide context, discussion, and data to inform stakeholder decision making regarding the future direction of the U.S. power sector. As an extension to this report, the Standard Scenarios outputs are presented in a downloadable format online using the Standard Scenarios' Results Viewer at en.openei.org/apps/reeds. This report reflects high-level observations and analysis, whereas the Standard Scenarios' Results Viewer includes scenario results at the state level that can be used for more in-depth analysis. 


\section{Table of Contents}

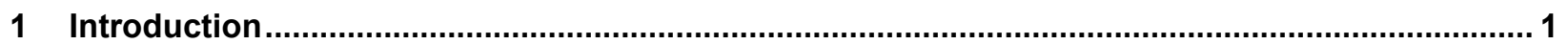

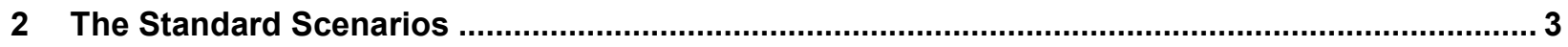

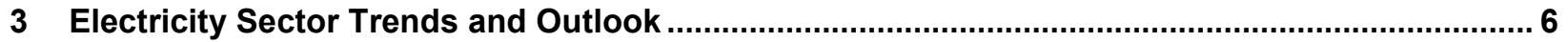

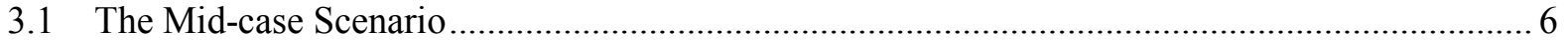

3.2 A Promising Future for Natural Gas, Renewable Energy, or Both? ........................................ 9

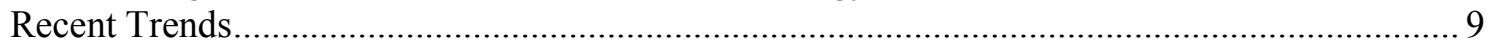

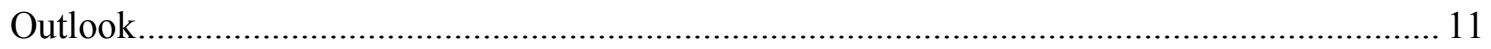

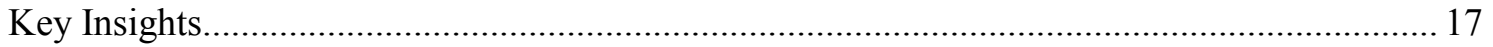

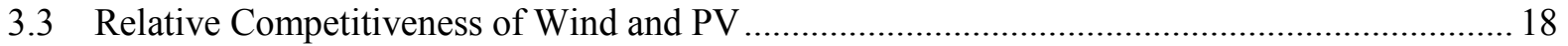

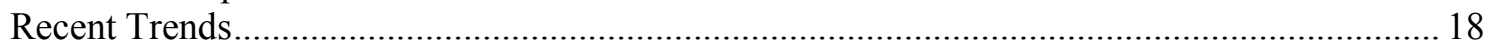

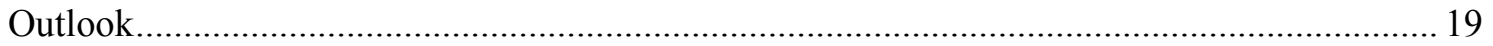

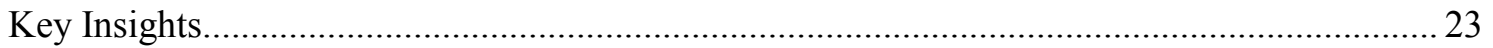

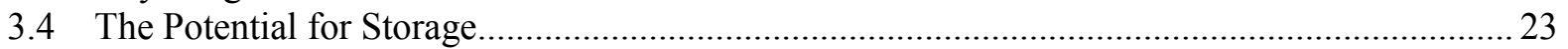

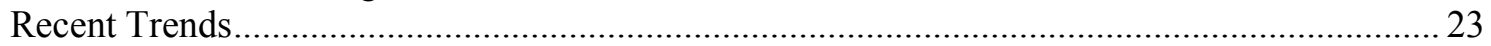

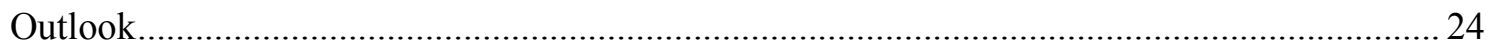

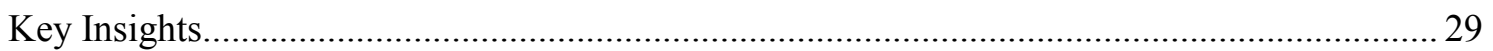

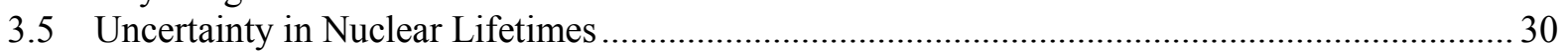

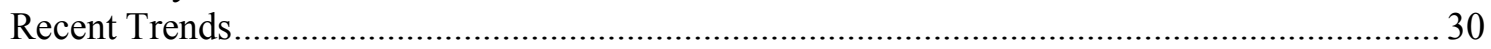

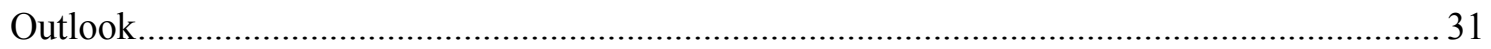

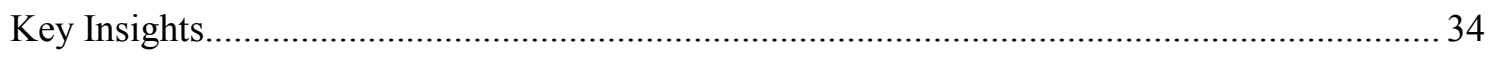

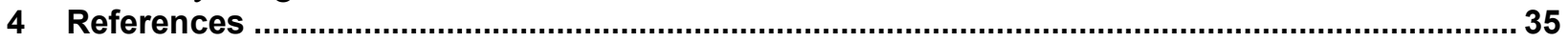

Appendix

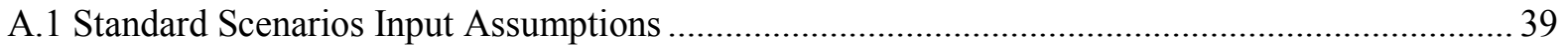

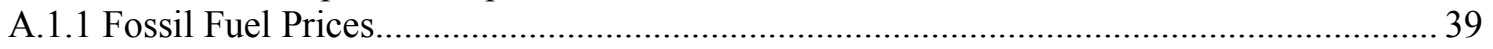

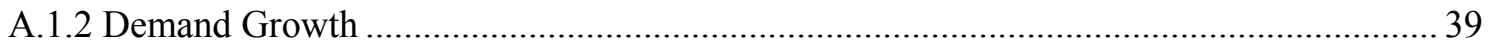

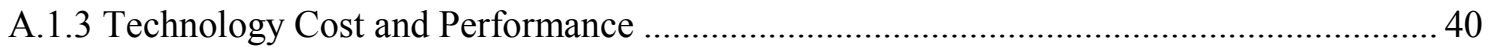

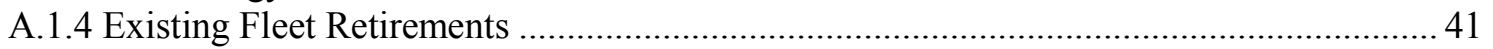

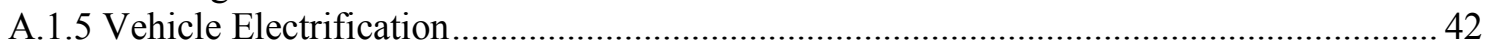

A.1.6 Extended Incentives for Renewable Energy Generation ................................................ 43

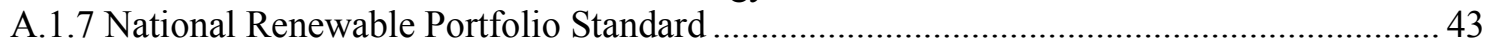

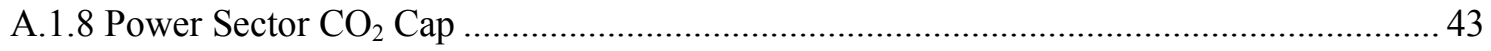

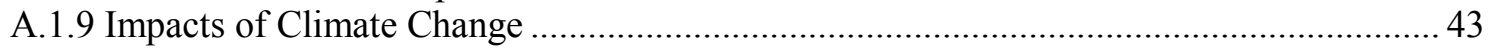

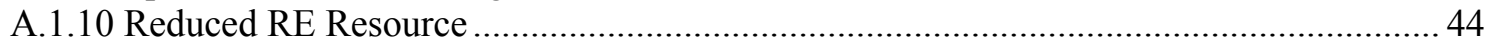

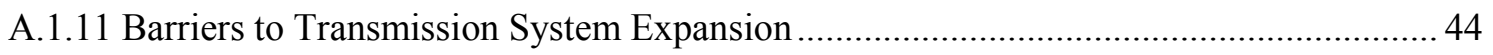

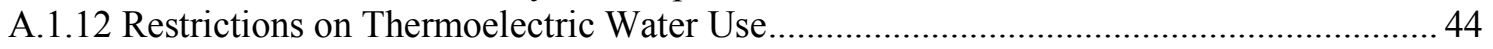

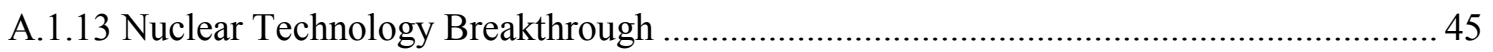

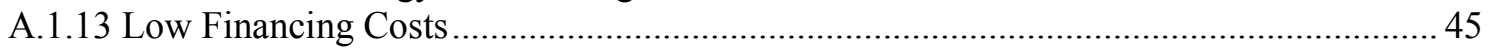

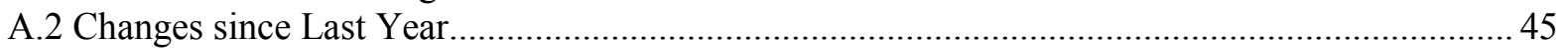




\section{List of Figures}

Figure 1. U.S. power sector evolution over time for the Mid-case scenario.

Figure 2. The U.S. power system evolves from the current system (above) to one powered primarily by renewable energy and natural gas capacity (below) in all regions in the Mid-case scenario... 8

Figure 3. Recent historical and planned capacity additions are dominated by natural gas and renewable energy technologies.

Figure 4. Projections of future market and technology conditions are often inaccurate, particularly for

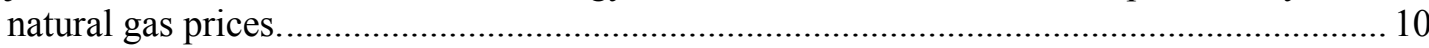

Figure 5. Actual and predicted PV module prices. ......................................................................... 11

Figure 6. Uncertainties in future technology and market conditions drive uncertainties across many

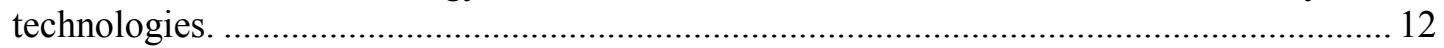

Figure 7. Annual renewable energy builds (left) and natural gas builds (right). ................................... 13

Figure 8. Although future competition for RE and NG exists, complementary generation and capacity

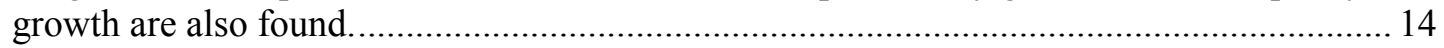

Figure 9. 2050 capacity mix in the (top) Low RE Cost and (bottom) Low NG Price scenarios .............. 15

Figure 10. Difference in generation between the Low Cost Financing scenario and the Mid-case............ 16

Figure 11. Power sector emissions and water use decline slowly in all non-policy scenarios. .................. 17

Figure 12. Recent growth in RE generation is primarily from wind and from PV ............................... 18

Figure 13. Recent declines in wind and PV costs observed in power purchase agreement prices. ........... 19

Figure 14. Relative wind and solar costs along with natural gas prices are major factors driving VRE

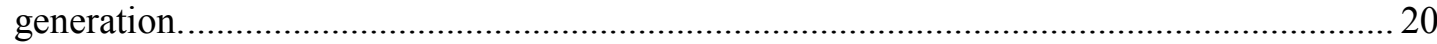

Figure 15. Generation differences between the Low RE Cost (left), Low Wind Costs (middle), and Low

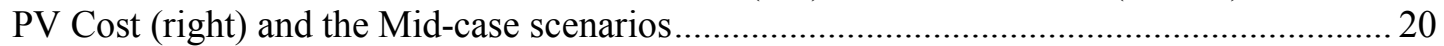

Figure 16. Relative wind and PV levelized costs compared to natural gas fuel price. ............................ 22

Figure 17. Battery costs from 2005 through 2014 (Nykvist and Nilsson 2015) ..................................... 24

Figure 18. Overnight capital cost projections for eight-hour lithium-ion batteries (blue) and NG-CT plants

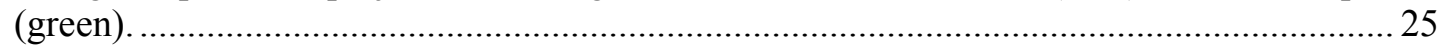

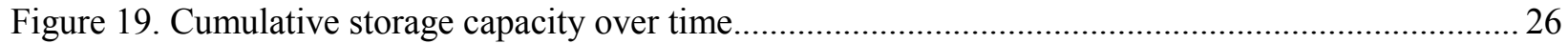

Figure 20. Storage capacity in 2050 versus VRE generation penetration fraction in 2050 ..................... 27

Figure 21. Difference in generation (left) and capacity (right) between the Low Battery Cost and Mid-case

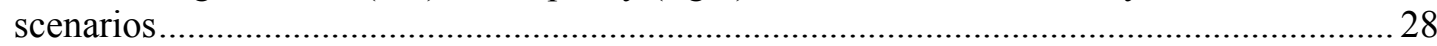

Figure 22. Nationwide average generation in each of the ReEDS time slices in 2050 for the Low Battery

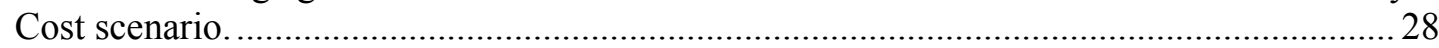

Figure 23. Cost-of-service electricity prices over time normalized to 2016 electricity prices. ................. 29

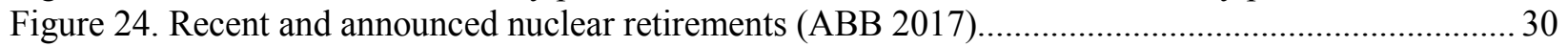

Figure 25. Nuclear capacity over time across the four retirement scenarios ......................................... 31

Figure 26. Generation and capacity differences by technology relative to the Mid-case scenario for 2030 and 2050

Figure 27. Annual power sector $\mathrm{CO}_{2}$ emissions over time (left) and cumulative $\mathrm{CO}_{2}$ emissions from 2016

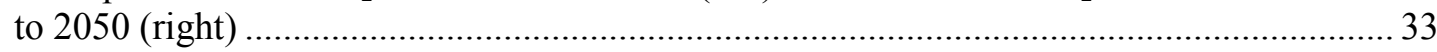

Figure 28. Water withdrawal by year (left) and cumulative withdrawals (right) .................................. 33

Figure 29. Fuel price trajectories used in the Standard Scenarios .......................................................... 39

Figure 30. Demand growth trajectories used in the Standard Scenarios................................................ 40

Figure 31. Battery system capital costs for an eight-hour battery on a $\$ / \mathrm{kW}$ basis (left) and a $\$ / \mathrm{kWh}$ basis

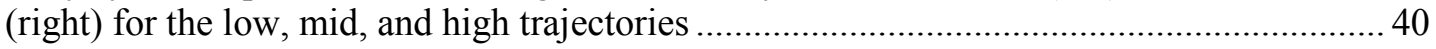

Figure 32. Electric vehicle charging demand under the Vehicle Electrification scenario......................... 42

Figure 33. Comparison of prescribed electric sector $\mathrm{CO}_{2}$ cap to the $\mathrm{CO}_{2}$ emissions path in the Mid-case

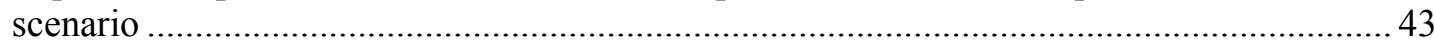

Figure 34. Distributed PV (DPV) capacity in the Standard Scenarios................................................ 47

Figure 35. Mid-case projections from the 2015, 2016, and 2017 editions of the Standard Scenarios........ 48 


\section{List of Tables}

Table 1. Summary of the 2017 Standard Scenarios........................................................................... 3

Table 2. CO2 Emissions and System Costs Relative to the Mid-case Scenario ........................................ 22

Table 3. Amount of Nuclear Power Plant Capacity (in GW) in Each Bin................................................. 41

Table 4. Nuclear Power Plant Lifetime (in Years) for Each Scenario by Bin ......................................... 42

Table 5. Key Differences in Model Inputs and Treatments for ReEDS Model Versions.......................... 46

Table 6. Key Differences in dGen Model Versions............................................................................... 47

\section{List of Text Boxes}

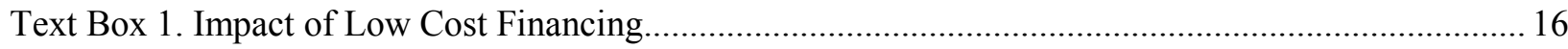




\section{Introduction}

Because the U.S. electricity sector continues to undergo rapid change with little indication that the rate of change will slow, we are introducing this, the third ${ }^{1}$ installment of the Standard Scenarios. With the Standard Scenarios and this associated report, we present an examination of some of the key aspects of the change occurring, and anticipated to occur, in the power sector from present day through 2050. This year's Standard Scenarios consist of 26 power sector scenarios for the contiguous United States that have been studied using the National Renewable Energy Laboratory's (NREL's) Regional Energy Deployment System (ReEDS) long-term capacity expansion model (Eurek et al. 2016) and NREL's dGen rooftop photovoltaic (PV) diffusion model (Sigrin et al. 2016). ${ }^{2}$

The Standard Scenarios provide a means for understanding changes in the power sector. They enable a quantitative examination of how various assumptions impact the development of the power sector. In this report, we use the Standard Scenarios as the basis for describing how the U.S. power sector might evolve in the context of four key storylines:

- The large fraction of new natural gas and renewable energy generation capacity across a wide range of future conditions

- The relative competitiveness of wind and PV

- The potential impacts of storage being available at low cost

- The impacts of nuclear lifetimes on the evolution of the generation mix.

The objective of this analysis is not to predict the future grid evolution but to consider a range of possible futures in an attempt to better understand and articulate key drivers, important implications, and necessary decision points that can contribute to better-informed investment and policy decisions. The Standard Scenarios are not "forecasts," and we make no claims that our scenarios have been or will be more indicative of actual future power sector evolution than projections made by others. Instead, we note that a collective set of projections from diverse analytical frameworks and perspectives could offer a more robust platform for decision-making (Mai et al. 2013). In addition, our modeling tools and analysis have been designed with particular emphasis on capturing the unique traits of renewable energy generation technologies and the resulting implications to the rest of the power system. Thus, this work provides a perspective on the electricity sector that complements those provided by other organizations. The modeling tools used in this work have been designed with a specific emphasis on issues related to renewable energy integration, including ensuring capacity adequacy and capturing curtailment and forecast error impacts in investment decisions. Other modeling and analysis frameworks will have different emphases, strengths, and weaknesses.

\footnotetext{
${ }^{1}$ See Sullivan et al. (2015) for the 2015 Standard Scenarios and Cole et al. (2016) for the 2016 Standard Scenarios.

${ }^{2}$ For more information about ReEDS and dGen, see www.nrel.gov/analysis/reeds and www.nrel.gov/analysis/dgen respectively. For lists of published work using ReEDS and dGen, see http://www.nrel.gov/analysis/reeds/publications.html and http://www.nrel.gov/analysis/dgen/publications.html respectively.
} 
The ultimate purpose of the Standard Scenarios and this associated report is to provide context, discussion, and data to inform stakeholder decision making regarding the future direction of the U.S. power sector. As a key feature of this report, the state-level Standard Scenarios outputs are presented in a downloadable format online using the Standard Scenarios' Results Viewer at en.openei.org/apps/reeds. This report reflects high-level observations, trends, and analysis, whereas the Standard Scenarios' Results Viewer includes the detailed scenario results needed for more in-depth analysis. 


\section{The Standard Scenarios}

The 2017 Standard Scenarios comprise 26 power sector scenarios that are run using the ReEDS model (Eurek et al. 2016) and the dGen model (Sigrin et al. 2016). Eight of the scenarios are new to this year's edition, and scenario assumptions have been updated since last year to reflect the many policy, technology, and other changes occurring in the power sector (see Appendix A.2). The scenarios are summarized in Table 1 and details on specific scenario inputs are provided in the appendix. Although more than 26 scenario settings are shown in the table, the scenarios settings in blue italics are part of the same Mid-case scenario resulting in 26 distinct potential futures. These scenarios were selected in order to capture a breadth of trajectories of costs, performance, policy, and other drivers. ${ }^{3}$ The diversity of scenarios covers a range of potential futures rather than focus on a single-scenario outlook. For example, in addition to considering traditional sensitivities such as demand growth and fuel prices, we explicitly account for possible water constraints and select earth system feedbacks, and we assess a considerable number of other critical factors that impact the development of the power system such as transmission buildout, policies, and technology progress. Throughout this report, the non-policy ${ }^{4}$ scenarios (i.e., all scenarios except the four policy scenarios that are shaded in Table 1 are presented primarily to summarize results.

Table 1. Summary of the 2017 Standard Scenarios. The scenario settings listed in blue italics correspond to the settings used in the Mid-case scenario, which is used in this analysis as a reference scenario reflecting "business-as-usual" conditions. All the non-shaded scenarios are presented through this report as the "non-policy" scenarios. Additional scenario details are provided in the Section A.1 of the appendix.

\begin{tabular}{|l|l|l|}
\hline \multirow{2}{*}{ Group } & Scenario & Notes \\
\hline \multirow{2}{*}{$\begin{array}{l}\text { Electricity Demand } \\
\text { Growth }\end{array}$} & Reference Demand Growth & AEO 2017 Reference \\
\cline { 2 - 3 } & Low Demand Growth & AEO 2017 Low Economic Growth \\
\cline { 2 - 3 } & High Demand Growth & AEO 2017 High Economic Growth \\
\cline { 2 - 3 } & Vehicle Electrification & $\begin{array}{l}\text { PEV/PHEV adoption reaches 40\% of sales } \\
\text { by 2050; 45\% of charging utility-controlled, } \\
55 \% \text { opportunistic }\end{array}$ \\
\hline Fuel Prices & Reference Natural Gas Prices & AEO 2017 Reference \\
\hline
\end{tabular}

\footnotetext{
${ }^{3}$ Although the scenarios cover a wide range of futures, they are not exhaustive. For example, carbon capture and sequestration, marine hydrokinetic wave, and a variety of non-traditional battery storage technologies are currently active areas of research and could become significant contributors to the electricity system.

${ }^{4} \mathrm{We}$ recognize that every scenario is in some way impacted by policy (e.g., liquefied natural gas permitting or natural gas drilling requirements can impact natural gas prices), but we nonetheless refer to these scenarios as "nonpolicy" scenarios because they do not explicitly consider a policy sensitivity.
} 


\begin{tabular}{|c|c|c|}
\hline Group & Scenario & Notes \\
\hline & Low Natural Gas Prices & $\begin{array}{l}\text { AEO } 2017 \text { High Oil \& Gas Resource } \\
\text { and Technology }\end{array}$ \\
\hline & High Natural Gas Prices & $\begin{array}{l}\text { AEO } 2017 \text { Low Oil \& Gas Resource } \\
\text { and Technology }\end{array}$ \\
\hline \multirow{6}{*}{$\begin{array}{l}\text { Electricity } \\
\text { Generation } \\
\text { Technology Costs }\end{array}$} & Mid Technology Cost & $\begin{array}{l}2017 \text { Annual Technology Baseline (ATB) } \\
\text { Mid-case Projections }\end{array}$ \\
\hline & Low RE Cost & $\begin{array}{l}2017 \text { ATB Renewable Energy Low-Case } \\
\text { Projections }\end{array}$ \\
\hline & High RE Cost & $\begin{array}{l}2017 \text { ATB Renewable Energy High-Case } \\
\text { Projections }\end{array}$ \\
\hline & Low Wind Cost & 2017 ATB Low-case projection for Wind \\
\hline & Low PV Cost & 2017 ATB Low-case projection for PV \\
\hline & Nuclear Technology Breakthrough & $\begin{array}{l}50 \% \text { reduction in nuclear capital costs over } \\
\text { all years }\end{array}$ \\
\hline \multirow{3}{*}{$\begin{array}{l}\text { Battery Storage } \\
\text { Costs }\end{array}$} & Mid Battery Storage Cost & $\begin{array}{l}\text { Mid-case projection from Cole, Marcy, et al. } \\
\text { (2016) }\end{array}$ \\
\hline & Low Battery Storage Cost & $\begin{array}{l}\text { Low-case projection from Cole, Marcy, et al. } \\
\text { (2016) }\end{array}$ \\
\hline & High Battery Storage Cost & $\begin{array}{l}\text { High-case projection from Cole, Marcy, et al. } \\
(2016)\end{array}$ \\
\hline \multirow{2}{*}{$\begin{array}{l}\text { Financing } \\
\text { Assumptions }\end{array}$} & Long-term Financing Trends & $\begin{array}{l}\text { Interest rate } 8 \% \text {, equity rate of return } 13 \% \text {, } \\
\text { Weighted Average Cost of Capital } 8.1 \% \\
\text { (all nominal) }\end{array}$ \\
\hline & Low-cost Financing & $\begin{array}{l}\text { Interest rate } 4.4 \% \text {, equity rate of return } \\
9.5 \% \text {, Weighted Average Cost of Capital } \\
5.4 \% \text { (all nominal) }\end{array}$ \\
\hline \multirow{3}{*}{$\begin{array}{l}\text { Existing Fleet } \\
\text { Retirements }\end{array}$} & Reference Retirement & $\begin{array}{l}\text { Lifetime retirements for non-nuclear based } \\
\text { on ABB Velocity Suite database (ABB } \\
\text { 2017); At-risk nuclear retired at } 60 \text { years, } \\
\text { all other nuclear at } 80 \text { years. }\end{array}$ \\
\hline & 80-year Nuclear Lifetime & All nuclear plants have 80 -year life \\
\hline & 60-year Nuclear Lifetime & All nuclear plants have 60 -year life \\
\hline
\end{tabular}




\begin{tabular}{|c|c|c|}
\hline Group & Scenario & Notes \\
\hline & Accelerated Nuclear Retirement & $\begin{array}{l}\text { At-risk plants retired at } 50 \text { years, all others } \\
\text { at } 60 \text { years }\end{array}$ \\
\hline & Accelerated Coal Retirement & Coal plant lifetimes reduced by 10 years \\
\hline \multirow[b]{2}{*}{$\begin{array}{l}\text { Earth System } \\
\text { Feedbacks }\end{array}$} & No Climate Feedback & No feedback due to changes in the climate \\
\hline & Impacts of Climate Change & $\begin{array}{l}\text { Temperature impacts on generators, } \\
\text { precipitation, transmission, and demand; } \\
\text { derived from Integrated Global System } \\
\text { Model (IGSM)-Community Atmosphere } \\
\text { Model (CAM) climate scenario }\end{array}$ \\
\hline \multirow{4}{*}{$\begin{array}{l}\text { Resource and } \\
\text { System Constraints }\end{array}$} & Default Resource Constraints & Used for the Mid-case scenario ${ }^{5}$ \\
\hline & Reduced RE Resource & $\begin{array}{l}25 \% \text { cut to each resource in input supply } \\
\text { curves }\end{array}$ \\
\hline & $\begin{array}{l}\text { Barriers to Transmission System } \\
\text { Expansion }\end{array}$ & $\begin{array}{l}3 x \text { transmission capital cost } \\
\text { No new AC-DC-AC interties } \\
2 x \text { transmission loss factors }\end{array}$ \\
\hline & Restricted Cooling Water Use & $\begin{array}{l}\text { New construction may not use freshwater } \\
\text { for cooling }\end{array}$ \\
\hline \multirow{5}{*}{$\begin{array}{l}\text { Policy/Regulatory } \\
\text { Environment }\end{array}$} & Current Law & $\begin{array}{l}\text { Includes state, regional, and federal } \\
\text { policies as of spring } 2017 \text {, does not } \\
\text { include the Clean Power Plan }\end{array}$ \\
\hline & Clean Power Plan & $\begin{array}{l}\text { Mass-based policy with new source } \\
\text { compliments and unrestricted national } \\
\text { allowance trading }{ }^{6}\end{array}$ \\
\hline & $\begin{array}{l}\text { National Renewable Portfolio } \\
\text { Standard (RPS) }\end{array}$ & $\begin{array}{l}43 \% \text { of generated electricity from } \\
\text { renewables by } 2030,80 \% \text { by } 2050\end{array}$ \\
\hline & $\begin{array}{l}\text { Power Sector Carbon Dioxide } \\
\left(\mathrm{CO}_{2}\right) \text { Cap }\end{array}$ & $\begin{array}{l}\text { Power sector emissions } 30 \% \text { below } \\
2005 \text { levels by } 2025,83 \% \text { by } 2050\end{array}$ \\
\hline & $\begin{array}{l}\text { Extended Incentives for RE } \\
\text { Generation }\end{array}$ & $\begin{array}{l}\text { Extend ITC/PTC through } 2030 \text { for eligible } \\
\text { technologies }\end{array}$ \\
\hline
\end{tabular}

\footnotetext{
${ }^{5}$ See the ReEDS documentation (Eurek et al. 2016) for details on default resource and system constraints.

${ }^{6}$ See the ReEDS documentation (Eurek et al. 2016) for details on the Clean Power Plan implementation.
} 


\section{Electricity Sector Trends and Outlook}

We present the electricity sector trends and outlook from the 2017 Standard Scenarios by first examining the Mid-case scenario. We then highlight four primary trends that could yield significant changes to the power sector.

\subsection{The Mid-case Scenario}

The Mid-case scenario reflects the default or central assumptions in the various categories shown by Table 1 . This scenario reflects a business-as-usual perspective and serves as a reference to better understand the impacts of various drivers described in the following sections. As the scenario name suggests, the default assumptions used in the Mid-case scenario reflects median or mid-line expectations for each category based on current information (e.g., reference case fuel prices and mid-case technology costs); however, the Mid-case scenario should not be taken by itself as a forecast or prediction due to the wide uncertainty space. It is for this reason that we include 26 distinct scenarios as part of the Standard Scenarios (see Section 2). ${ }^{7}$ The Mid-case serves as a useful snapshot of our business-as-usual outlook and was developed in 2017.
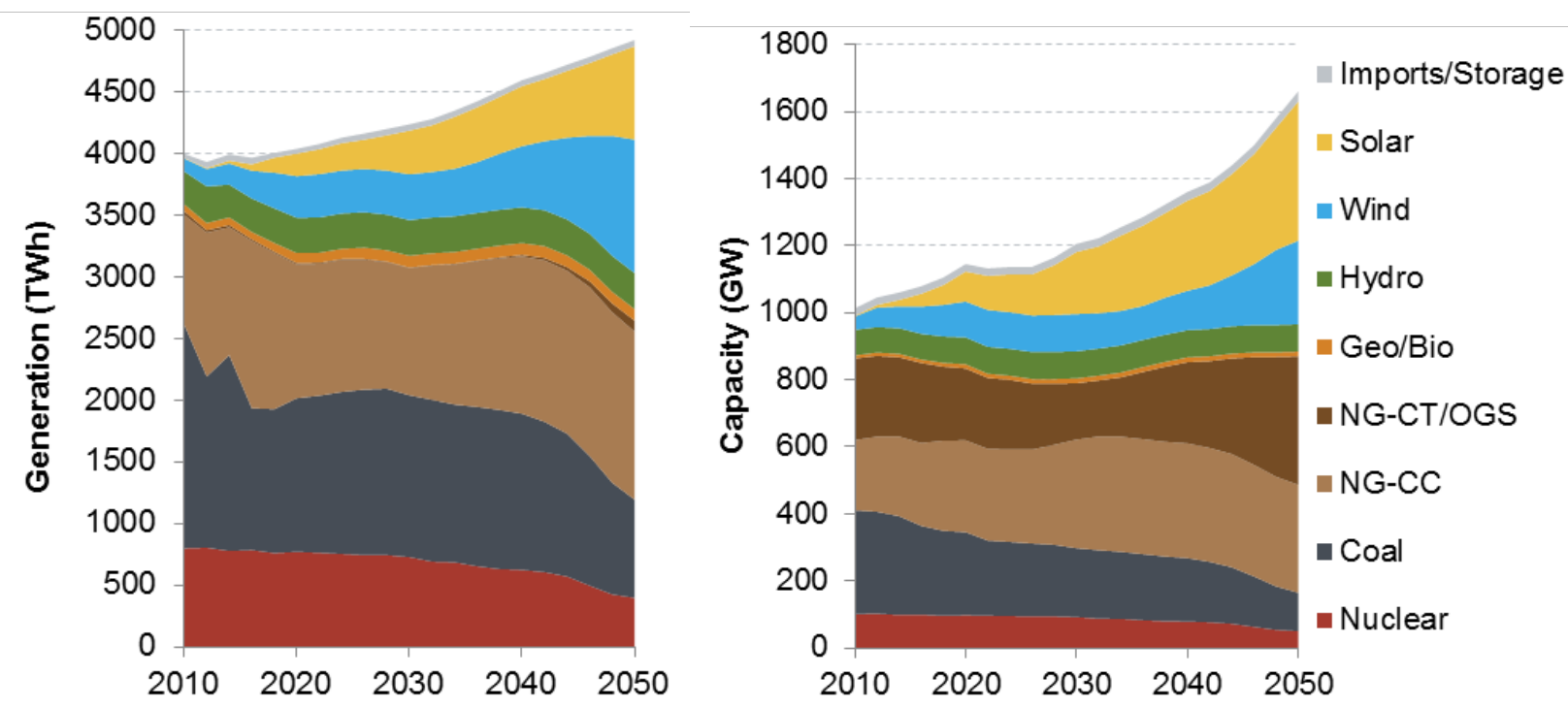

Figure 1. U.S. power sector evolution over time for the Mid-case scenario. Annual generation (left) shows electricity imports from Canada and Mexico while installed capacity (right) shows storage capacity for the gray area. NG-CC is natural gas combined cycle, NG-CT is natural gas combustion turbine, OGS is oil-gas-steam, and Geo/Bio is geothermal and biopower.

Figure 1 shows the generation and capacity mix through 2050 in the Mid-case scenario. In the near term, renewable energy generation grows at a slightly faster rate of growth than incremental electricity demand does, while fossil fuel and nuclear generation experience slight declines through 2030. In 2030, renewable generation comprises $26 \%$ of total generation, while fossil and nuclear are found to be 55\% and 17\% respectively. For comparison, 2016 generation shares were $15 \%, 65 \%$, and $20 \%$ for renewable, fossil, and nuclear electricity respectively. More significant changes are observed in the long run from a combination of retirements of older coal, oil-gas-

\footnotetext{
${ }^{7}$ While the Standard Scenarios consider a wide range of future conditions, they are certainly not all-inclusive.
} 
steam (OGS), and nuclear capacity and the increase in variable renewable energy (VRE) generation. ${ }^{8}$ Annual coal and nuclear generation drop to $16 \%$ and $8 \%$ respectively, while renewable generation reaches $45 \%$ by 2050 . Natural gas generation remains relatively steady through most of the study period and provides $30 \%$ of total generation in 2050 .

The change in capacity mix largely mirrors the evolution of generation under the Mid-case scenario; however, some important qualitative differences exist. As new renewable growth is primarily met through wind and solar technologies (see Section 3.3), which often have lower capacity factors and capacity value than nuclear, coal, or NG-CC plants, growth in net capacity additions outpace demand growth. On a related noted, we also observe steady growth in natural gas capacity, including NG-CT and NG-CC capacity, despite the relatively flat natural gas generation projections. Overall, just as in today's power system, a variety of generators in our Mid-case scenario are found to provide different grid services modeled; however, renewable and natural gas technologies are anticipated to provide an increasingly larger share of all energy and capacity services over time (see Section 3.2).

The evolution of the U.S. electricity system toward one with higher shares of natural gas and renewable energy is estimated to occur in nearly all states in the Mid-case scenario (Figure 2). In this scenario, significant new generation capacity is deployed in nearly all states. Coal, nuclear, and other older steam-fired capacity decline both in relative and absolute terms while the vast majority of new capacity comes from renewable and natural gas technologies. At a high level, the regional distribution of power plants is estimated to be similar in 2050 as it was in 2016, with the largest installed capacity in states with the greatest electricity consumption (e.g., Texas, California, and Florida). However, proportionally larger future renewable deployment is found in some states (e.g., Iowa and Arizona) with particularly high quality wind and solar resources. ${ }^{9}$

\footnotetext{
${ }^{8}$ Recent experiences with high levels of VRE penetration in the United States (Goggin 2016; California ISO 2016) have shown the power system can remain functional even at very high penetration levels; however, questions remain about the technical and market implications of sustained levels - at the seasonal or annual scale — of high variable generation. A large body of research has concluded that there is still considerable ability for the system to integrate additional VRE generation (Ahlstrom et al. 2015; Brinkman et al. 2016), but issues surrounding curtailment, and thereby costs, can become significant (Denholm and Hand 2011; Denholm, Clark, and O'Connell 2016). The ReEDS model considers many, but not all, of the technical and economic factors related to renewable grid integration when it develops its least-cost generation mix (Eurek et al. 2016).

${ }^{9}$ Specific state-level scenario results can be downloaded using the Standard Scenario Results Viewer for all scenarios at en.openei.org/apps/reeds.
} 

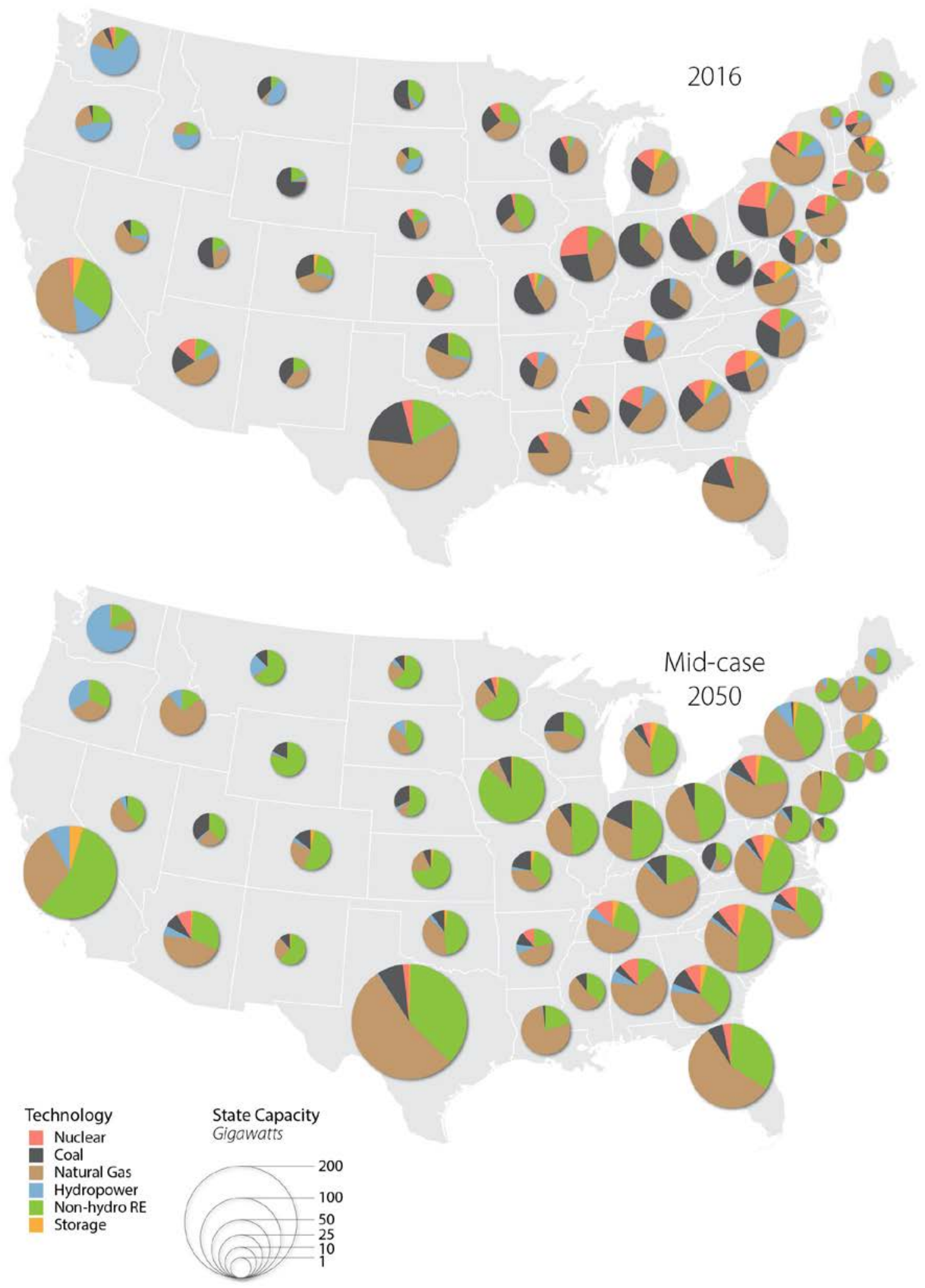

Figure 2. The U.S. power system evolves from the current system (above) to one powered primarily by renewable energy and natural gas capacity (below) in all regions in the Midcase scenario. 


\subsection{A Promising Future for Natural Gas, Renewable Energy, or Both? Recent Trends}

Recent and planned capacity additions in the U.S. electricity sector have come almost entirely from natural gas-fired and renewable energy technologies. ${ }^{10}$ Figure 3 shows the annual net change in installed capacity from 2006 to 2016 as well as planned net additions through 2020. Across all historical years shown (2006-2016), net additions total 64 gigawatts (GW) of natural gas capacity and $114 \mathrm{GW}$ of renewable energy capacity, whereas all other technology categories are estimated to have nearly zero or negative net additions over that same period. ${ }^{11}$ The drivers behind the recent and expected growth of natural gas and renewable energy are well-documented (Wiser and Bolinger 2017; Bolinger and Seel 2016; NREL 2017; Cole, Medlock III, and Jani 2016; EIA 2016a) and include a combination of technology advancements and policy support. Innovations in hydraulic fracturing and horizontal drilling have enabled access to large unconventional natural gas reserves, thereby causing fuel prices to drop in the late 2000s and remain low since then (Figure 4). During the same period, renewable technology advancements, coupled with state and federal policies, have enabled historically low renewable prices and unprecedented capacity growth (Figure 5 and Section 3.3).

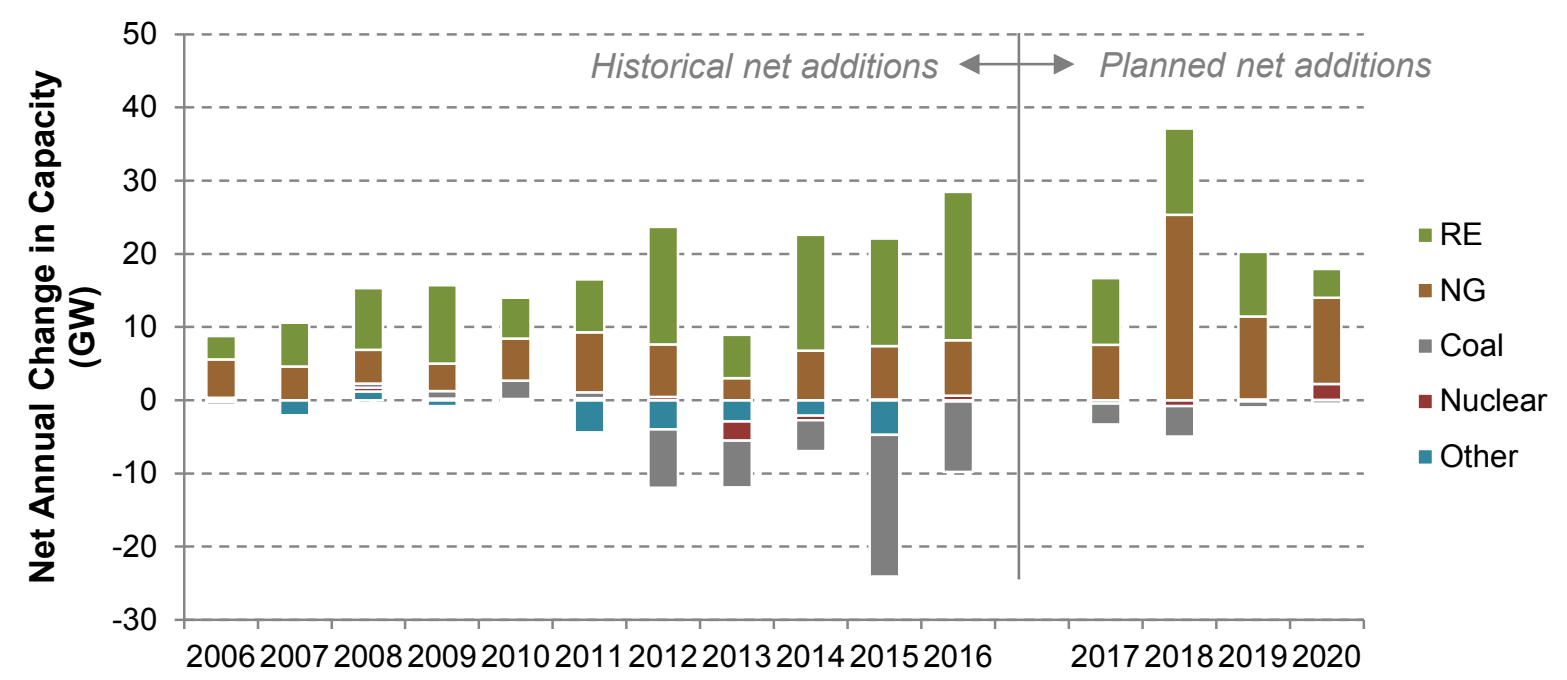

Figure 3. Recent historical and planned capacity additions are dominated by natural gas and renewable energy technologies. Historical net additions are defined as the differences in installed net summer capacity at the end of the year shown from the end of the prior year. Planned net additions are defined as planned capacity minus planned retirements. Planned additions differ from forecasted additions and can understate the amount of renewable capacity under consideration, as renewable technologies can have short siting and construction periods.

Data sources: EIA Electric Power Annual and Electric Power Monthly

\footnotetext{
${ }^{10}$ Within the RE sector, wind and solar PV have comprised the predominant share of new capacity over the past decade, as discussed in Section 3.3.

${ }^{11}$ For all years shown (2006-2020), net additions total $120 \mathrm{GW}$ and $148 \mathrm{GW}$ for natural gas and RE capacity respectively. Planned additions may omit a sizeable amount of renewable energy capacity, as planning horizons for wind and solar plants can be quite short (less than one year in many cases).
} 
Although planned net capacity additions through 2020 suggest that the growth trends for natural gas and renewables will continue in the near-term, longer-term trends are more uncertain for multiple reasons. First, natural gas price forecasts have generally been inaccurate predictors of actual prices, especially over multiple decades due to inherent uncertainties in both supply (e.g., economic ultimate recovery and new technology innovation) and demand (e.g., multi-sectoral use of gas and possibilities for imports and exports). ${ }^{12}$ Figure 4 shows the variability in annual historical prices as well as the difficulties of projecting future prices over many years. Gas prices have historically experienced hard-to-predict volatility across years, seasons, and regions. Second, the evolution of renewable energy technology cost and performance is also difficult to predict. Figure 5 shows how estimated PV module prices have been systematically high compared with historical prices (Margolis, Feldman, and Boff 2017). Predictions for other renewable technologies have also proven challenging. Third, uncertainties exist as to when market equilibrium or saturation will be reached for both natural gas and renewable energy. Saturation can be impacted by low demand growth or over-capacity conditions, infrastructure constraints (for both natural gas pipeline as well as electricity transmission), or declining economic value and grid integration challenges (particularly for variable renewable energy). Fourth, future policies can impact technology innovation and can steer or override market forces. Finally, some of these factors have various positive and negative feedback loops and interact with global forces and conditions that further complicate their assessment and increase uncertainty.

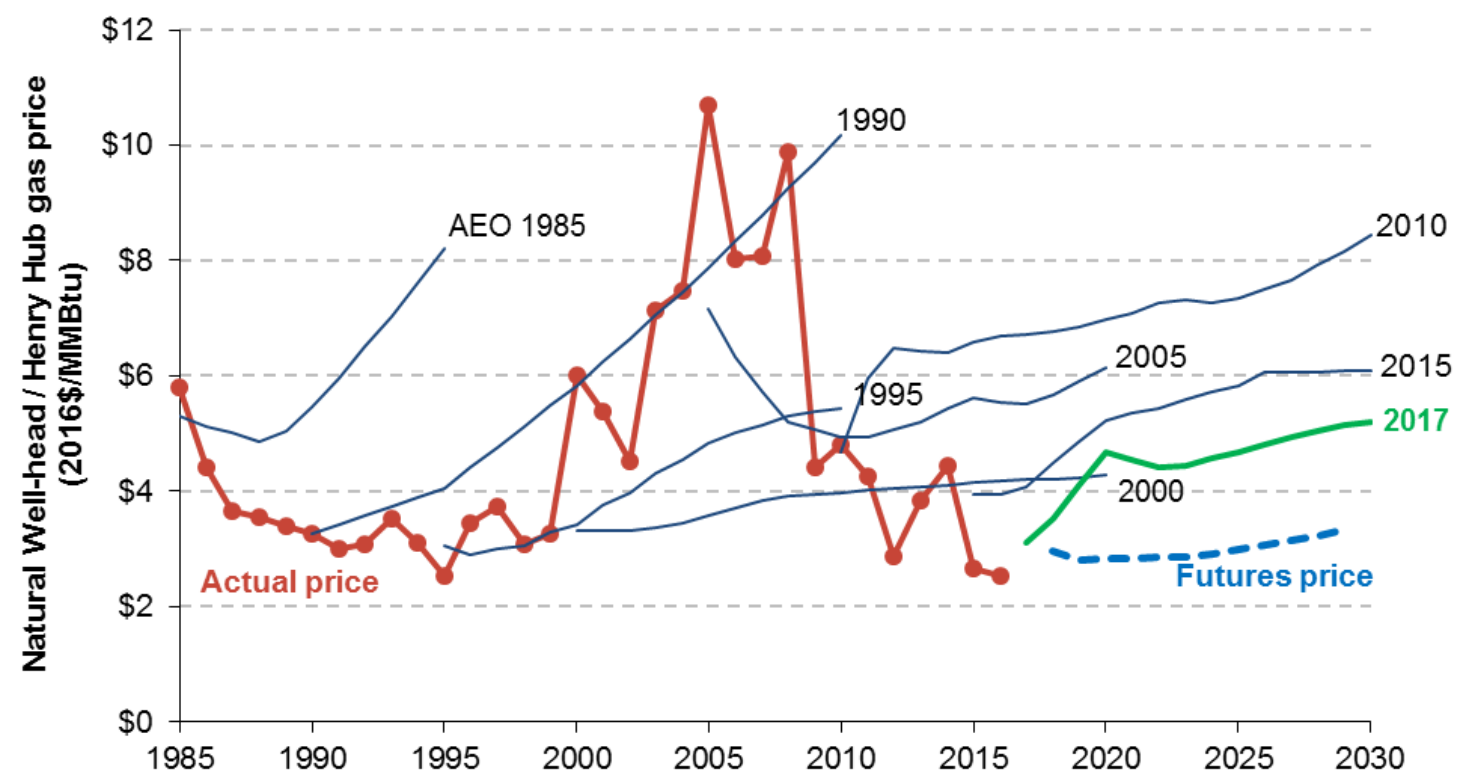

Figure 4. Projections of future market and technology conditions are often inaccurate, particularly

for natural gas prices. Actual natural gas prices reflect average-for the lower 48 states-well-head prices from 1985 to 1996 and Henry Hub prices from 1997 to 2016, as reported by EIA. Projected gas prices are from select AEO editions (reference cases), and they reflect Henry Hub prices for 2015 and 2017 projections and average well-head prices for earlier AEOs. The AEO often also

\footnotetext{
${ }^{12}$ Future policy decisions can affect both supply and demand, such as through export licensing authorizations, local drilling restrictions, and environmental policies. Uncertainties in future policies can, of course, add to the uncertainty in future gas prices.
} 
includes high/low cases, which are not shown in the figure. Futures prices are NYMEX prices accessed July 26, 2017.

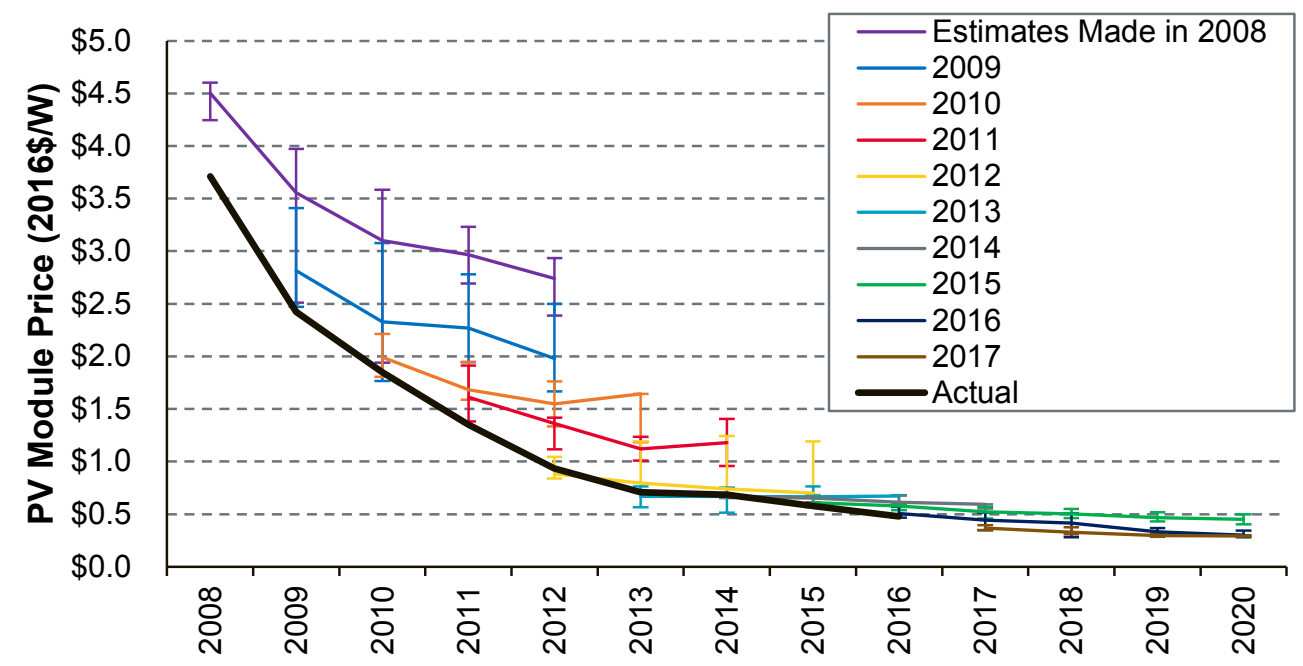

Figure 5. Actual and predicted PV module prices. The figure is a modified version of one from Margolis, Feldman, and Boff (2017).

\section{Outlook}

The significant uncertainties presented in the previous section prevent accurate quantitative predictions of capacity deployment for any individual technology; however, insightful trends can emerge from a collection of scenarios. Figure 6 compares the Mid-case generation results with the range of results from the non-policy scenarios. As expected, the Mid-case results fall toward the middle of the range for most energy sources. One important trend from our analysis is that new generation and capacity growth is comprised almost entirely of natural gas and renewable energy in nearly all scenarios modeled. On an energy basis, renewable energy penetration is estimated to range from $26 \%$ to $62 \%$ of total generation in 2050 across the non-policy scenarios compared with $15 \%$ in 2016 . While growth in natural gas generation is estimated to be more modest in most cases, in part due to the larger starting point for gas $(34 \%$ of total generation in 2016), gas generation reaches $56 \%$ of total generation in its highest-growth scenario. Annual generation is found to decline for all other technologies in nearly all scenarios. ${ }^{13}$

\footnotetext{
${ }^{13}$ The exception is the increase in coal-fired generation in the near term (see Figure 2), which reflects gas-back-tocoal switching driven by an anticipated uptick in natural gas prices with the reference and high natural gas price assumptions. Increases in coal generation are not found in the low natural gas price scenario and are found to be short-lived in all scenarios.
} 

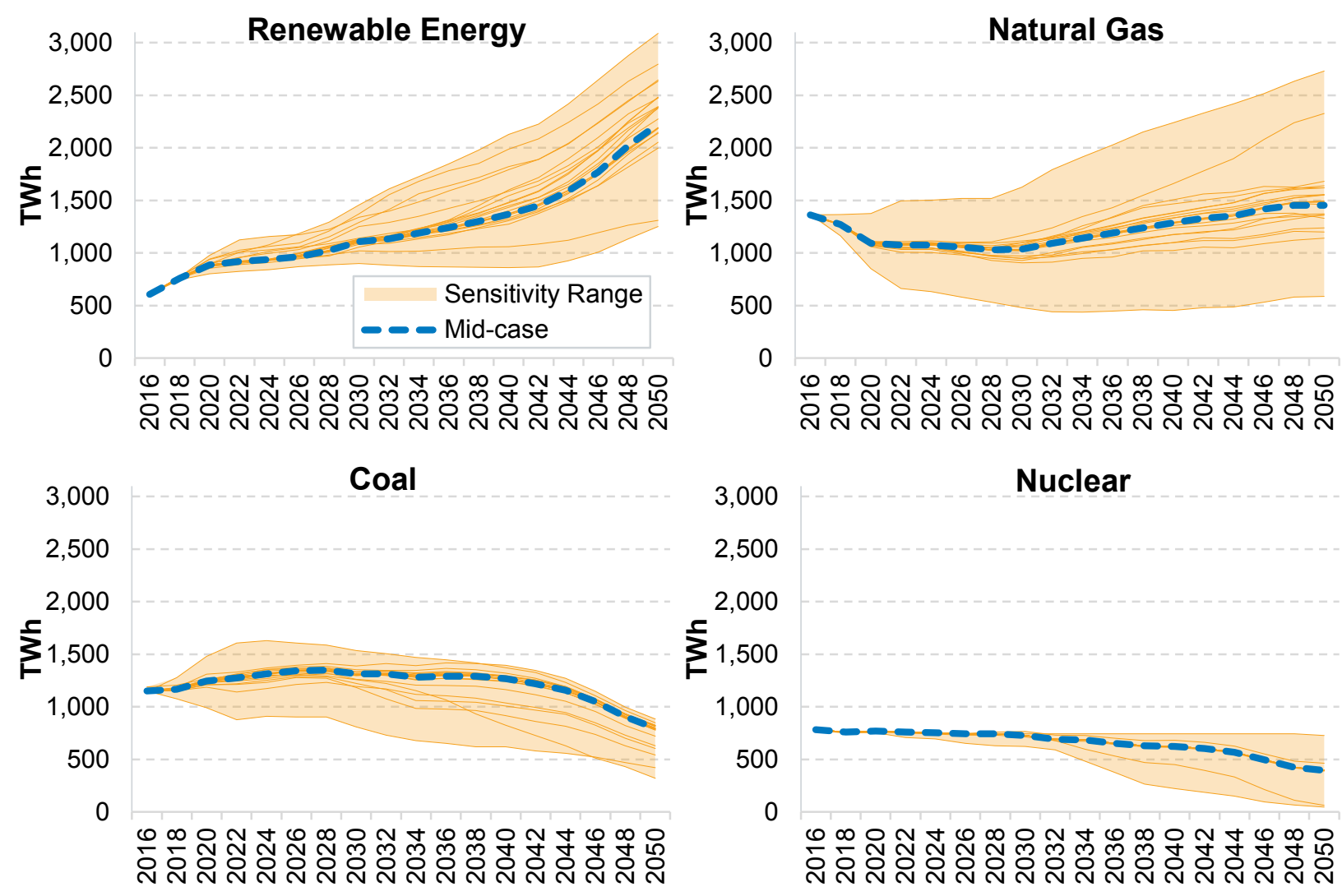

Figure 6. Uncertainties in future technology and market conditions drive uncertainties in projected generation across many technologies. The figure shows annual generation for the Mid-case scenario and the sensitivity range for the non-policy sensitivity scenarios.

Figure 7 shows estimated annual capacity additions for renewable and natural gas technologies for the Mid-case scenario as well as the range across all non-policy scenarios. ${ }^{14}$ As expected, new capacity growth generally follows the generation growth trends for renewables. In the Midcase scenario renewable capacity deployment is found to approach (or even exceed) recent historical additions in the near term, slow in the early 2020s as federal tax credits expire or decline, rebound to recent levels during the 2030s, and finally grow dramatically in the long run in large part because of repowering during the 2040s. ${ }^{15}$ Some of these qualitative trends hold across all non-policy scenarios, but a wide range of results are found particularly through 2040. Capacity growth for natural gas is somewhat decoupled from generation trends due to the excess "headroom" in the current natural gas fleet as well as the role that natural gas plays in providing

\footnotetext{
${ }^{14}$ Figure 7 shows all new capacity additions, including new and repowered capacity. It does not show net changes that, by definition, would be lower than or equal to the new additions due to retirements. Modeled near-term additions do not include all planned additions shown in Figure 3.

${ }^{15}$ In ReEDS, natural gas and renewable plant retirements are modeled based on assumed lifetimes (e.g., 55 years for natural gas plants, 30 years for solar PV, and 24 years for wind). Repowering of renewable capacity is a model decision after the plant retirement occurs that is based on the assumed cost for repowering, which includes the full installed cost of a new power plant minus the transmission equipment. Performance of the repowered capacity corresponds with the assumed performance of the new vintage technology in the year repowering occurs.
} 
capacity reserve requirements. ${ }^{16}$ In particular, our modeling suggests little need for new firm capacity resources as many regions have capacity in excess of the NERC reference levels (NERC 2017). Starting in the late 2020 s as peak demand requirements grow and older plants retire, we find significant annual growth in natural gas capacity_particularly for natural gas combustion turbines.
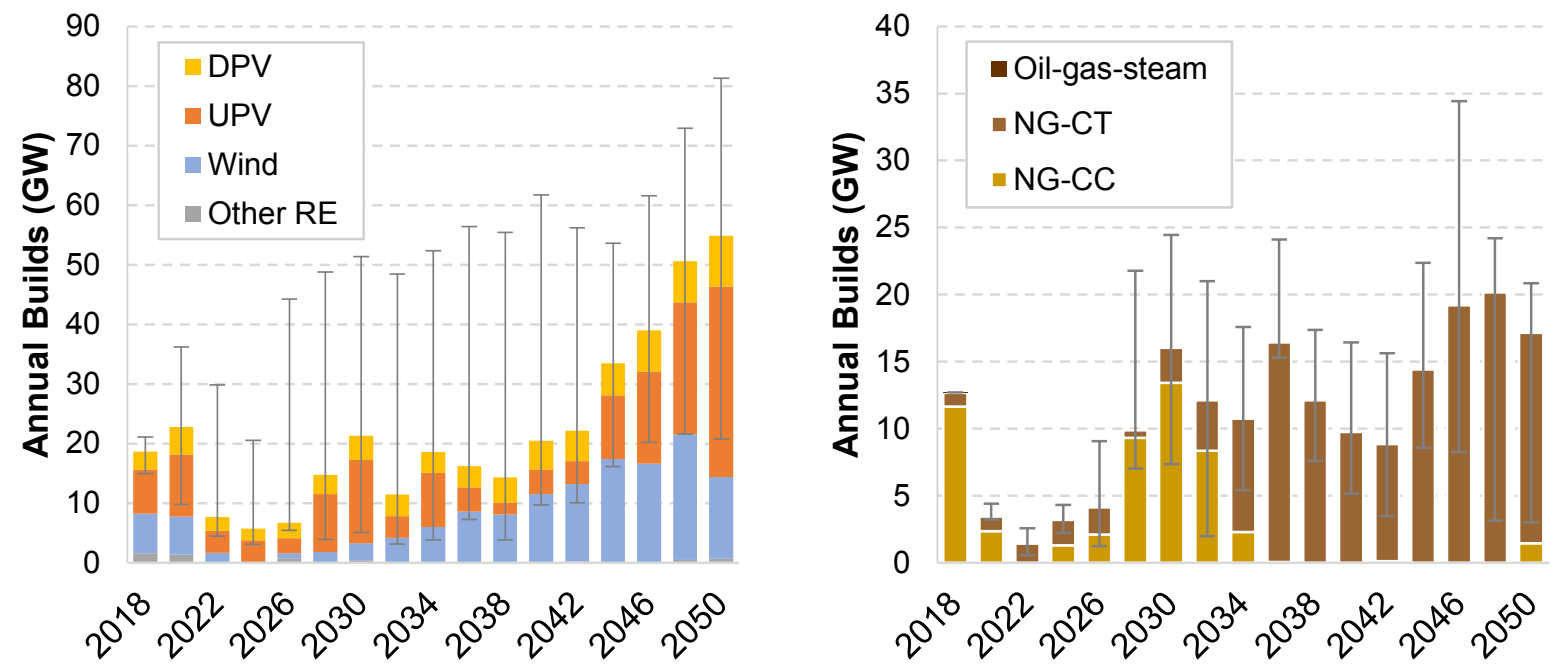

Figure 7. Annual renewable energy builds (left) and natural gas builds (right). Values represent only new capacity builds (retirements are not subtracted) and include repowered capacity where applicable. Bars show the values from the Mid-case scenario and error bars show the total range of builds across the non-policy scenarios.

While the collection of scenarios demonstrates significant growth opportunities for both natural gas and renewable energy, the scenarios also suggest both competitive and complementary aspects. Figure 8 shows the relationship between projected natural gas and renewable generation and capacity across all non-policy scenarios for four select years. The movement over time of the markers toward the upper-right corner suggests the potential generation growth in both natural gas and renewable generation as discussed previously. However, the slope of this movement is found to be either very steep (suggesting greater natural gas growth than renewable energy growth) or very shallow (suggesting the opposite) for a subset of scenarios. This behavior reveals the inherent competition between natural gas and renewable generation as both are vying to meet new opportunities from demand growth or generator retirements.

\footnotetext{
${ }^{16}$ ReEDS does not model all local reliability or congestion needs and therefore may understate peaking capacity needs for specific regions.
} 

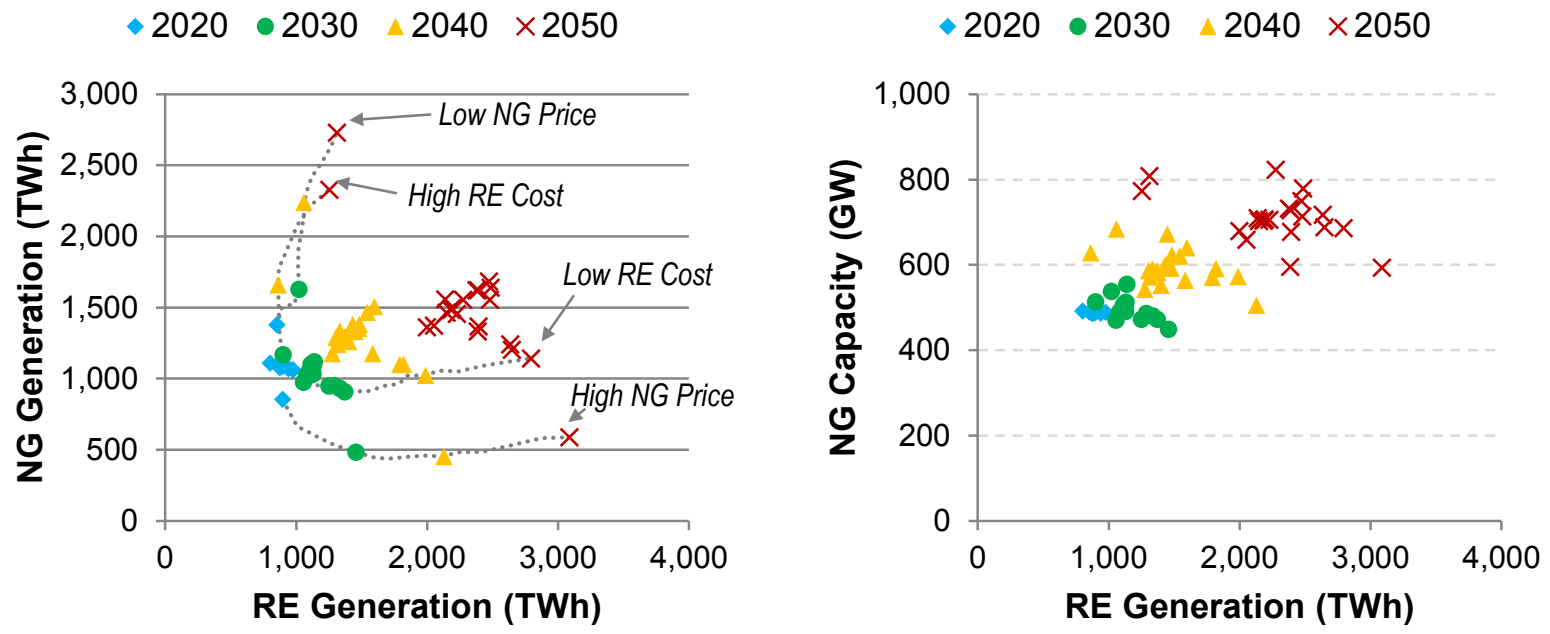

Figure 8. Although future competition for RE and NG exists, complementary generation and capacity growth are also found. Results for the non-policy scenarios are shown.

Figure 8 also shows how renewable generation growth is more strongly correlated with natural gas capacity than natural gas generation. The reason for this is that new renewable capacity growth is dominated by variable wind and solar technologies, which typically have lower capacity credit than dispatchable technologies, especially at increasing penetration levels, and natural gas plants are among the lowest-cost options to serve these capacity services. ${ }^{17}$ As a result, even as renewables serve a growing share of energy needs, their contributions to capacity services are more limited and new natural gas capacity is found to fulfill these services. ${ }^{18}$ In this way, renewable energy and natural gas can be complementary and serve different system needs in the future. The flexibility of natural gas power plants further adds to this complementarity (Logan et al. 2012). The relative growth of each technology depends upon the cost of financing, which is discussed in Text Box 1.

The growth in natural gas and renewable energy and the concomitant reduction in older coal and nuclear capacity in many of the scenarios can affect the generation mix and regional distribution of power plants. Figure 9 shows the 2050 capacity mix by state in the Low RE Cost and Low NG Price scenarios. The capacity mix in 2016 is shown in Figure 2 for comparison. In the Low RE Cost scenario, widespread renewable capacity deployment is found in nearly all states including in regions where historical renewable deployment has not been as robust (e.g., Great Lakes and southeastern states). In the Low NG Price scenario, renewable capacity is not as widely deployed but new natural gas becomes the dominant form of capacity particularly in these regions. In both scenarios, the 2050 renewable and natural gas capacity envisioned replace the coal and nuclear capacity that is present in the eastern half of the country today (see Figure 2 for a map of the current system). These regional and technological changes would require expansion of electrical transmission and natural gas pipeline and storage infrastructure.

\footnotetext{
${ }^{17}$ Capacity credit is a measure of contribution to firm capacity requirements (i.e., planning reserves).

${ }^{18}$ The type of natural gas technology — combined cycle vs. simple combustion turbine - deployed is sensitive to the distribution of capacity and energy services needed.
} 

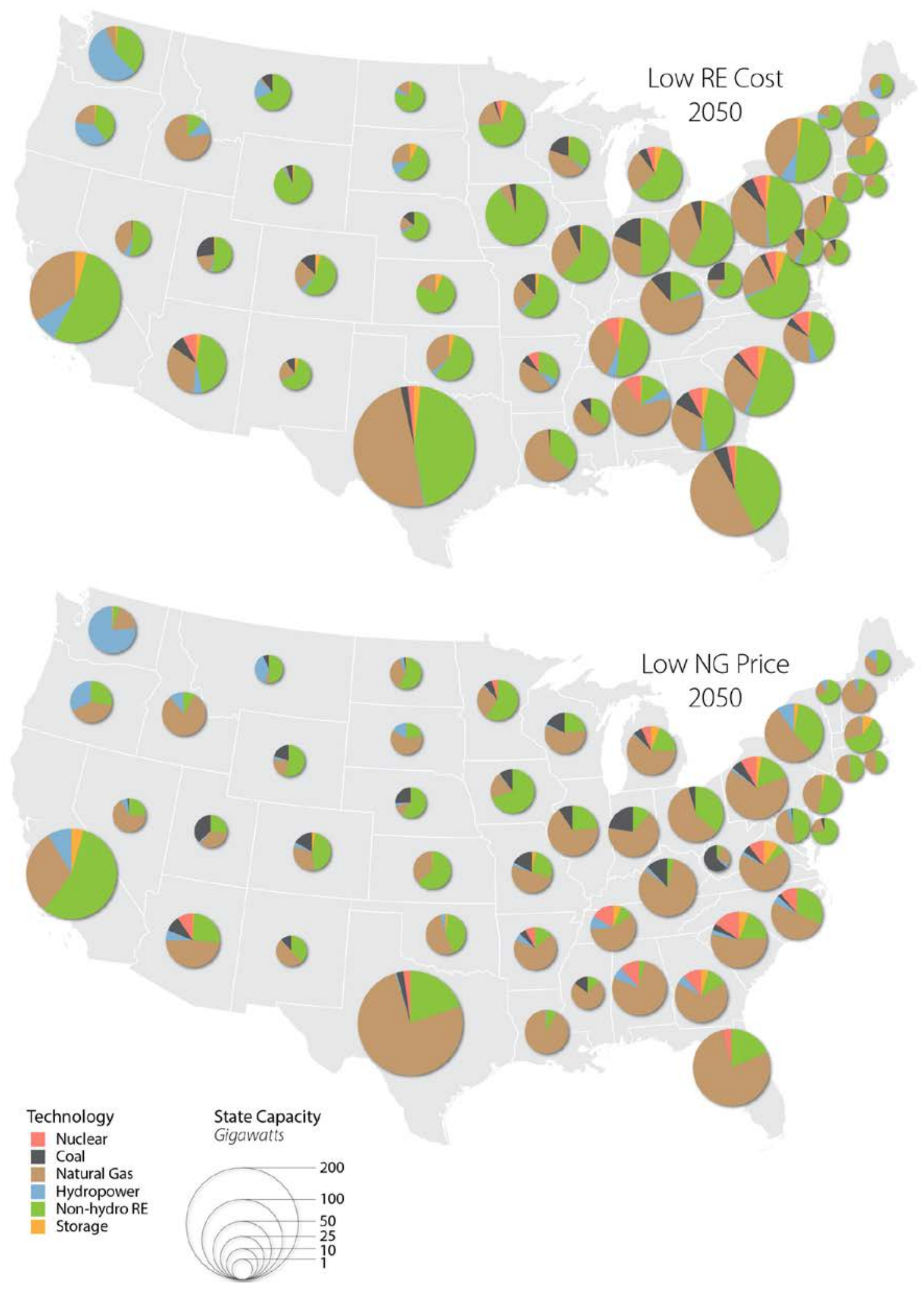

Figure 9. 2050 capacity mix in the (top) Low RE Cost and (bottom) Low NG Price scenarios 


\section{Text Box 1. Impact of Low Cost Financing}

While the cost to deploy new generating technologies is dominated by the total capital costs needed to purchase and install the generating equipment, the cost of financing that capital is also significant and affects the total cost of building new generation capacity. Because financing costs only impact capital costs and not operating costs, technologies with a higher ratio of capital costs will be more significantly impacted by changes in financing assumptions. For example, renewable technologies have no fuel costs, so their total life-cycle costs are more sensitive to financing assumptions than many conventional generators, which have a larger fraction of total costs coming from operating costs (primarily from fuel).

The Mid-case scenario assumes that the weighted average cost of capital (WACC) is $8.1 \%$ nominal across all technologies. This is based on the long-term interest and equity rates of return observed in the utility industry (Eurek et al. 2016). However, since the economic recession in 2008, interest rates have been much lower than their historical averages, and it is unknown whether they will return to their former levels or if there will be a period of protracted low interest rates. In addition, the ownership type (e.g., merchant vs. utility) can impact the financing mechanism, including debt fraction, thereby altering the WACC.

To explore this sensitivity, the Low Cost Financing scenario uses a lower constant WACC of $5.4 \%$ nominal for all technologies, which is representative of recent values observed in the power sector (EIA 2017a). As observed in Figure 9, in the short term, lower cost financing increases both wind and utility PV generation and displaces coal and natural gas generation. However, in the long term (i.e., past 2030), the lower cost financing results in further increased wind generation but no additional utility PV generation as compared to the Mid-case. This could be due to wind having in general higher overnight capital costs $(\sim \$ 1,250-\$ 1,600 / \mathrm{kW})$ than PV $(\sim \$ 920 / \mathrm{kW})$ in 2030 and beyond, which increases the impact of lower cost financing.

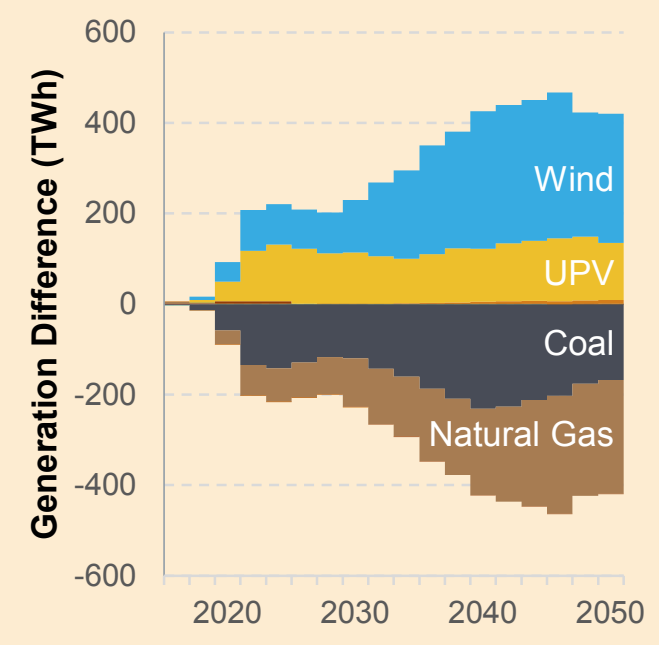

Figure 10. Difference in generation between the Low Cost Financing scenario and the Mid-case 
The increases in natural gas and renewable energy found in all scenarios can reduce emissions intensities due to the lower combustion-related emissions of these technologies relative to coalfired technologies without carbon capture. The same applies to power sector water use, as natural gas and renewable energy technologies require little water compared to coal and nuclear technologies (Macknick et al. 2012; Meldrum et al. 2013). Figure 11 shows how U.S. power sector direct $\mathrm{CO}_{2}$ emissions and water consumption in the Mid-case and non-policy scenarios remain relatively flat through about 2040 and decline thereafter. ${ }^{19}$ Due to increasing load growth, the emissions and water use intensities begin to decline more rapidly and to a greater extent. For example, we estimate that while absolute $\mathrm{CO}_{2}$ emissions are $20 \%$ percent lower in 2050 than modeled 2016 emissions in the Mid-case scenario, the emission intensity declines by $35 \%$ over the same period. Water consumption by the power sector exhibits the same behavior, with a $26 \%$ absolute water consumption reduction resulting in a 40\% intensity reduction from 2016 to 2050 . Similar behavior is observed for other air pollutants modeled in $\operatorname{ReEDS}\left(\mathrm{SO}_{2}\right.$ and $\left.\mathrm{NO}_{\mathrm{x}}\right)$ and for water withdrawals. ${ }^{20}$
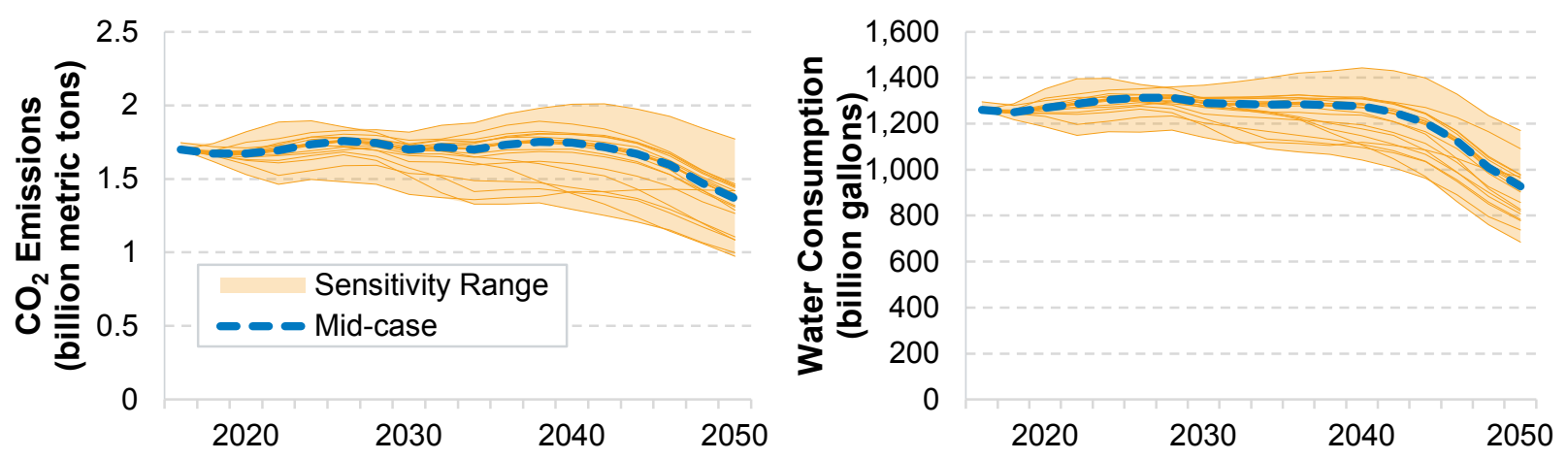

Figure 11. Power sector emissions and water use decline slowly in all non-policy scenarios.

\section{Key Insights}

- Nearly all of the new capacity and growth in electricity generation is projected to be from the renewable energy and natural gas sectors in all non-policy scenarios modeled.

- Future natural gas prices and renewable technology advancements are the greatest determinants of the long-term relative generation shares for natural gas and renewable energy, but they can be extremely difficult to accurately predict. Thus, a wide uncertainty range is found across all non-policy scenarios.

- Both competitive and complementary relationships are found between natural gas and renewable energy technologies. The scenarios demonstrate a wide spectrum of results ranging from one with predominant growth in renewable generation to others where natural gas generation serves the majority of electricity consumption and those with growth from both renewable energy and natural gas. However, the range of grid services offers capacity growth opportunities for both groups of technologies in many scenarios.

\footnotetext{
${ }^{19}$ In the Mid-case, $2030 \mathrm{CO}_{2}$ emissions are estimated to be nearly identical to modeled 2016 emissions.

${ }^{20}$ Water consumption is water that is used for power plant cooling but not returned to the source, whereas water withdrawals are returned to the source but at a higher temperature.
} 
- Growth in natural gas and renewable capacity is found in nearly all states.

- The greater reliance on natural gas and renewables - and the corresponding reduction in coal and nuclear - results in consistent reductions in power sector emissions intensity and water use intensity; however, absolute emissions and water use decline more slowly.

\subsection{Relative Competitiveness of Wind and PV}

\section{Recent Trends}

Wind and solar photovoltaics (both utility-scale and distributed) have grown sharply over the last decade, increasing by nearly an order of magnitude from $0.7 \%$ of the generation mix in 2006 to $6.8 \%$ in 2016 (EIA 2017b). In comparison, total generation from hydropower, geothermal, concentrating solar power, and biomass sources has been relatively constant (see Figure 12). This growth has been due to improvements in wind and PV technology cost and performance along with a variety of supporting factors such as state renewable portfolio standards, federal tax incentives, corporate and consumer preferences, and state and federal environmental regulations.

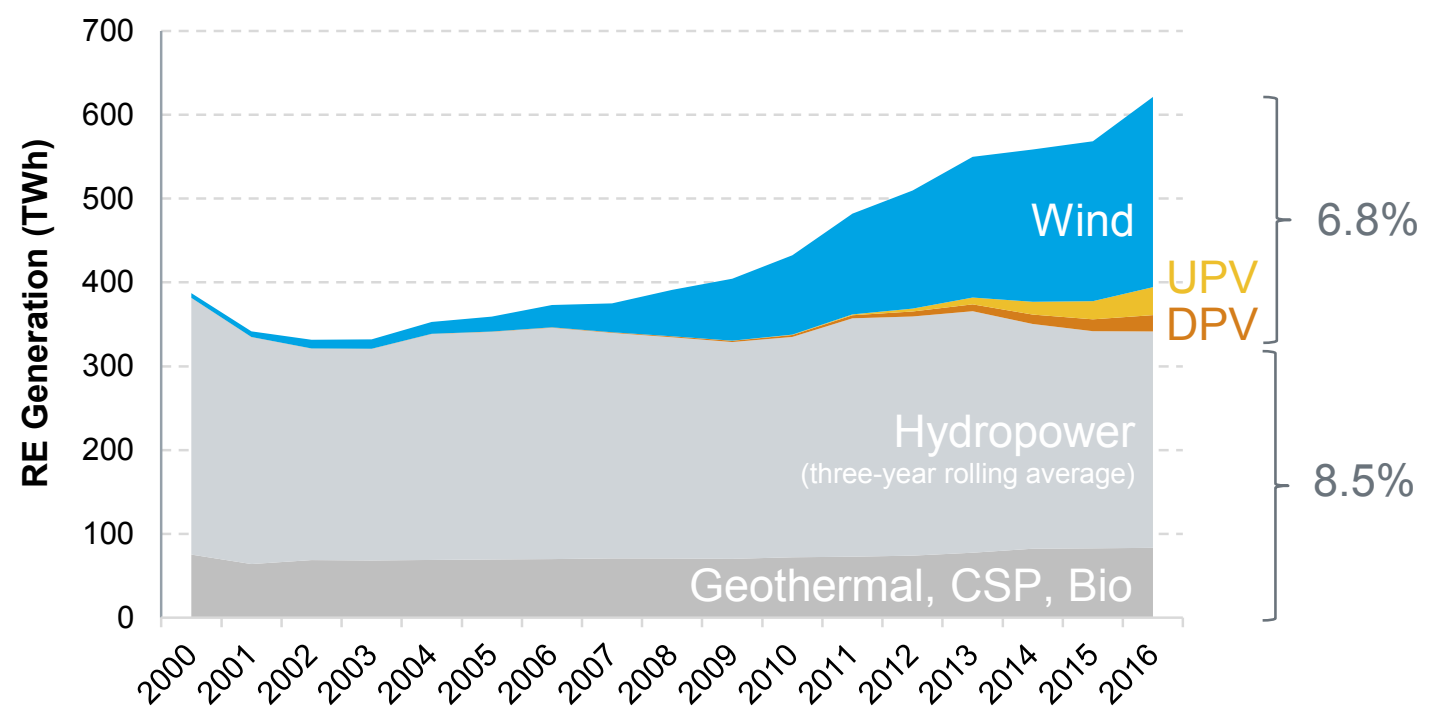

Figure 12. Recent growth in RE generation is primarily from wind and from PV (EIA 2017b)

Reported power purchase agreement (PPA) prices offer a way to gauge the relative changes in the cost of wind and PV over the past few years, including the effects of direct state and federal incentives and technology improvements. Figure 13 highlights how both wind and PV costs have fallen in recent years as measured by average PPAs. Average wind PPAs have fallen from a high of over \$70/MWh in 2009 to around \$20/MWh in 2017, driven in part by installations in the interior of the country at high resource quality wind sites and technology advancements that improve performance. Utility-scale PV PPAs have also fallen dramatically, from nearly $\$ 200 / \mathrm{MWh}$ in 2008 to under $\$ 40 / \mathrm{MWh}$ in 2017 . As the level of incentives has been relatively 
constant over this period, a major driver of these cost declines can be attributed to improvements in technology cost and performance. ${ }^{21}$

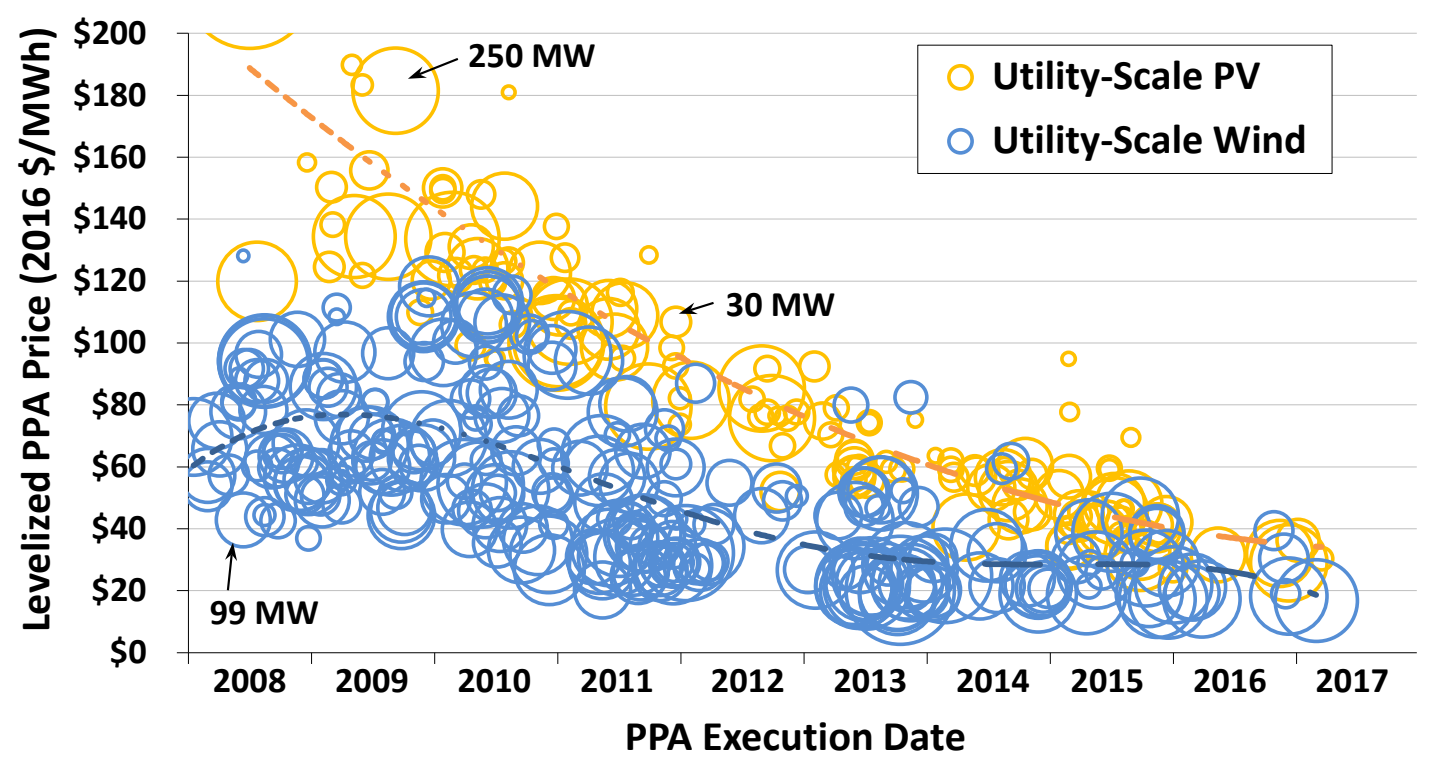

Figure 13. Recent declines in wind and PV costs observed in power purchase agreement prices. $\mathrm{PV}$ is increasingly cost competitive with wind PPAs and is approaching natural gas fuel only prices. Note that PPAs are market values that reflect the impact of tax credits and other incentives.

Figure from Wiser, Bolinger, and Seel (2017)

The rapid decline in PV PPAs also highlights how both wind and PV are much more costcompetitive today with other generators, including natural gas. The relatively similar prices of wind and PV today mean they are also increasingly competing with each other for market share. This dynamic of the relative competitiveness of wind and PV is likely to play a larger role as costs of these technologies continue to evolve.

\section{Outlook}

As outlined in Section 3.1, natural gas and renewable energy experience strong growth across a wide range of scenarios. As natural gas, wind, and PV continue to be cost-competitive with one another, small relative changes to their assumed future costs can have a large impact on their projected future deployment. Figure 14 shows total VRE generation as percent of total generation, with the VRE cost and natural gas price sensitivities highlighted. The high and low natural gas price sensitivities impact the VRE penetration by basically the same magnitude as high and low RE cost scenarios. VRE penetration in 2050 ranges from approximately $17 \%$ to $50 \%$ in both high and low RE cost and NG price scenarios, as compared to $37 \%$ in the Mid-case scenario. In addition, these sensitivities have the largest impact on VRE penetration of any other sensitivity explored in the set of Standard Scenarios.

\footnotetext{
${ }^{21}$ The 30\% ITC for PV has been constant over this period, and while the PTC for wind has lapsed and been renewed multiple times, the majority of wind generators were put in service when the PTC was active, and are thus eligible to receive the PTC. For further discussion of technology improvements, see Wiser and Bolinger (2017) and Bolinger and Seel (2016).
} 


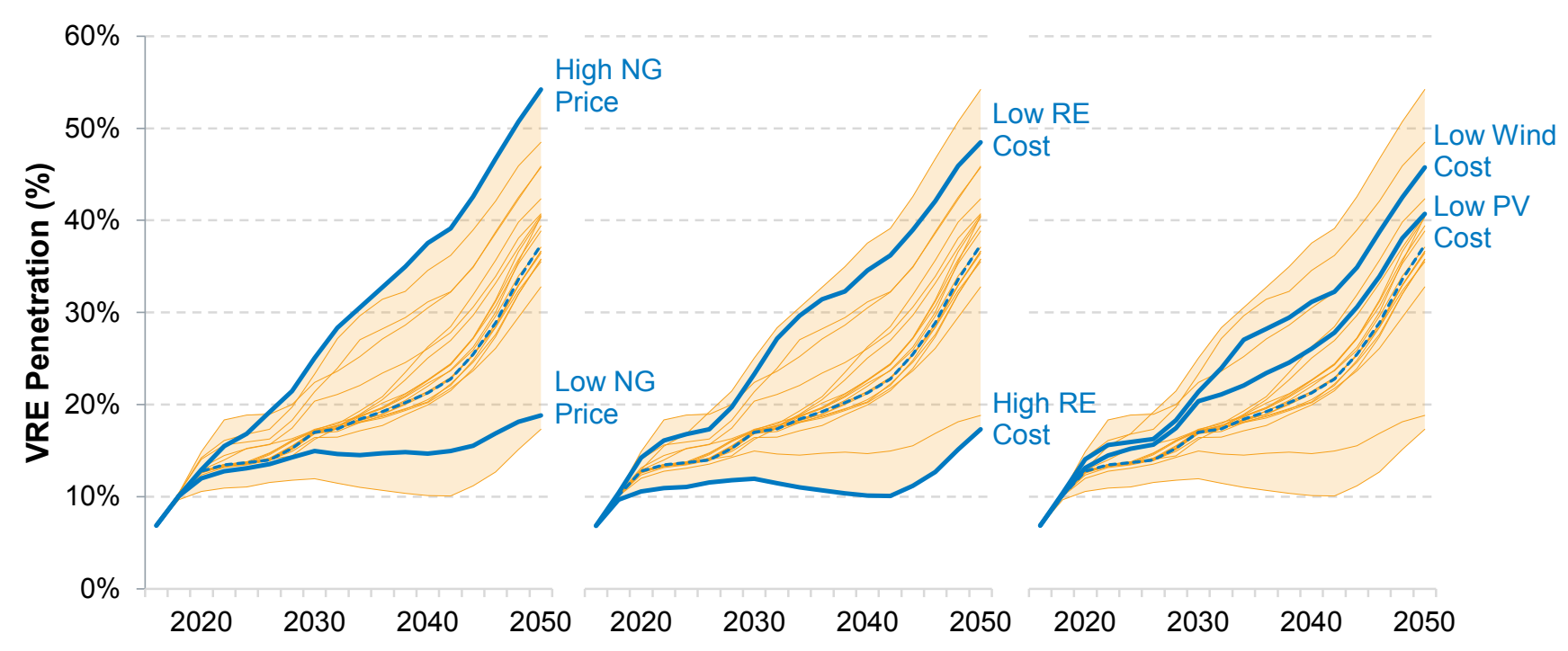

Figure 14. Relative wind and solar costs along with natural gas prices are major factors driving VRE generation. High natural gas price scenarios provide nearly as much range in VRE generation (left) as does the range in future VRE technology costs (middle). Either low-cost wind or low-cost solar results in nearly the same share of VRE generation by 2030 (right). Dotted blue line represents the Mid-case.

However, the future trajectories for each individual RE technology are highly uncertain and there is little reason why future cost reductions in both wind and solar would be correlated as in the Low RE Cost scenario. Therefore, we also examine the Low Wind Cost and Low PV Cost scenarios separately to see the impacts if only one technology experiences more aggressive cost declines relative to the other. Figure 14 (right) shows that total VRE penetration for both scenarios are roughly the same in the near term, reaching $21 \%$ by 2030 . The Low Wind Cost scenario goes on to reach $46 \%$ VRE generation in 2050 compared to $41 \%$ in the Low PV Cost scenario.

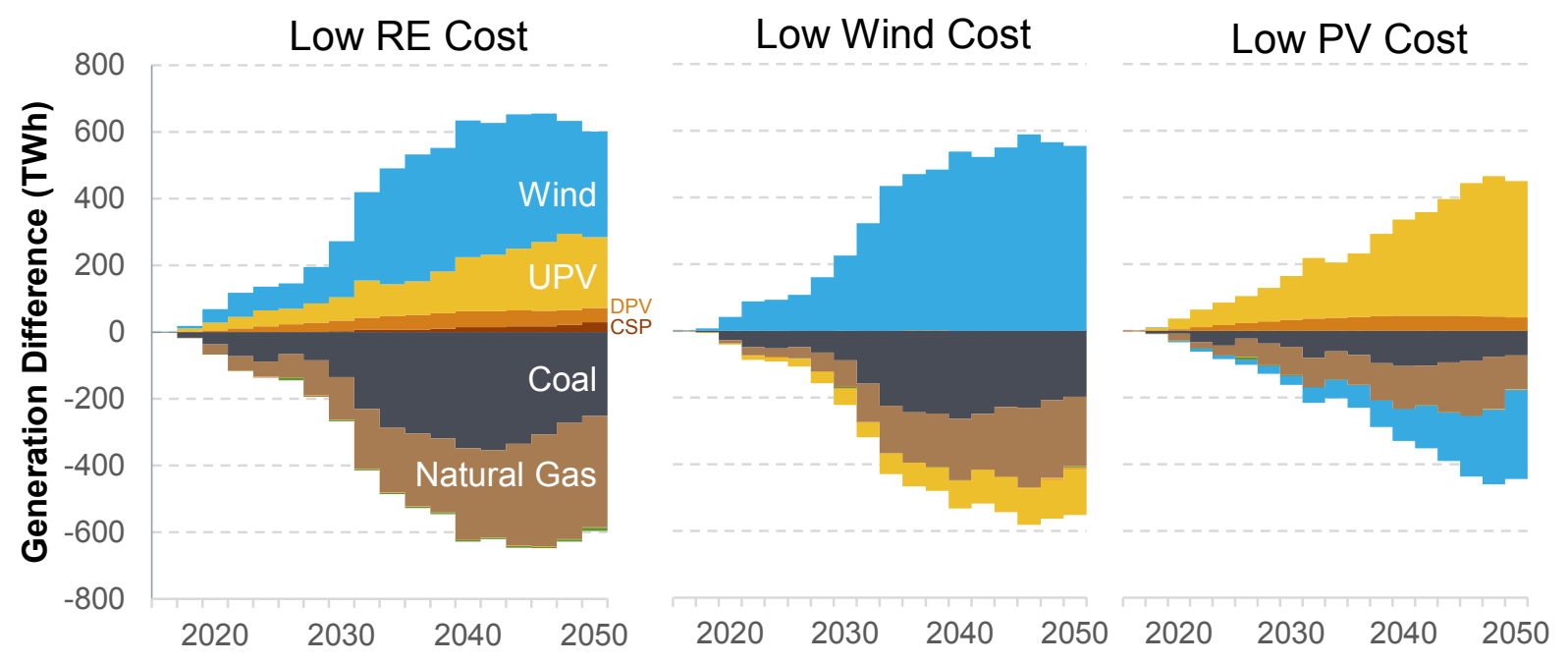

Figure 15. Generation differences between the Low RE Cost (left), Low Wind Costs (middle), and Low PV Cost (right) and the Mid-case scenarios 
The generation profile relative to the Mid-case changes significantly under the different low renewable cost scenarios. Figure 15 highlights that in the Low RE Cost case, there are 260 additional terawatt-hours (TWh) of renewable generation by 2030, rising to nearly 600 additional TWh by 2050 , with the additional generation being split roughly equally between wind and solar in those years. This additional generation in turn displaces approximately equal amounts of coal and natural gas generation

The Low Wind Cost scenario keeps the wind costs on an aggressively low trajectory, while maintaining Mid-case costs for solar. The additional generation is entirely wind, but it reaches nearly the same levels of wind and solar in the Low RE Cost scenario: 225 TWh of additional wind in 2030 and 554 TWh in 2050. Again, while this displaces roughly equal amounts of coal and natural gas generation, it also displaces a smaller but still-significant amount of utility PV generation: 136 TWh by 2050 representing $25 \%$ of the total displaced generation that year. This indicates that these technologies are in competition, especially in the 2030-2050 timeframe. ${ }^{22}$ Distributed PV generation is relatively unaffected by additional wind generation, as those two technologies do not compete directly at the utility level.

Similarly the Low PV Cost scenario results in additional PV generation, at $+163 \mathrm{TWh}$ and +448 TWh over the Mid-case by 2030 and 2050 respectively. These results are lower than the additional generation observed in the Low RE Cost and Low Wind Cost scenarios. Interestingly, while the additional PV generation mostly deplaces coal and nautral gas generation through 2030, from 2030 to 2050, it increasingly displaces wind generation relative to the Mid-case. In 2050, the 448 TWh of displaced generation is only 39\% from coal and natural gas compared to 59\% from wind. This change in generation mix again highlights how PV and wind costs are competitive with one another, and a shift in the relative costs results in generation shifting from one technology to the other and not just reduced generation from conventional sources. In both the Low PV Cost and Low Wind Cost scenarios, however, there is still an increase in net renewable energy generation.

The difference in the generation mix across the RE cost senstivities is evidenced in the impact on $\mathrm{CO}_{2}$ emissions and system costs shown in Table 2. As seen in Table 2, in 2030 there is a relatively limited range of impact on $\mathrm{CO}_{2}$ emissions and system costs for the RE cost sensitivity scenarios. By 2050, the absolute impact of each scenario grows substantially, except for the $\mathrm{CO}_{2}$ emissions in the Low PV Cost, which only increases in magnitude from $-5 \%$ in 2030 to $-7 \%$ in 2050. This highlights how additional PV generation tends to displace wind power in the later years instead of $\mathrm{CO}_{2}$-emitting resources such as coal and natural gas. The 2050 system costs also demonstrate that reaching the low RE costs results in nearly double the reduction in total system costs of only low-cost wind or low-cost PV.

\footnotetext{
${ }^{22}$ Wind and PV have generation profiles that differ by time and season, so they are not in direct competition for many hours of the year. However, both technologies compete indirectly through displaced natural gas fuel costs. The level of competition will vary regionally, while we have only shown nationally aggregated results here.
} 
Table 2. CO2 Emissions and System Costs Relative to the Mid-case Scenario

\begin{tabular}{|l|c|c|c|c|}
\cline { 2 - 5 } \multicolumn{1}{c|}{} & \multicolumn{2}{c|}{$\begin{array}{c}\text { CO2 Emissions Relative } \\
\text { to Mid-case }\end{array}$} & \multicolumn{2}{c|}{$\begin{array}{c}\text { Total System Costs } \\
\text { Relative to Mid-case }\end{array}$} \\
\hline Scenario & $\mathbf{2 0 3 0}$ & $\mathbf{2 0 5 0}$ & $\mathbf{2 0 3 0}$ & $\mathbf{2 0 5 0}$ \\
\hline High RE Cost & $+7 \%$ & $+30 \%$ & $+0.4 \%$ & $+6.3 \%$ \\
\hline Low RE Cost & $-11 \%$ & $-27 \%$ & $-0.6 \%$ & $-3.8 \%$ \\
\hline Low Wind Cost & $-7 \%$ & $-20 \%$ & $-0.4 \%$ & $-2.0 \%$ \\
\hline Low PV Cost & $-5 \%$ & $-7 \%$ & $-0.8 \%$ & $-2.3 \%$ \\
\hline
\end{tabular}
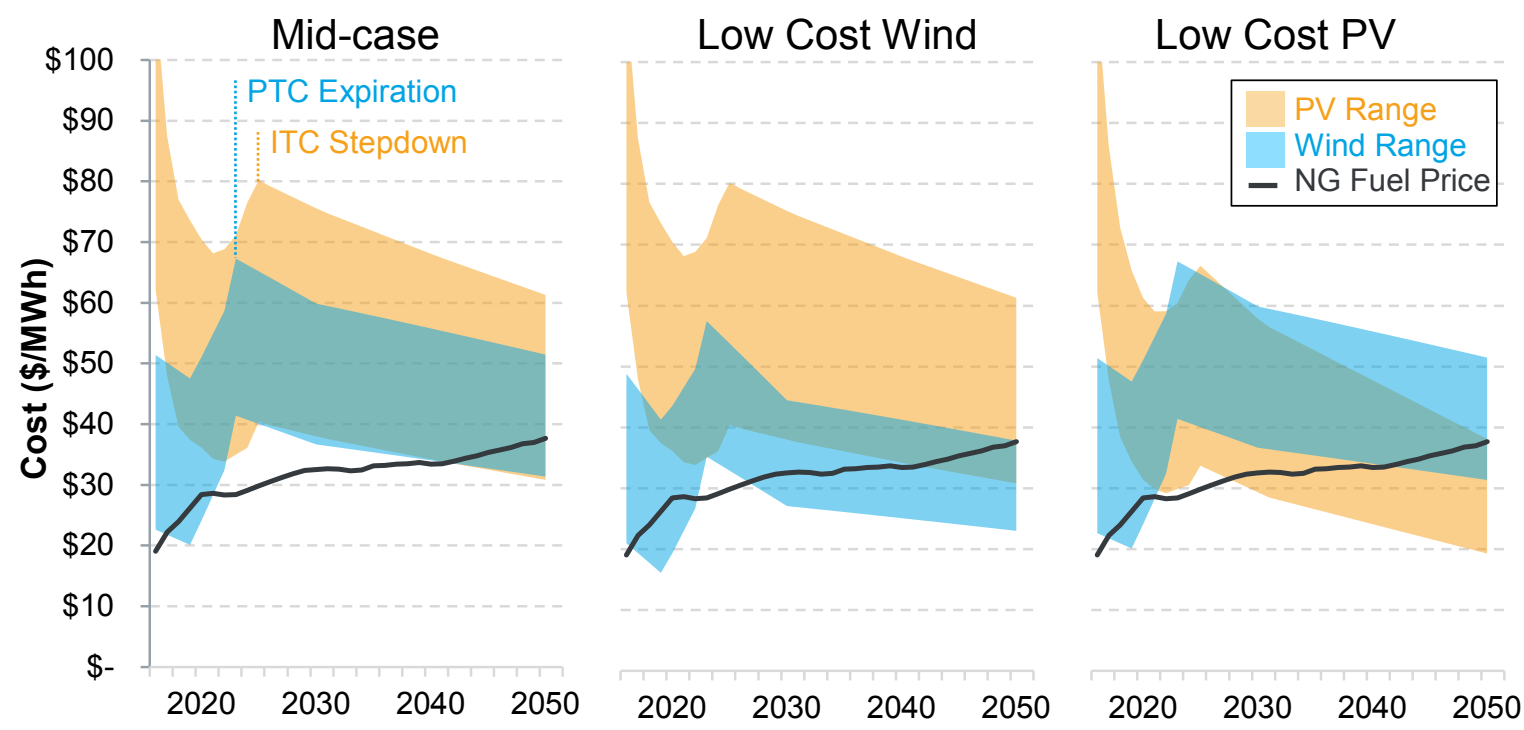

Figure 16. Relative wind and PV levelized costs compared to natural gas fuel price. Costs include effects of tax credits but exclude the highest cost, lowest resource quality wind resources (technoresource groups [TRGs] 8-10) for ease of comparison. These ranges also exclude geographic capital cost factors, and only account for costs within the plant boundary. Fuel price assumes combined-cycle heat rate. For details, see Eurek et al. (2016) and the 2017 Annual Technology Baseline (ATB) (NREL 2017)

The ranges of cost trajectories for wind and PV in each scenario can help readers interpret some of these results. Figure 16 shows the relative range in levelized costs for wind and PV across various resource qualities, and it includes the impact of tax credits. After the tax credits expire or revert to their permanent levels, the range of wind and utility PV costs strongly overlap. In either the Low Cost Wind or Low Cost PV scenario, this overlap in cost ranges is lessoned such that one technology range separates from the other, resulting in increased deployment and generation for that technology.

In addition to the differences in costs between wind and PV, the ReEDS model considers the temporal and spatial value of each technology, which impacts deployment and generation even if costs are equivalent for the technologies. In regions with low PV penetration, PV generally provides a higher capacity value, as it typically generates during peak demand hours. Therefore in these regions, PV may be preferentially deployed in some areas over similar cost wind. 
However, the capacity and energy value of PV tends to fall faster than wind as a function of PV penetration, because most $\mathrm{PV}$ produces during the same time of day, shifting the timing of when additional capacity or when more-expensive units are needed to later in the day. Therefore, at greater PV penetrations, similar cost wind generation may offer higher value (Denholm et al. 2016). Therefore, even as PV in the Low-Cost PV scenario reaches the same range of costs as wind in the Low-Cost Wind scenario, the reduction in PV value at higher penetrations may limit further PV deployment relative to wind.

The sensitivity of results to changes in the relative competitiveness between wind and PV means that for similar cost wind and PV projects, future outcomes are likely to be sensitive to other local non-economic factors that are not fully captured in the scenarios here. As an example, the transmission needs differ between the Low Cost Wind and Low Cost PV scenarios. By 2050, the transmission additions in the Low Cost Wind scenario are $26 \%$ greater than the transmission additions in the Low Cost PV scenario. This reflects the relatively greater need for transmission to access more remote wind resources as compared to PV, and highlights one of the additional factors beyond just technology cost or system benefit that could affect the relative deployment of these technologies. These other factors include the local perception of wind and PV, costs to develop specific locations, and the generation profile of an individual wind or PV site relative to the local demand profile and capacity needs at a specific location.

\section{Key Insights}

- In the long term, the range of projected wind and PV costs are nearly the same, resulting in deployment projected outcomes that are highly sensitive to relative costs.

- Higher deployment of either wind or PV displaces a portion of the other technology, but not on a direct one-to-one basis.

- Total VRE generation through 2030 is not as affected by whether wind or PV is lower in cost; by 2050, the net VRE generation is higher in the Low Wind Cost and Low PV Cost scenarios relative to the Mid-case, but neither is as high as the Low RE Cost scenario.

- Differences in modeled value such as capacity credit and energy value drive differences in modeled deployment; other non-economic factors not captured in the modeled results for wind and PV, such as transmission and local considerations, will be increasingly important in determining the future deployment of each of these technologies.

\subsection{The Potential for Battery Storage}

\section{Recent Trends}

Cumulative battery storage capacity in the United States as of the first quarter of 2017 was over $600 \mathrm{MW}$ and nearly $900 \mathrm{MWh}^{23}$ (GTM Research and ESA 2017). Although battery storage represents a small fraction of the overall electricity system - there are $22 \mathrm{GW}$ of existing pumped-storage hydropower in a system with around $1,000 \mathrm{GW}$ of total capacity-the costs of battery storage have been dropping rapidly (see Figure 17) and many groups are increasingly bullish in their projections of how storage might shape the electricity sector (GTM Research and ESA 2017; Schmidt et al. 2017; Kittner, Lill, and Kammen 2017). Battery storage was recently

\footnotetext{
${ }^{23}$ Storage is rated in both power capacity (MW) and energy capacity (MWh). We report both values here.
} 
deployed to address the Aliso Canyon natural gas storage leak, with systems put in place in just nine months (Trabish 2017). And, Tesla recently announced the largest lithium-ion battery storage project to be built, in Australia with $100 \mathrm{MW}$ and $129 \mathrm{MWh}$ of capacity (Tesla 2017). ${ }^{24}$

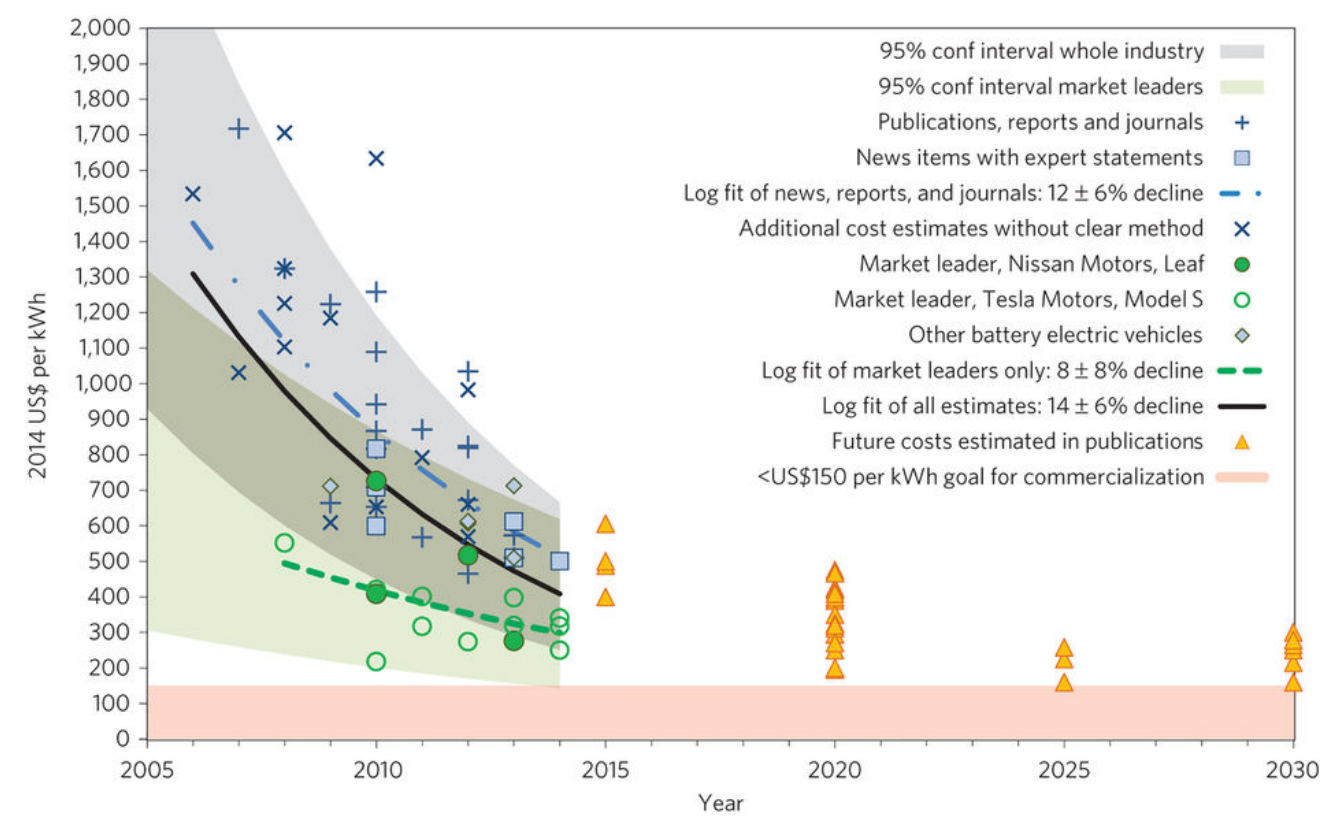

Figure 17. Battery costs from 2005 through 2014 (Nykvist and Nilsson 2015)

\section{Outlook}

Projections for battery costs in the three battery cost scenarios are shown in Figure 18 for eighthour duration batteries. In the Low Battery Cost scenario, battery costs approach those of NG-CT units, which have traditionally been used to meet peak demand and resource adequacy requirements.

\footnotetext{
${ }^{24}$ Pumped storage hydropower is another storage technology with potential for cost declines, but that technology is not considered in detail in this report. However, a detailed analysis, including the consider of low-cost pumped storage hydropower projections, can be found in the Hydropower Vision Study (DOE 2016).
} 


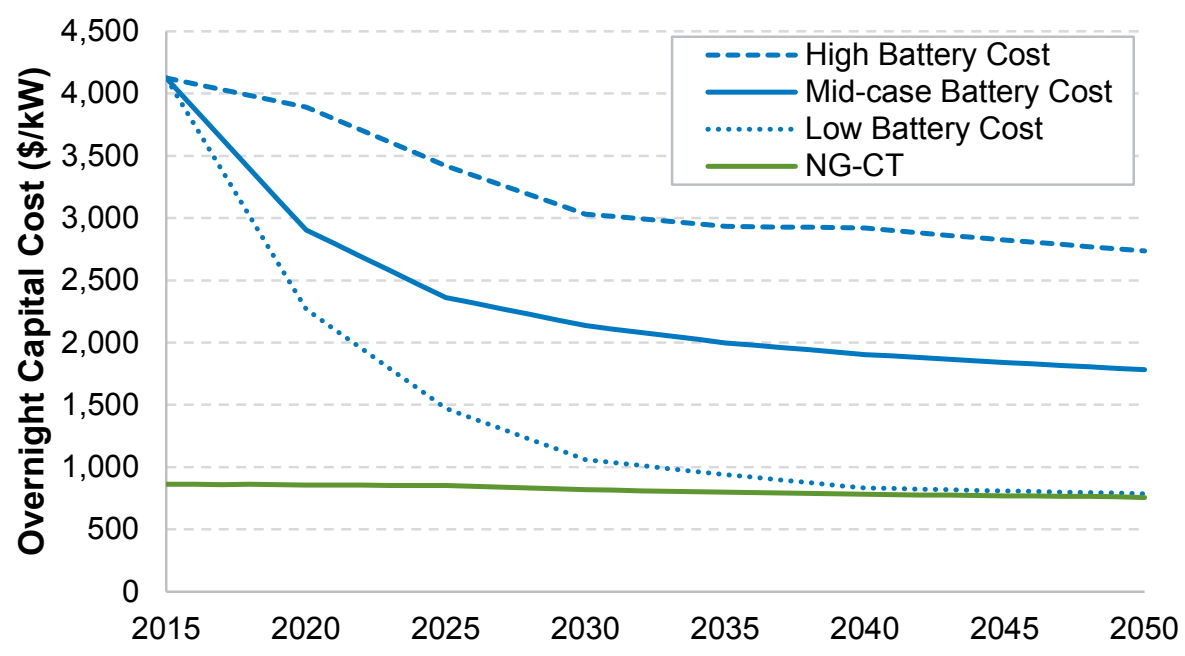

Figure 18. Overnight capital cost projections for eight-hour lithium-ion batteries (blue) and NG-CT plants (green). Battery costs are from Cole, Marcy, et al. (2016) and NG-CT costs are from the 2017 Annual Technology Baseline (NREL 2017).

Cumulative storage deployment across the Standard Scenarios is shown in Figure 19. All scenarios see some amount of growth in storage capacity, ${ }^{25}$ though in many scenarios that growth is quite small. Only four of the scenarios in Figure 19 exceed $50 \mathrm{GW}$ of storage deployment by 2050 , and two of those scenarios are policy scenarios that favor high penetrations of VRE. The Low Battery Cost scenario yields $140 \mathrm{GW}$ of cumulative storage by 2050 , which represents 15 times more new storage capacity than is built in the Mid-case scenario. Nearly all new storage is built after 2030, which in part reflects that the model is not representing shortduration storage that has been more commonly deployed historically and that is expected to be a significant part of near-term market growth (GTM Research and ESA 2017). ${ }^{26}$

\footnotetext{
${ }^{25}$ Nearly all of the new storage capacity is battery storage as opposed to pumped storage hydropower or compressed air energy storage.

${ }^{26}$ The battery storage represented in the Standard Scenarios runs is exclusively eight-hour storage.
} 


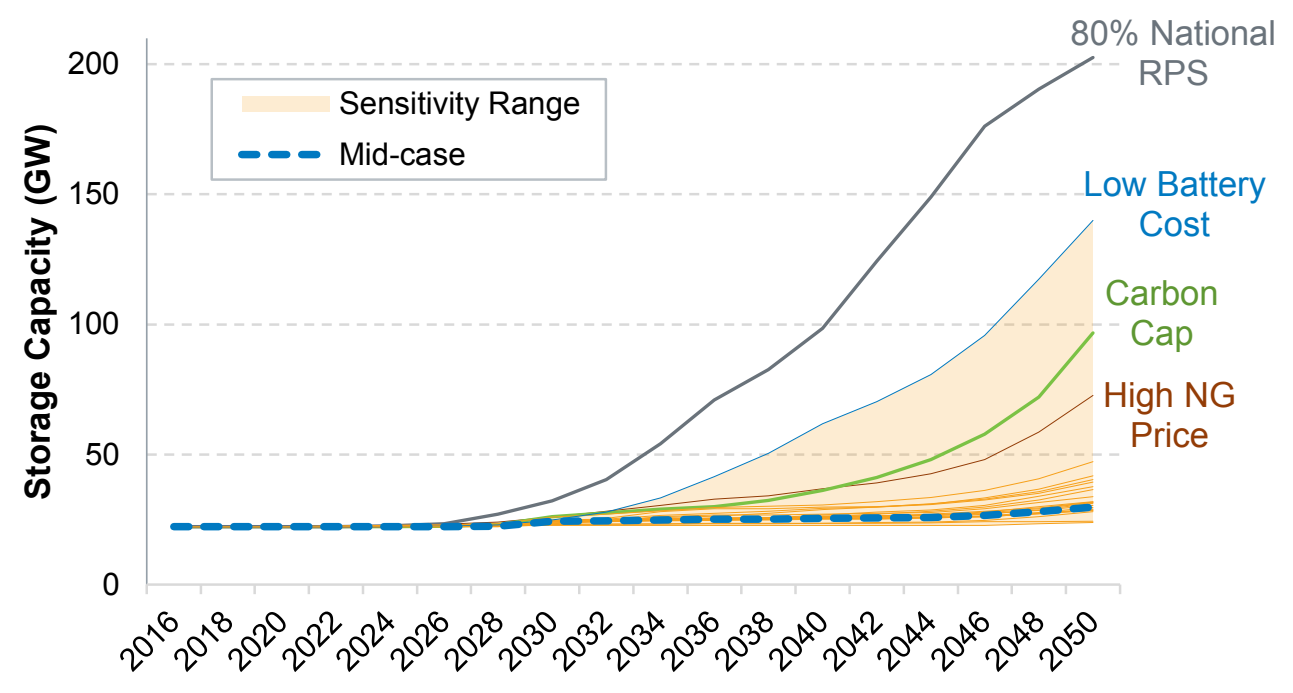

Figure 19. Cumulative storage capacity over time. In addition to the non-policy scenario sensitivity range, the two policy scenarios are also shown because of their high level of storage deployment.

Energy storage deployment is strongly correlated in the Standard Scenarios with VRE penetration (see Figure 20). Higher VRE penetration typically results in higher curtailment, and because storage is able to recover curtailed energy by charging during periods of curtailment, the value proposition for storage increases as curtailment increases. Higher VRE penetration also increases the amount of reserves that need to be held in order to account for the variability and uncertainty of VRE resources, and battery storage is able to provide those reserves. As shown in Figure 20, low-cost battery storage can alter the relationship between VRE and storage deployment. In the Low Battery Cost scenario, storage is inexpensive enough to also be the lowest-cost mechanism for providing firm capacity to the system, allowing it to be deployed independent of any VRE-related value streams. Capacity is the highest value stream for longerduration storage (Denholm, Diakov, and Margolis 2015), so this transition in competitiveness with other options for meeting peak load enables storage to grow rapidly independent of other value streams. 


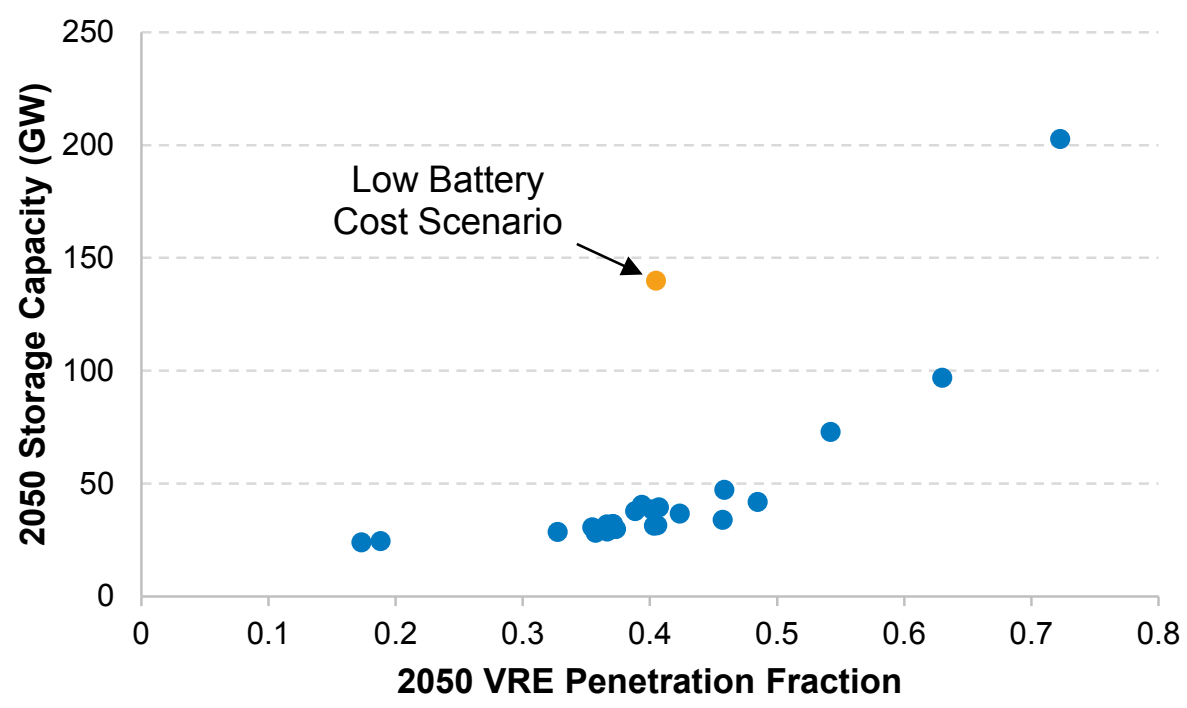

Figure 20. Storage capacity in 2050 versus VRE generation penetration fraction in 2050. The points on the figure are from the scenarios shown in Figure 19.

The impact of low storage costs on the model results relative to the Mid-case scenario is shown in Figure 21. The additional storage capacity (and resulting reduction in NG-CT/OGS capacity) can readily be seen on the right, demonstrating the value that storage receives from providing firm capacity. The increase in storage capacity is also accompanied by an increase of $50 \mathrm{GW}$ in solar PV capacity. The storage allows the PV to have a lower effective marginal curtailment rate and thus be more cost competitive with other resources. And in contrast to what was seen in Section 3.3, this increase in PV capacity comes without any decrease in 2050 wind deployment. In other words, low-cost storage enables increased deployment of PV while also maintaining the value of wind. That effect can also be seen in the left generation figure, as both solar PV and wind generation increase in 2050 . The increase in wind generation is primarily a result of less wind curtailments as storage is able to recover most of the curtailed energy. 

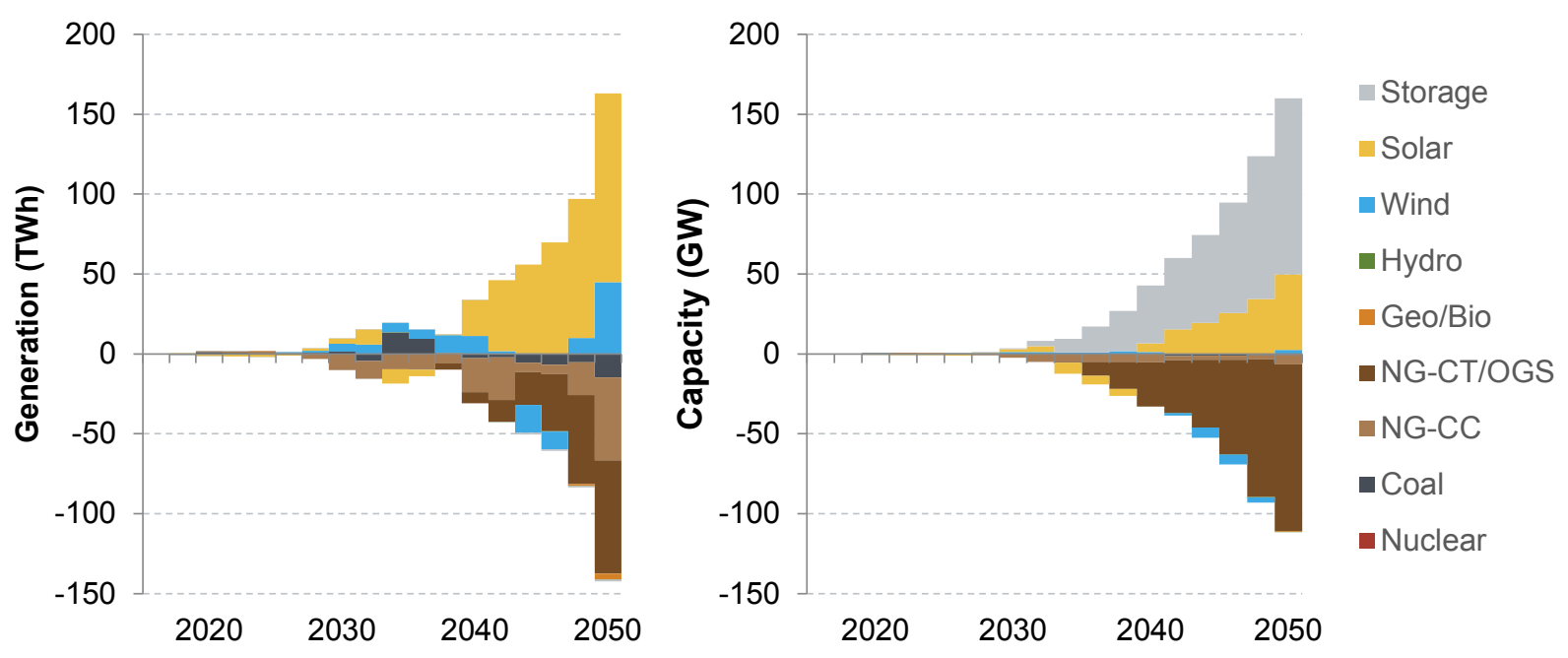

Figure 21. Difference in generation (left) and capacity (right) between the Low Battery Cost and Mid-case scenarios

The reduced-form system operation for the Low Battery Cost scenario is shown in Figure 22. Unlike most long-term storage facilities today (which are typically pumped storage hydropower systems) that store energy overnight and discharge during the afternoon, the storage in 2050 in the Low Battery Cost scenario stores energy during daytime hours and discharges primarily in the evening and overnight. Figure 22 also shows that most of the flexibility is provided by a combination of storage and natural gas generators, allowing coal and nuclear units to have nearconstant generation across all periods. Additionally, Figure 22 demonstrates the effectiveness of storage reducing curtailment. The Low Battery Cost scenario had the lowest curtailment rate $(<1 \%$ curtailment $)$ of all of the Standard Scenarios.

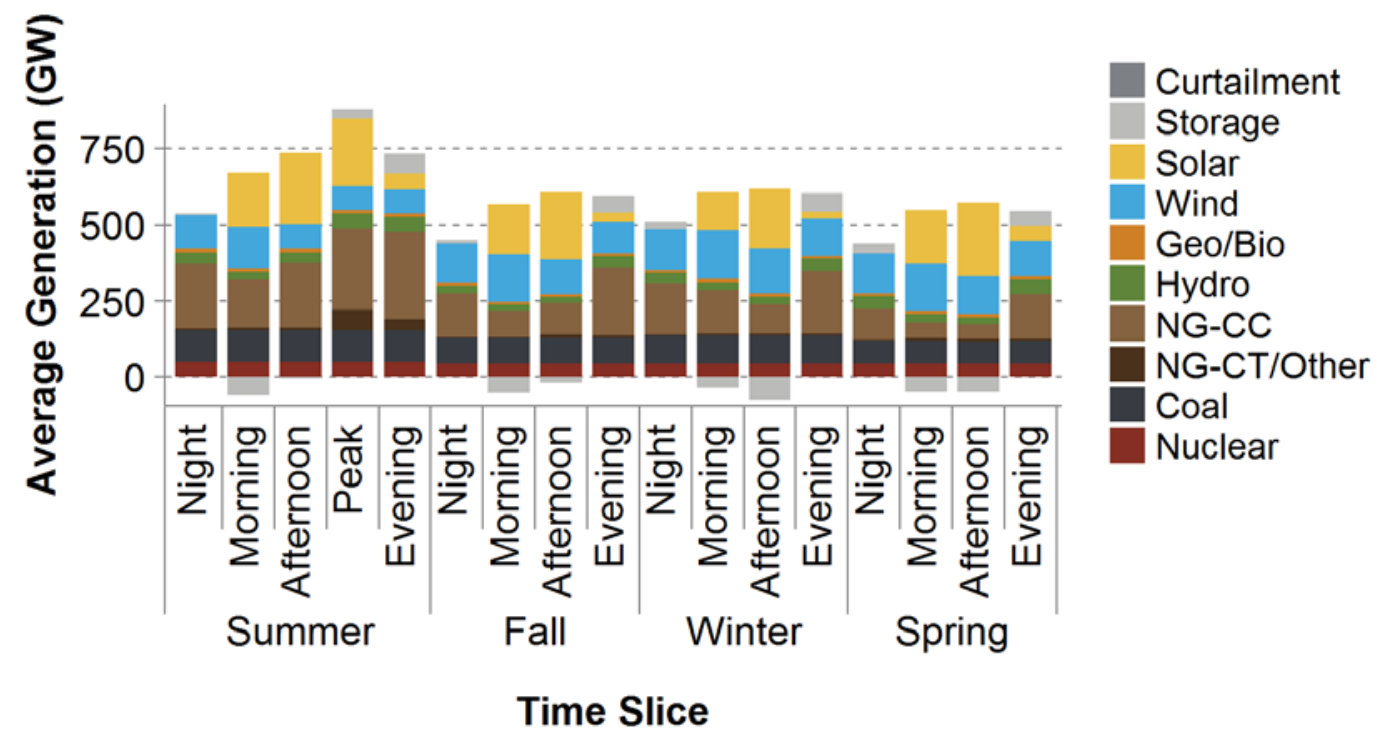

Figure 22. Nationwide average generation in each of the ReEDS time slices in $\mathbf{2 0 5 0}$ for the Low Battery Cost scenario. Storage is charging in the morning and, except for summer, the afternoon (as shown by the negative gray bars during those periods) and discharging in the evening and overnight periods (shown by the positive gray bars), and almost none of the VRE generation is curtailed. 
Figure 23 shows the normalized cost-of-service electricity prices in the non-policy scenarios. Of the 22 scenarios shown, two have electricity prices in 2050 that are lower than the 2016 prices: the Low NG Price scenario and the Low Battery Cost scenario. As has been shown above, low-cost storage increases the value of variable renewable energy, which by 2050 is projected to be among the lowest cost energy available (see Section 3.3), while simultaneously providing a lower-cost form of capacity. Cost reductions in wind and PV primarily reduce energy costs and provide little savings in terms of reducing capacity costs (because of their lower capacity credit at high penetrations), while storage is the opposite. Cost reductions in storage primarily serve to reduce capacity costs, but storage also provides considerable value in recovering curtailed energy and in serving as a flexible resource.

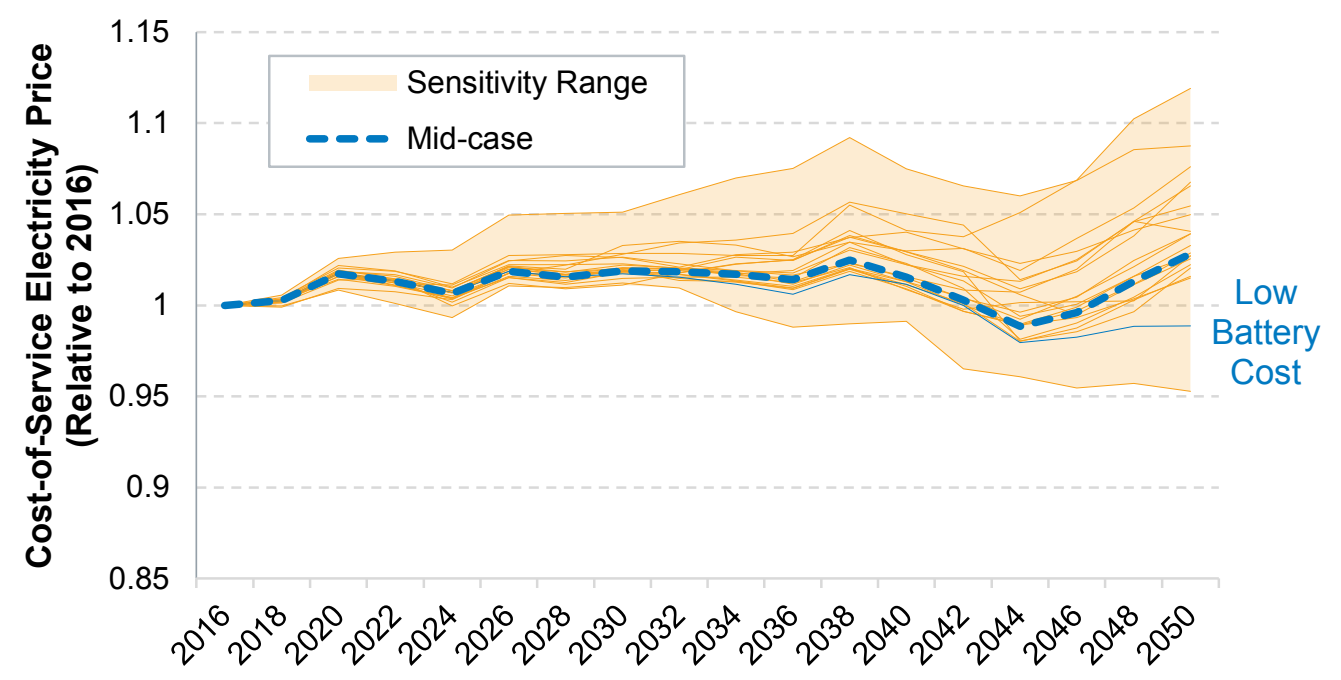

Figure 23. Cost-of-service electricity prices over time normalized to 2016 electricity prices. The Low Battery Cost scenario is one of two scenarios that have 2050 electricity prices that are lower than 2016 prices (the lowest scenario is the Low NG Price scenario).

\section{Key Insights}

- Among the twenty-six 2017 Standard Scenarios, variable renewable energy curtailment is lowest in the Low Battery Cost scenario.

- Low-cost battery storage can be the lowest-cost option for peaking capacity, resulting in new battery storage capacity offsetting new NG-CT capacity.

- Low battery costs increase PV deployment without decreasing wind deployment, which is counter to what was discussed in Section 3.3.

- The Low Battery Cost scenario leads to long-term electricity prices that are lower than current day prices because low-cost storage can lower both energy and capacity costs. 


\subsection{Uncertainty in Nuclear Lifetimes}

A number of nuclear power plants have retired before reaching the end of their operating licenses over the past several years, and several others have announced that they will retire before their licenses expire. What happens with the remainder of the nuclear fleet could have significant impacts on the remaining generation mix and associated emissions, water use, and renewable energy curtailment.

\section{Recent Trends}

Due to low sustained wholesale electricity prices, many nuclear power plants have faced revenue sufficiency challenges. Five nuclear power plants have retired over the last five years, and an additional six plants have announced they will retire before reaching the end of their operating licenses (CEE 2017; ABB 2017). Figure 24 shows the nuclear plants that retired since 2013 or have announced retirements. Several recent analyses have shown that approximately half of the current nuclear fleet is losing money (Haratyk 2017; Roth and Jaramillo 2017; Steckler 2017). Nuclear plants in restructured markets have had an especially difficult time competing against other generating technologies. With gas prices below four dollars per million British thermal units (MMBtu), average wholesale electricity prices are between $\$ 30$ and $\$ 35 / \mathrm{MWh}$ (Haratyk 2017). The average cost of nuclear generation is $\$ 35.5 / \mathrm{MWh}$ (NEI 2016), meaning that many reactors are likely selling power at a loss. In Figure 24, five of the six plants with announced retirement dates operate in restructured markets.

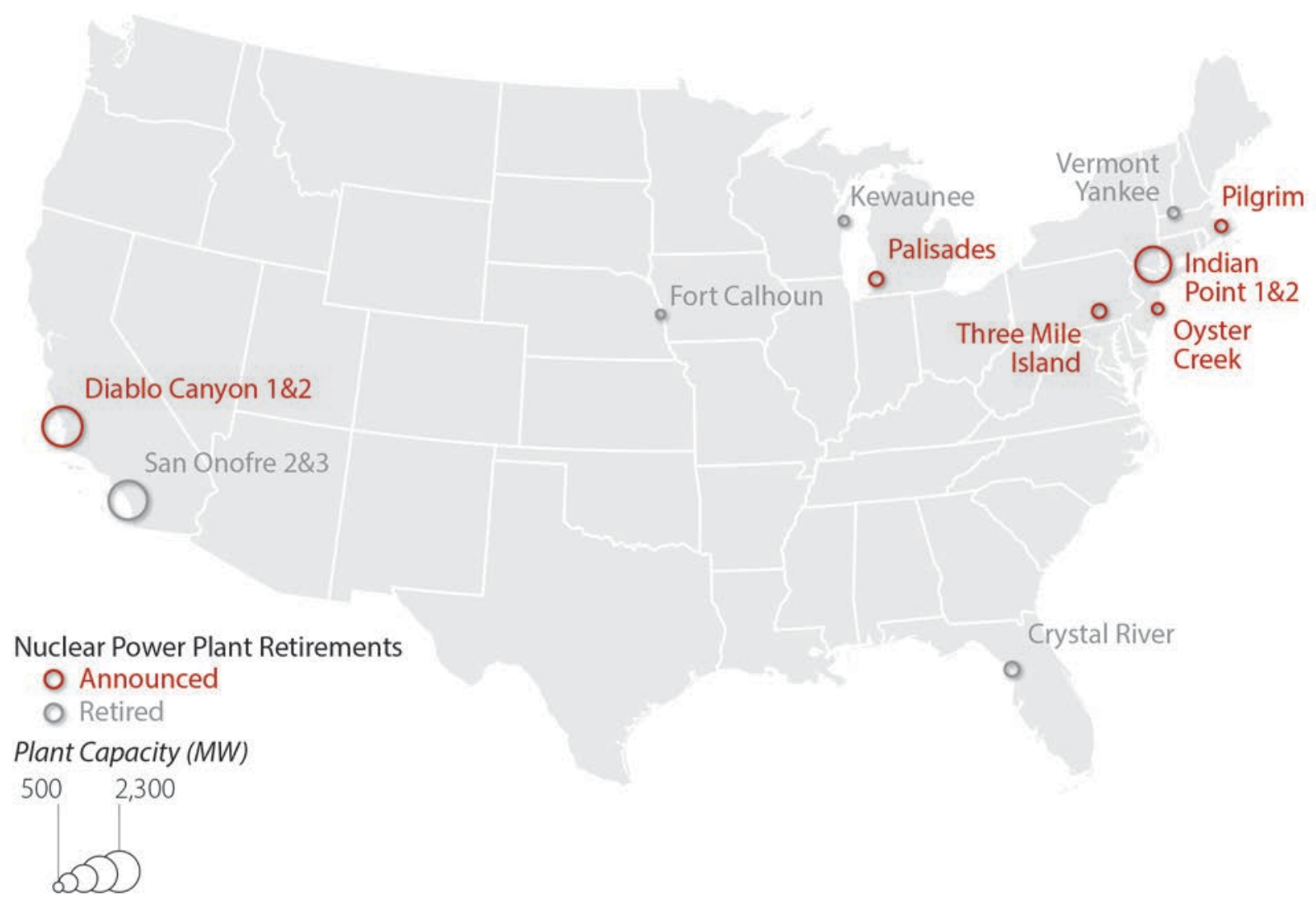

Figure 24. Recent and announced nuclear retirements (ABB 2017) 
Some states, such as Illinois and New York have passed legislation to financially support nuclear power plants within their states in order to prevent early retirements. Other states, including Pennsylvania, Ohio, and Connecticut are considering similar proposed legislation (Maloney 2017). Whether these state actions will spread or be successful might have a major impact on the continued operation of many existing nuclear units.

\section{Outlook}

Figure 25 shows the nuclear capacity across the four nuclear retirement scenarios that are included in the suite of Standard Scenarios. Although these retirements are exogenously specified (see Appendix A.1.4), they cover a wide range of potential future nuclear lifetimes and illustrate how nuclear lifetimes can impact the evolution of the power system. In the 80-year Lifetime scenario, no capacity is retired (other than announced retirements) until 2050. The Midcase sees approximately half of the current fleet capacity retire by 2050 , while the 60 -year and Early Retirement scenarios have very little nuclear capacity remaining by 2050 .

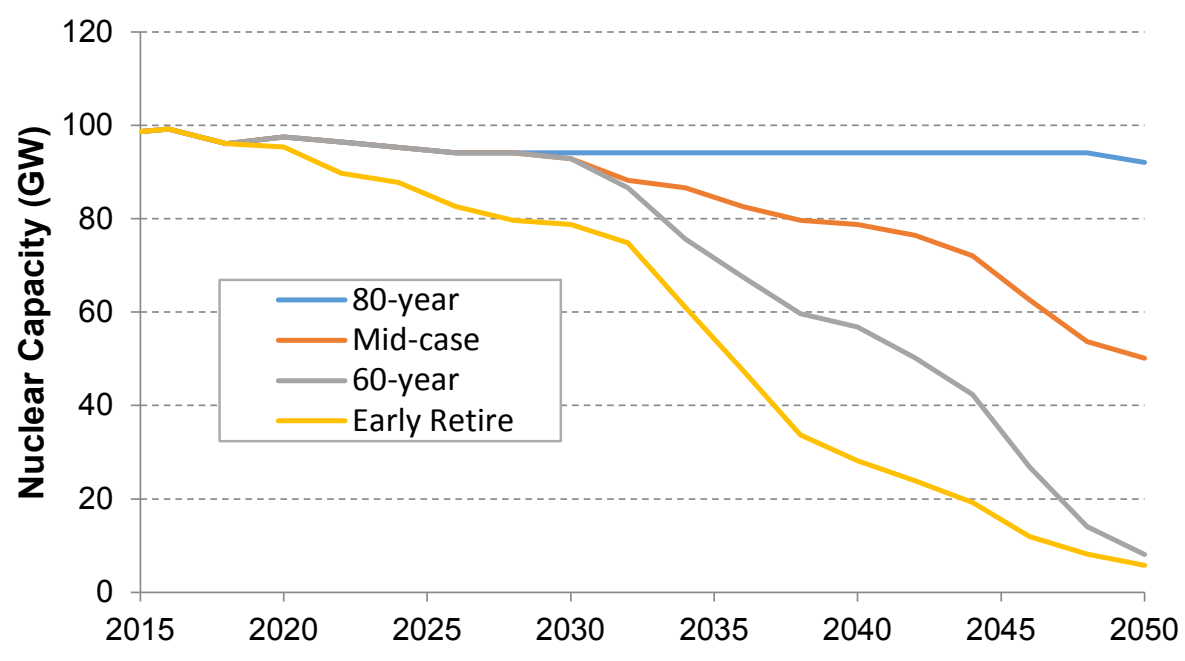

Figure 25. Nuclear capacity over time across the four retirement scenarios

Because nuclear plants have higher capacity factors in aggregate ( $>90 \%)$ than other plant types, less overall capacity is needed in the scenarios with longer nuclear lifetimes. For example, two $500-\mathrm{MW}$ combined-cycle plants operating at $45 \%$ capacity factor would be needed to replace the energy from a single 500 -MW nuclear plant operating at $90 \%$ capacity factor. ${ }^{27}$ This is demonstrated in Figure 26, which summarizes total capacity and generation changes relative to the Mid-case scenario. Because demand growth is constant across the four scenarios, the difference in total generation among the scenarios is almost zero (there is a small change due to different levels of system losses). And because of the high capacity factors of the nuclear plants, scenarios with more nuclear capacity have less total capacity. In 2050, the 80-year Lifetime scenario has nearly $50 \mathrm{GW}$ less total capacity than the Mid-case scenario while the Early Retirement scenario has about $60 \mathrm{GW}$ more total capacity than the Mid-case scenario.

\footnotetext{
${ }^{27}$ This substitution only applies to energy. Obviously, two 500-MW combined-cycle plants would provide twice the capacity of a single 500-MW nuclear plant, regardless of capacity factor.
} 
On average, by 2050 every $1.0 \mathrm{GW}$ of retired nuclear capacity is replaced by $2.2 \mathrm{GW}$ of other capacity.
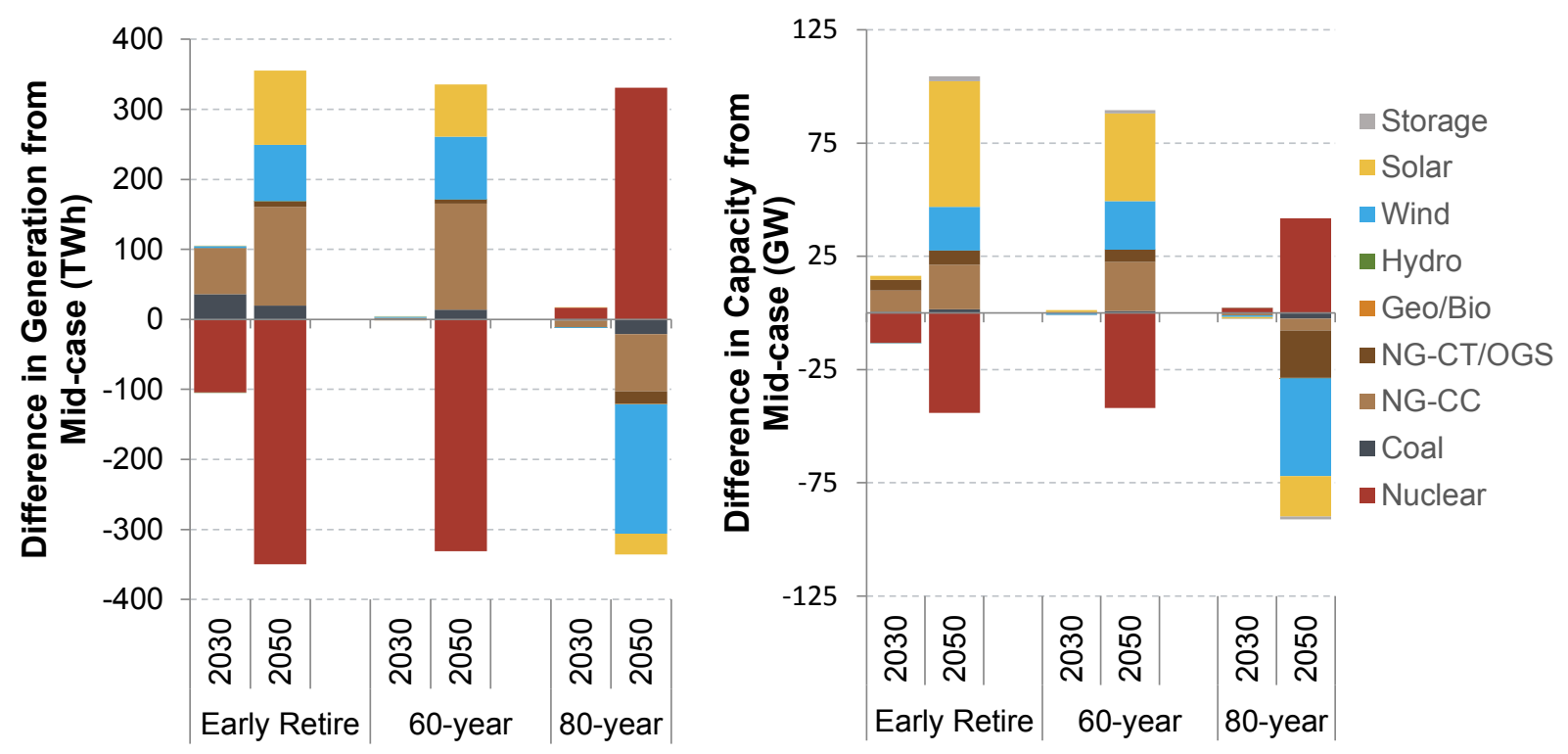

Figure 26. Generation and capacity differences by technology relative to the Mid-case scenario for 2030 and 2050. NG-CC is natural gas combined cycle, NG-CT is natural gas combustion turbine, OGS is oil-gas-steam, and Geo/Bio is geothermal and biopower.

The impact of the changing generation mix using the different nuclear retirement assumptions can also be seen in Figure 26. Retired nuclear generation in 2030 in the Early Retirement scenario is replaced by a mix of gas and coal generation, while the nuclear capacity is replaced by a mix of NG-CT and NG-CC units. In 2050, the impact on the mix varies across the scenarios. The Early Retirement and 60-year Lifetime scenarios have nuclear generation replaced by natural gas, wind, and solar generation, with natural gas being the largest contributor. In the 80-year Lifetime scenario, wind generation is the most impacted. As noted in Section 3.1, wind grows significantly in the 2040s; the effect of keeping more nuclear capacity online through the 2040s is a large reduction in wind generation and capacity. The capacity differences in 2050 reflect the generation differences with the magnitudes being different because of differences in capacity factors. For example, the 2050 fleet-wide capacity factor for solar is $21 \%$, for NG-CC is $49 \%$, and for nuclear is $90 \%$.

Other system impacts follow the capacity and generation trends from Figure 26. Because nuclear power plants are a non- $\mathrm{CO}_{2}$-emitting resource and are replaced by a mix of emitting and nonemitting resources, it is not surprising that $\mathrm{CO}_{2}$ emissions increase in proportion to the amount of nuclear capacity that retires. Figure 27 shows the $\mathrm{CO}_{2}$ emissions by year and as well as the cumulative emissions (2016-2050) for each scenario. The Early Retirement scenario sees emissions increase as soon as the first early retirements take place, because (as discussed in the Section 3.4) the nuclear generation is replaced in part by coal and gas generators. The Mid-case and 80-year Lifetime scenarios result in nearly-flat emissions in the 2030s, while the Early Retirement and 60-year Lifetime scenarios have increasing emissions during this time. In the 2040s, electricity sector emissions decline in all scenarios due to coal plant retirements and 
increases in renewable energy generation driven by continued cost declines. Also of note is that the Early Retirement scenario has a faster rate of $\mathrm{CO}_{2}$ emissions decline in the 2040s and ultimately converges to the emissions rate of the 60 -year Lifetime scenario.
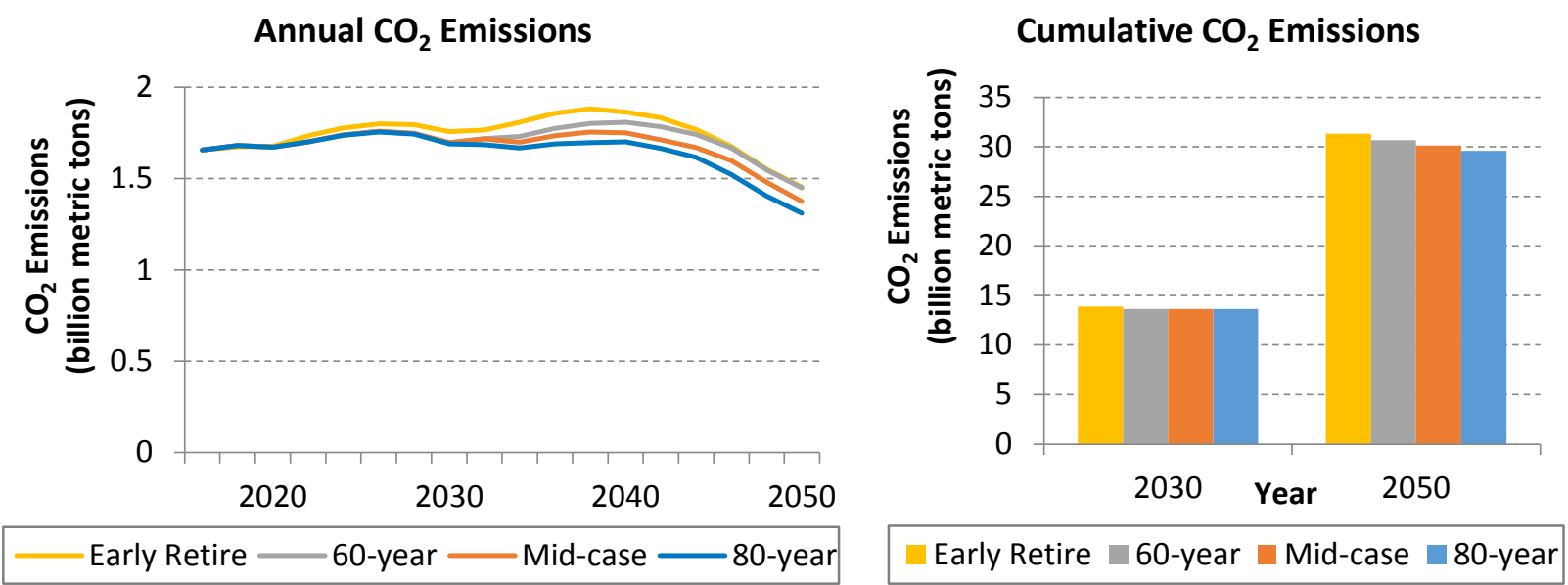

Figure 27. Annual power sector $\mathrm{CO}_{2}$ emissions over time (left) and cumulative $\mathrm{CO}_{2}$ emissions from 2016 to 2050 (right)

Power sector water withdrawals impacts are opposite those of $\mathrm{CO}_{2}$ emissions. Current nuclear power plants are among the most water-intensive power sector technologies. Figure 28 shows water withdrawals by year and cumulative withdrawals (from 2016 to 2050) by scenario. Overall water withdrawals trend downward in all scenarios because both coal and nuclear plants are major water withdrawers, and both experience capacity declines in these scenarios. The greater the amount of nuclear capacity retired, the less water is needed for cooling. Water withdrawals are different than water consumption, however. Withdrawn water is returned to the waterway (albeit at a higher temperature), while consumed water is evaporated and therefore lost from the waterway. Water consumption in 2050 in these scenarios varies considerably less than water withdrawals, from 817 billion gallons/year in the Early Retirement scenario to 1,093 billion gallons/year in the 80-year Lifetime scenario.
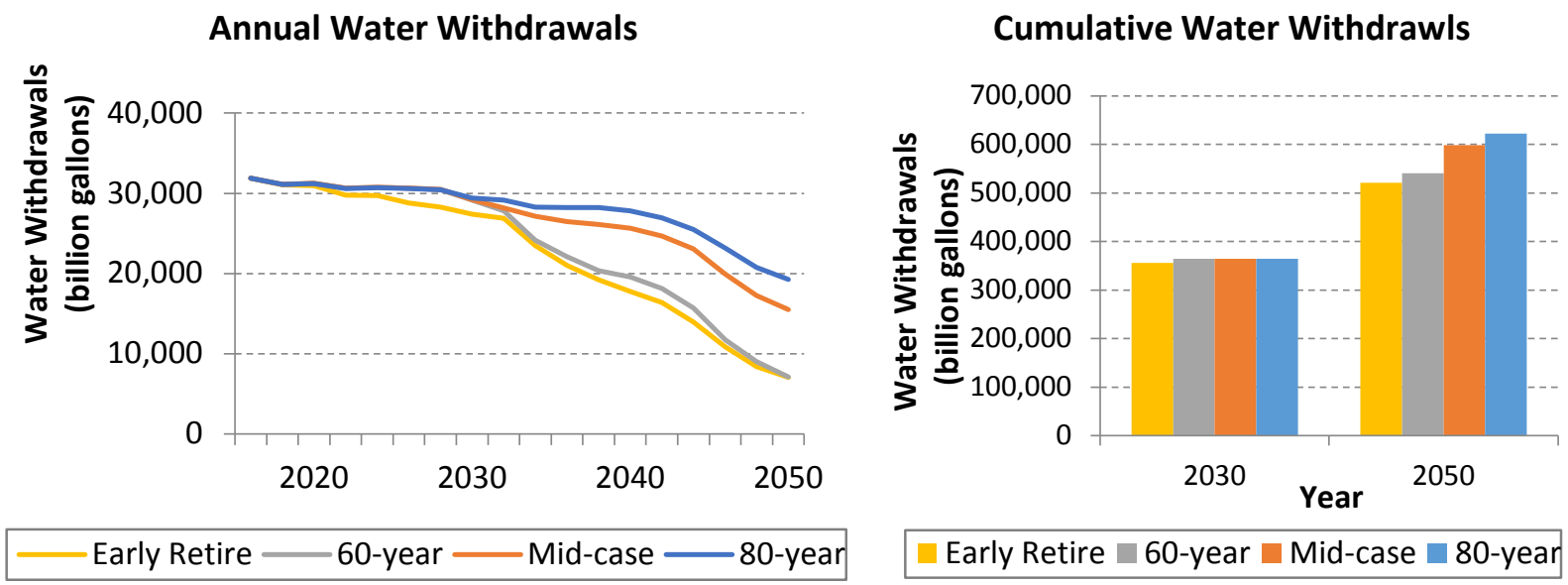

Figure 28. Water withdrawal by year (left) and cumulative withdrawals (right) 
Long-distance transmission builds increase with shorter nuclear lifetimes. The primary driver of the new transmission builds are the increases in variable renewable energy deployment. The highest quality wind and PV locations are often not located near major load center, so transmission is needed to get the power from the remote locations to the load. The Early Retirement scenario has $8 \%$ more transmission capacity than the 80 -year Lifetime scenario. Much of the incremental transmission relative to the 80-year scenario is from transmission lines in the Midwest build to access the rich wind resources in that area.

Finally, curtailment rates are seen to be higher for the same penetration of variable renewables in scenarios with longer nuclear lifetimes. Currently, nuclear power plants in the United States typically do not operate below their rated capacity (i.e., at part load). So, if nuclear generation plus renewable generation exceeds the load, renewable energy generation is typically curtailed. In other words, the scenarios with earlier nuclear retirements have lower minimum generation levels, so more renewable energy can be incorporated without being curtailed. For a given level of variable renewable energy penetration, curtailment is highest in the systems with more nuclear capacity, but overall curtailment in these scenarios still remains low $(<1.5 \%)$ across all scenarios.

\section{Key Insights}

- Additional nuclear retirements before 2030 generally lead to more gas and coal generation. Between 2030 and 2050, retired nuclear capacity is primarily replaced by a mix of natural gas, wind, and PV generation and capacity.

- Due to the high capacity factors of nuclear power plants, for every $1.0 \mathrm{GW}$ of nuclear power retired, it was replaced on average by $2.2 \mathrm{GW}$ of other capacity.

- Scenarios with longer nuclear lifetimes have lower $\mathrm{CO}_{2}$ emissions and fewer transmission builds, and higher water usage and renewable energy curtailment rates. 


\section{References}

ABB. 2017. “ABB Velocity Suite.” http://new.abb.com/enterprise-software/energy-portfoliomanagement/market-intelligence-services/velocity-suite.

Ahlstrom, M., C. Smith, D. Piwko, D. Lew, A. Bloom, Trieu Mai, K. Clark, and M. Miligan. 2015. "Relevant Studies for NERC's Analysis of EPA's Clean Power Plan 111(d) Compliance.” NREL/TP-5D00-63979. Golden, CO: National Renewable Energy Laboratory. http://www.nrel.gov/docs/fy15osti/63979.pdf.

Akhil, Abbas A., Georgianne Huff, Aileen B. Currier, Benjamin C. Kaun, Dan M. Rastler, Stella Bingqing Chen, Andrew L. Cotter, Dale T. Bradshaw, and William D. Gauntlett. 2013. "DOE/EPRI 2013 Electricity Storage Handbook in Collaboration with NRECA." SAND2013-5131. Albuquerque, NM: Sandia National Laboratory.

Bolinger, Mark, and Joachim Seel. 2016. "Utility-Scale Solar 2015: An Empirical Analysis of Project Cost, Performance, and Pricing Trends in the United States.” LBNL-1006037. Berkeley, CA: Lawrence Berkeley National Laboratory. https://emp.lbl.gov/sites/all/files/lbnl-1006037_report.pdf.

Brinkman, Gregory, Jennie Jorgenson, Ali Ehlen, and James Caldwell. 2016. "Low Carbon Grid Study: Analysis of a 50\% Emission Reduction in California.” NREL/TP-6A20-64884. Golden, CO: National Renewable Energy Laboratory. http://www.nrel.gov/docs/fy16osti/64884.pdf.

California ISO. 2016. "California ISO Solar Production Soars to New Record - 8,030 Megawatts.” California ISO. http://www.caiso.com/Documents/CaliforniaISOSolarProductionSoarsToNewRecord-8030Megawatts.pdf.

CEE. 2017. "U.S. Nuclear Power Reactors: At a Crossroads." Center for Energy Economics, January. http://www.beg.utexas.edu/energyecon/thinkcorner/CEE_SnapshotNuclear_Retirements-Jan17.pdf.

Cole, Wesley, Trieu Mai, Jeffrey Logan, Daniel Steinberg, James McCall, James Richards, Benjamin Sigrin, and Gian Porro. 2016. "2016 Standard Scenarios Report: A U.S. Electricity Sector Outlook.” NREL/TP-6A20-66939. Golden, CO: National Renewable Energy Laboratory. http://www.nrel.gov/docs/fy17osti/66939.pdf.

Cole, Wesley, Cara Marcy, Venkat Krishnan, and Robert Margolis. 2016. "Utility-Scale Lithium-Ion Storage Cost Projections for Use in Capacity Expansion Models." In Proceedings of the 2016 North American Power Symposium. Denver, CO, United States.

Cole, Wesley, Kenneth B. Medlock III, and Aditya Jani. 2016. "A View to the Future of Natural Gas and Electricity: An Integrated Modeling Approach.” Energy Economics 60 (November): 486-96. doi:10.1016/j.eneco.2016.03.005.

Collins, W. J., N. Bellouin, M. Doutriaux-Boucher, N. Gedney, P. Halloran, T. Hinton, J. Hughes, et al. 2011. "Development and Evaluation of an Earth-System Model HadGEM2.” Geosci. Model Dev. 4 (4): 1051-75. doi:10.5194/gmd-4-1051-2011.

Denholm, Paul, Kara Clark, and Matt O'Connell. 2016. "On the Path to SunShot: Emerging Issues and Challenges in Integrating High Levels of Solar into the Electrical Generation and Transmission System.” Golden, CO: National Renewable Energy Laboratory. http://www.osti.gov/scitech/biblio/1253978.

Denholm, Paul, Victor Diakov, and Robert Margolis. 2015. "Relative Economic Merits of Storage and Combustion Turbines for Meeting Peak Capacity Requirements under Increased Penetration of Solar Photovoltaics." Golden, CO: National Renewable Energy Laboratory. http://www.osti.gov/scitech/biblio/1225313. 
Denholm, Paul, and Maureen Hand. 2011. "Grid Flexibility and Storage Required to Achieve Very High Penetration of Variable Renewable Electricity.” Energy Policy 39 (3): 181730. doi:10.1016/j.enpol.2011.01.019.

Denholm, Paul, Joshua Novacheck, Jennie Jorgenson, and Matthew O'Connell. 2016. Impact of Flexibility Options on Grid Economic Carrying Capacity of Solar and Wind: Three Case Studies. Golden, CO: National Renewable Energy Laboratory. Denholm, Paul, and Robert Margolis. http://www.nrel.gov/docs/fy17osti/66854.pdf.

DOE. 2015. "Wind Vision: A New Era for Wind Power in the United States." DOE/GO-1020154557. Washington, D.C.: U.S. Department of Energy. http://www.energy.gov/sites/prod/files/WindVision_Report_final.pdf. . 2016. "Hydropower Vision: A New Chapter for America's 1st Renewable Electricity Source.” Technical Report DOE/GO-102016-4869. Washington, D.C.: U. S. Department of Energy. http://energy.gov/eere/water/articles/hydropower-vision-new-chapter-americas-1st-renewable-electricity-source.

Dragoon, K., and V. Dvortsov. 2006. "Z-Method for Power System Resource Adequacy Applications." IEEE Transactions on Power Systems 21 (2): 982-88. doi:10.1109/TPWRS.2006.873417.

EIA. 2013. "Updated Capital Cost Estimates for Utility Scale Electricity Generating Plants." Washington, D.C.: U.S. DOE Energy Information Administration. http://www.eia.gov/forecasts/capitalcost/pdf/updated_capcost.pdf.

—. 2016a. “Annual Energy Outlook 2016.” DOE/EIA-0383(2016). Washington, D.C.: U.S. DOE Energy Information Administration. . 2016b. "Capital Cost Estimates for Utility Scale Electricity Generating Plants." Washington, D.C.: U.S. DOE Energy Information Administration. http://www.eia.gov/analysis/studies/powerplants/capitalcost/pdf/capcost_assumption.pdf. —. 2017a. “Annual Energy Outlook 2017.” DOE/EIA-0383(2017). Washington, D.C.: U.S. DOE Energy Information Administration.

—. 2017b. "Monthly Energy Review." Washington, D.C.: U.S. DOE Energy Information Administration. https://www.eia.gov/totalenergy/data/monthly/.

EIPC. 2012. "Phase 2 Report: DOE Draft - Parts 2-7 Interregional Transmission Development and Analysis for Three Stakeholder Selected Scenarios.” Eastern Interconnect Planning Collaborative. http://nebula.wsimg.com/2964d965b867c8786028b950057c7e52?AccessKeyId=E28DF A42F06A3AC21303\&disposition=0\&alloworigin=1.

EPA. 2017. "Avoiding and Reducing Long-term Risks of Climate Change: A Technical Report for the Fourth National Climate Assessment." EPA 430-R-17-001. Washington, D.C.: U.S. Environmental Protection Agency.

Eurek, Kelly, Wesley Cole, David Bielen, Stuart Cohen, Bethany Frew, Jonathan Ho, Venkat Krishnan, Trieu Mai, and Daniel Steinberg. 2016. "Regional Energy Deployment System (ReEDS) Model Documentation: Version 2016.” NREL/TP-6A20-67067. Golden, CO: National Renewable Energy Laboratory. http://www.nrel.gov/docs/fy17osti/67067.pdf.

Goggin, Michael. 2016. "The Records Keep Falling: More New Highs in Wind Energy Output." Into the Wind. February 23. http://www.aweablog.org/the-records-keep-falling-morenew-highs-in-wind-energy-output/.

GTM Research, and ESA. 2017. "U.S. Energy Storage Monitor: Q2 2017.” GTM Research and the Energy Storage Association. http:/www2.greentechmedia.com/Q2USESM17. 
Haratyk, Geoffrey. 2017. "Early Nuclear Retirements in Deregulated US Markets: Causes, Implications and Policy Options."

https://assets.documentcloud.org/documents/3723775/MIT-Early-Nuclear-Retirement-32017.pdf.

Hostick, D., D.B. Belzer, S.W. Hadley, T. Markel, C. Marnay, and M. Kintner-Meyer. 2012. "Renewable Electricity Futures Study Volume 3: End-Use Electricity Demand." NREL/TP-6A20-52409-3. National Renewable Energy Laboratory.

Kittner, Noah, Felix Lill, and Daniel M. Kammen. 2017. "Energy Storage Deployment and Innovation for the Clean Energy Transition." Nature Energy 2 (July): nenergy2017125. doi:10.1038/nenergy.2017.125.

Logan, Jeffrey, Garvin Heath, Jordan Macknick, Elizabeth Paranhos, William Boyd, and Ken Carlson. 2012. "Natural Gas and the Transformation of the US Energy Sector: Electricity." TP-6A50-55538. Joint Institute for Strategic Energy Analysis. http://www.fe.doe.gov/programs/gasregulation/authorizations/2012_applications/sierra_e x12_97/Ex._93_-_JISEA_Natural_Gas_GHG_LCA.pdf.

Macknick, Jordan, Robin Newmark, Garvin Heath, and Kathleen C. Hallett. 2012. "Operational Water Consumption and Withdrawal Factors for Electricity Generating Technologies: A Review of Existing Literature." Environmental Research Letters 7 (4): 045802. doi:10.1088/1748-9326/7/4/045802.

Mai, Trieu, Wesley Cole, Venkat Krishnana, and Mark Bolinger. 2015. "Impact of Federal Tax Policy on Utility-Scale Solar Deployment Given Financing Interactions.” NREL/PR6A20-65014. Golden, CO: National Renewable Energy Laboratory.

Mai, Trieu, Jeffrey Logan, Nate Blair, Patrick Sullivan, and Morgan Bazilian. 2013. "REASSUME: A Decision Maker's Guide to Evaluating Energy Scenarios, Modeling, and Assumptions." http://iea-retd.org/wp-content/uploads/2013/07/RE-ASSUME_IEARETD_2013.pdf.

Maloney, Peter. 2017. "Bloomberg: Nuclear Subsidies Could Cost Northeast Customers \$3.9B Annually." Utility Dive. http://www.utilitydive.com/news/bloomberg-nuclear-subsidiescould-cost-northeast-customers-39b-annually/438717/.

Margolis, Robert, David Feldman, and Daniel Boff. 2017. "Q4 2016/Q1 2017 Solar Industry Update.” NREL/PR-6A20-68425. Washington, D.C.: National Renewable Energy Laboratory. http://www.nrel.gov/docs/fy17osti/68425.pdf.

Meldrum, J., S. Nettles-Anderson, G. Heath, and J. Macknick. 2013. "Life Cycle Water Use for Electricity Generation: A Review and Harmonization of Literature Estimates."

Environmental Research Letters 8 (1): 015031. doi:10.1088/1748-9326/8/1/015031.

NEI. 2016. "Status and Outlook for Nuclear Energy In the United States." NEI.

NERC. 2017. "2017 Summer Reliability Assessment." http://www.nerc.com/pa/RAPA/ra/Reliability\%20Assessments\%20DL/2017\%20Summer $\% 20$ Assessment.pdf.

NREL. 2012. "Renewable Electricity Futures Study.” NREL/TP-6A20-52409. Golden, CO: National Renewable Energy Laboratory. . 2017. "2017 Annual Technology Baseline." Golden, CO: National Renewable Energy Laboratory. http://www.nrel.gov/analysis/data_tech_baseline.html.

Nykvist, Björn, and Måns Nilsson. 2015. "Rapidly Falling Costs of Battery Packs for Electric Vehicles." Nature Climate Change 5 (4): 329-32. doi:10.1038/nclimate2564. 
Roth, Michael Buchdahl, and Paulina Jaramillo. 2017. "Going Nuclear for Climate Mitigation: An Analysis of the Cost Effectiveness of Preserving Existing U.S. Nuclear Power Plants as a Carbon Avoidance Strategy." Energy 131 (July): 67-77. doi:10.1016/j.energy.2017.05.011.

Schmidt, O., A. Hawkes, A. Gambhir, and I. Staffell. 2017. "The Future Cost of Electrical Energy Storage Based on Experience Rates." Nature Energy 2 (8): nenergy2017110. doi:10.1038/nenergy.2017.110.

Sigrin, Benjamin, Michael Gleason, Robert Preus, Ian Baring-Gould, and Robert Margolis,. 2016. "The Distributed Generation Market Demand Model (DGen): Documentation." NREL/TP-6A20-65231. Golden, CO: National Renewable Energy Laboratory. http://www.nrel.gov/docs/fy16osti/65231.pdf.

Steckler, Nicholas. 2017. "Half of U.S. Nuclear Power Plants Are Underwater." Bloomberg New Energy Finance.

Sullivan, Patrick, Wesley Cole, Nate Blair, Eric Lantz, Venkat Krishnan, Trieu Mai, David Mulcahy, and Gian Porro. 2015. "2015 Standard Scenarios Annual Report: U.S. Electric Sector Scenario Exploration.” NREL/TP-6A20-64072. Golden, CO: National Renewable Energy Laboratory.

Tesla. 2017. "Tesla Powerpack to Enable Large Scale Sustainable Energy to South Australia." July 6. https://www.tesla.com/blog/tesla-powerpack-enable-large-scale-sustainableenergy-south-australia.

Trabish, Herman K. 2017. "Is Battery Energy Storage at a 'Turning Point' for US Utilities?" Utility Dive. April 11. http://www.utilitydive.com/news/is-battery-energy-storage-at-aturning-point-for-us-utilities/440055/.

Vajjhala, Shalini P, and Paul S Fischbeck. 2007. "Quantifying Siting Difficulty: A Case Study of US Transmission Line Siting.” Energy Policy 35 (1): 650-71.

Wiser, Ryan, and Mark Bolinger. 2017. "2016 Wind Technologies Market Report.” Department of Energy.

https://energy.gov/sites/prod/files/2017/08/f35/2016_Wind_Technologies_Market_Repor t_0.pdf.

Wiser, Ryan, Mark Bolinger, and Joachim Seel. 2017. "Wind Cost and Performance Improvements: Where Have We Been, Where Are We Going, and Why Does It Matter?" presented at the WINDPOWER 2017, Anaheim, CA, May.

http://s23.a2zinc.net/clients/AWEA/WP17/Custom/Handout/Speaker2525_Session222_1. pdf. 


\section{Appendix}

\section{A.1 Standard Scenarios Input Assumptions}

This section describes the input assumptions used in the scenarios listed in Table 1. For details on model assumptions, see the documentation for ReEDS (Eurek et al. 2016) and dGen (Sigrin et al. 2016).

\section{A.1.1 Fossil Fuel Prices}

The natural gas input price points are based on the trajectories from the AEO 2017 (EIA 2017a). The prices are shown in Figure 29 (left) and are from the AEO 2017 Reference scenario, the Low Oil and Gas Resource and Technology scenario, and the High Oil and Gas Resource and Technology scenarios (EIA 2017a). Actual natural gas prices in ReEDS are based on the AEO scenarios, but they are not exactly the same; instead, they are price-responsive to ReEDS natural gas demand. Each census region includes a natural gas supply curve that adjusts the natural gas input price based on both regional and national demand (Cole, Medlock III, and Jani 2016). The reference coal and uranium price trajectories are from the AEO 2017 Reference scenario and are shown in Figure 29 (right). Both coal and uranium prices are assumed to be fully inelastic. Figure 29 shows the national prices for the resources, but input prices for ReEDS are taken from the AEO 2017 census region projections.
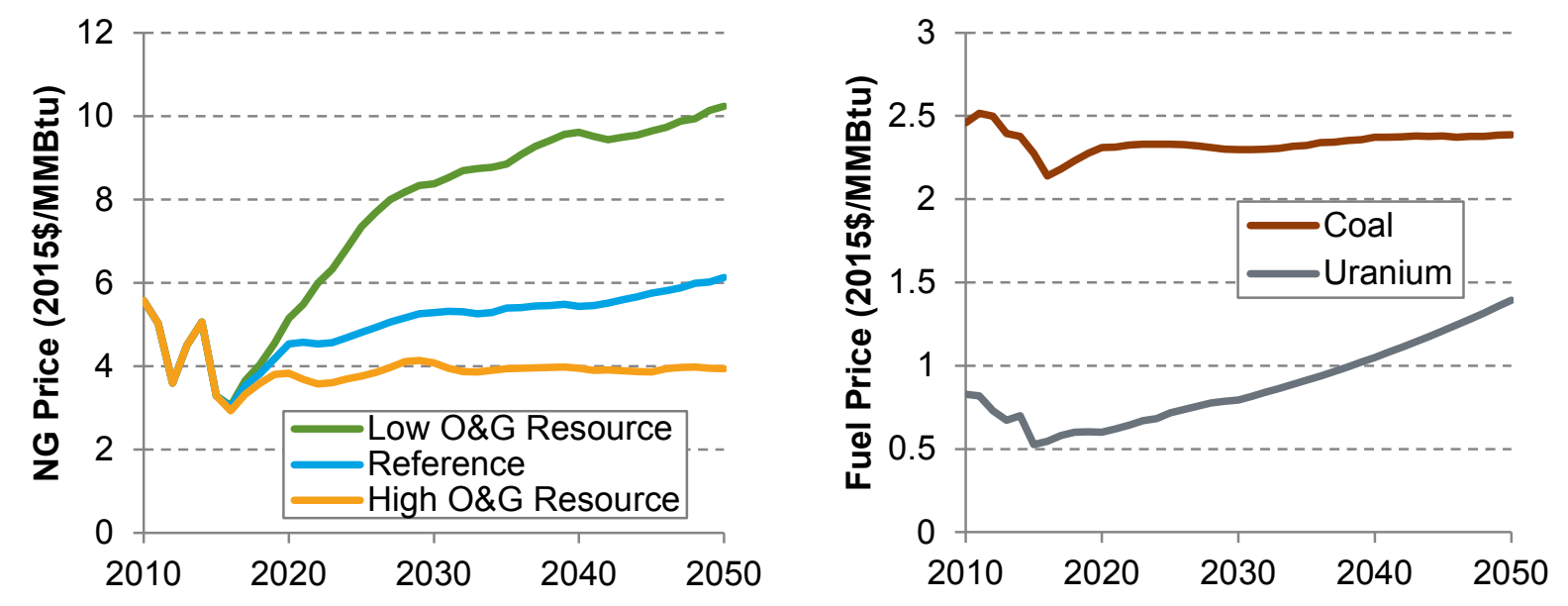

Figure 29. Fuel price trajectories used in the Standard Scenarios

\section{A.1.2 Demand Growth}

The Mid-case scenario is based on the AEO 2017 Reference scenario load growth (EIA 2017a). The high and low load growth scenarios are also from AEO 2017 based on the Low and High Economic Growth scenarios, which use lower/higher rates of population growth, productivity, and lower/higher inflation than the Reference scenario (see Figure 30). We assume inelastic electricity demand in all scenarios presented. 


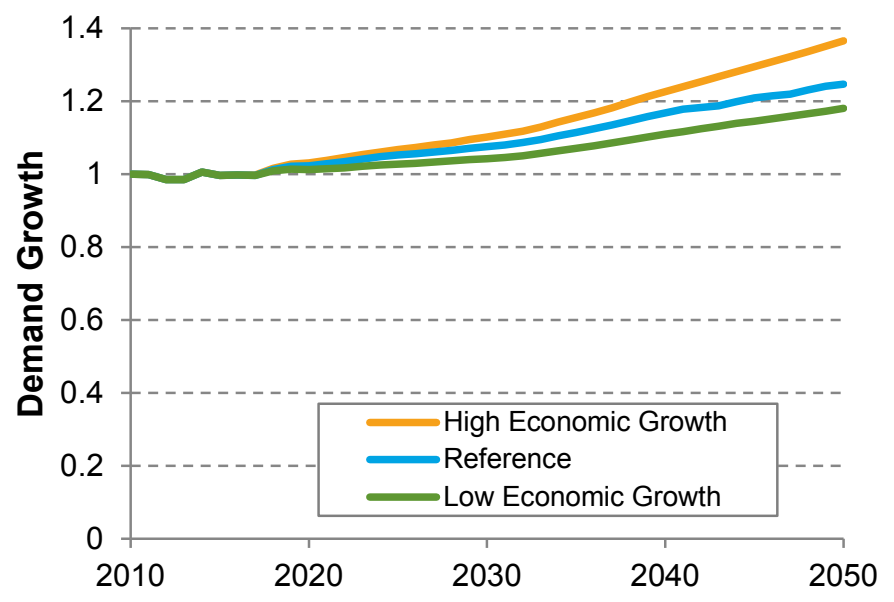

Figure 30. Demand growth trajectories used in the Standard Scenarios

\section{A.1.3 Technology Cost and Performance}

Technology cost and performance assumptions are taken from the 2017 Annual Technology Baseline (ATB) (NREL 2017). The ATB includes low, mid, and high cost and performance projections through 2050 for the generating (except storage) technologies used in the ReEDS and dGen models. The Low RE Cost scenario uses the low-cost projections for all renewable energy technologies. The Low PV Cost scenario uses the low-cost projections for utility and distributed PV technologies, and the Low Wind Cost scenario uses the low-cost projections for land-based and offshore wind technologies.

Battery storage costs are from Cole, Marcy, et al. (2016) and are shown in Figure 31. The midcost projection is used in all scenarios except the Low and High Battery Cost scenarios, which use the low and high projections respectively.
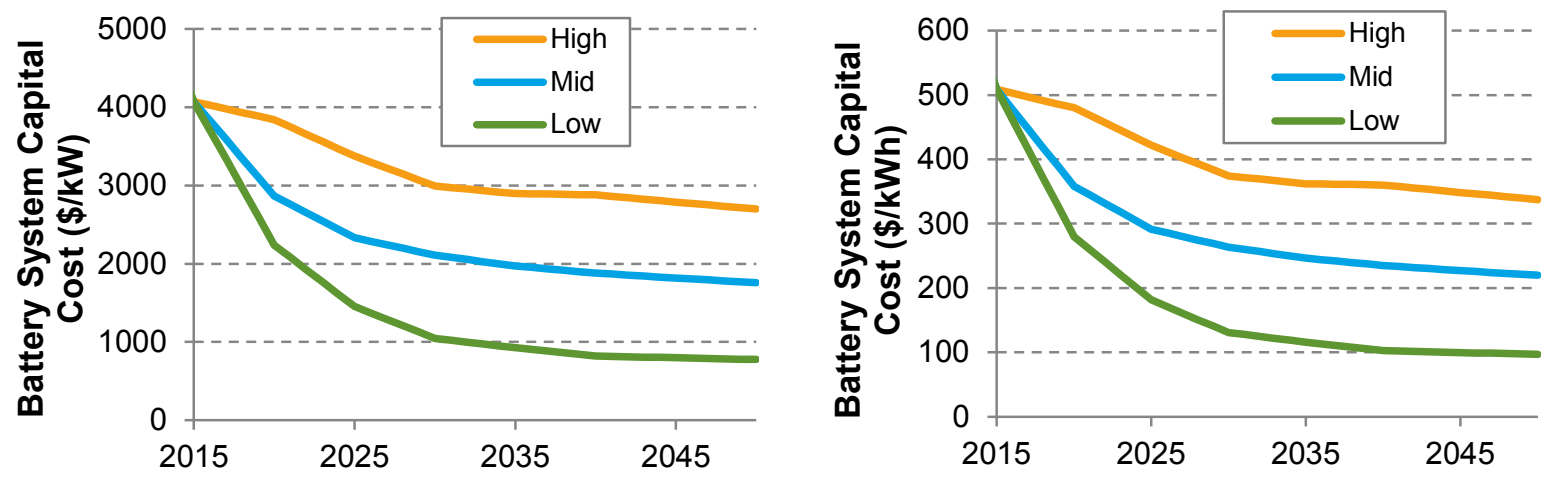

Figure 31. Battery system capital costs for an eight-hour battery on a $\$ / k W$ basis (left) and a $\$ / k W h$ basis (right) for the low, mid, and high trajectories 


\section{A.1.4 Existing Fleet Retirements}

Retirements for conventional power plants are taken from the ABB Velocity Suite database (ABB 2017), which uses age-based retirements unless an official retirement date has been announced. For coal plants, we also apply a utilization-based retirement, as a proxy for economic considerations, for aggregate coal capacity in each of the model balancing areas (see Eurek et al. [2016] for details). All other generator types use strictly age-based retirement schedules (Eurek et al. 2016).

The Accelerated Coal Retirements scenario reduces coal plant age-based retirements by 10 years. The four nuclear retirement scenarios were defined by dividing the 99 currently operating reactors into one of two bins. Any plants participating in a restructured market and all singlereactor plants were assigned to Bin 1 . The remaining plants, which were all multi-reactor plants in a traditional regulated environment, were assigned to Bin 2 . The only exception to this categorization was that the two plants that have announced their intent to seek a second operating license renewal from the Nuclear Regulatory Commission are included in Bin 2. Table 3 breaks down the bins and shows total capacity in each case. These bins are not meant to be predictions of which plants are more "at-risk" or more likely to retire. Rather, they represent a simple categorization that reflects the current discussion, which points to more economic pressure for restructured and single-reactor units (Haratyk 2017; Steckler 2017). Current under-construction nuclear power plants are assumed to come online according to the online dates in the May 2017 version of the Velocity Suite database (ABB 2017).

Table 3. Amount of Nuclear Power Plant Capacity (in GW) in Each Bin

\begin{tabular}{lcc}
\hline & Bin 1 & Bin 2 \\
\hline Restructured, single reactor & 8.7 & - \\
Restructured, multi reactor & 27.5 & $2.0^{\mathrm{a}}$ \\
Regulated, single reactor & 15.7 & - \\
Regulated, multi reactor & - & 42.1 \\
Total & $\mathbf{5 1 . 9}$ & $\mathbf{4 4 . 1}$ \\
\hline
\end{tabular}

${ }^{a}$ The Peach Bottom plant $(2.0 \mathrm{GW})$ has announced its intent to seek a second license renewal. Therefore, it is assigned to Bin 2 even though it is in a restructured market.

The four nuclear retirement scenarios in the Standard Scenarios are Early Retirement, 60-year Lifetime, Mid-case (mix of 60 and 80-year lifetimes), and 80-year Lifetime (see Table 4). The Early Retirement scenario retires nuclear capacity in Bin 1 when its lifetime reaches 50 years, and capacity in Bin 2 at 60 years. The 50-year lifetime emulates the retirements of recent plants that did have a renewed operating license but retired before they reached the end of their license. The 60 -year Lifetime scenario retires all plants at 60 years, which would be at the end of their first operating license renewal. The 80 -year Lifetime scenario retires all plants at 80 years, simulating a successful completion of a second operating license renewal from the Nuclear Regulatory Commission. The Mid-case scenario serves as the baseline scenario in which ReEDS retires capacity in Bin 1 at 60 years and capacity in Bin 2 at 80 years. 
Table 4. Nuclear Power Plant Lifetime (in Years) for Each Scenario by Bin

\begin{tabular}{lcc}
\hline Scenario Name & Bin 1 & Bin 2 \\
\hline Early retirement & 50 & 60 \\
60-year lifetime & 60 & 60 \\
Mid-case & 60 & 80 \\
80-year Lifetime & 80 & 80 \\
\hline
\end{tabular}

\section{A.1.5 Vehicle Electrification}

The Vehicle Electrification scenario assumes $40 \%$ of passenger vehicle sales are sales of electric vehicles in 2050 . The charging profile defined for this scenario assumes that $55 \%$ (energy-basis) was owner-controlled (static, evening-weighted) and the utility/model could control timing of the remaining 45\%. Figure 32 shows the charging load atop the base load for 2050 in this scenario. The dynamic-charging portion has been assigned based on the scenario outcome. For details on how the charging demand and profiles were developed, see Appendix K of the Renewable Electricity Futures Study, Volume 3 (Hostick et al. 2012). ${ }^{28}$

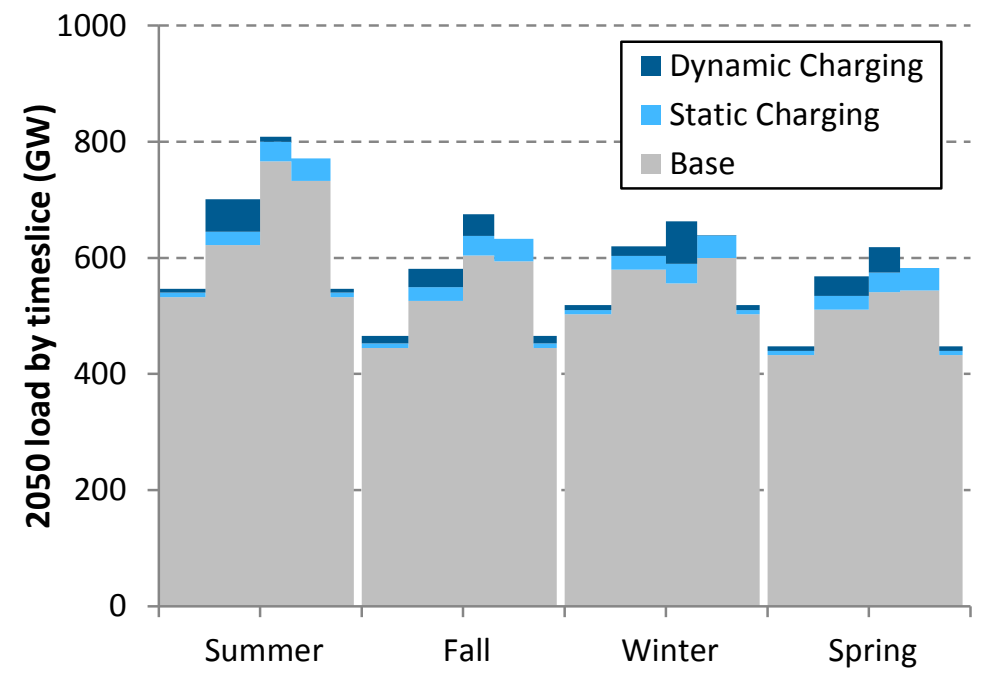

Figure 32. Electric vehicle charging demand under the Vehicle Electrification scenario. Each block represents the load adjustments for each ReEDS time slice.

\footnotetext{
${ }^{28}$ A recent analysis, the National Economic Value Assessment of Plug-In Electric Vehicles (Melaina et al. 2016), uses ReEDS and other models to provide another assessment of electric vehicles and their impacts to the electricity system under different charging regimes.
} 


\section{A.1.6 Extended Incentives for Renewable Energy Generation}

The Extended Incentives scenario assumes the PTC and ITC are extended through 2030 for utility-scale projects after the ramp-down periods occur (i.e., the PTC and ITC return to their full amounts after the ramp-downs). The extensions used in this scenario are of the $\$ 23 / \mathrm{MWh}$ PTC for wind, geothermal, and biopower, the $\$ 11 / \mathrm{MWh}$ PTC for new hydropower, and the $30 \%$ ITC for solar, both to 2030 - after which the ITC declines to $10 \%$ as planned. As the past program did, the PTC applies to the first 10 years of operation for new construction. During years where a tax credit is present, the equity fraction for that technology is increased (Mai et al. 2015).

\section{A.1.7 National Renewable Portfolio Standard}

The $80 \%$ National RPS scenario presents a future with a nationwide RPS on electricity production. The assumed standard ramps from $1 \%$ in 2010 to $80 \%$ in 2050 , with growth leveling off at that level. Eligible technologies include hydropower, wind, solar, geothermal, biopower (including any biomass cofired with coal), and landfill gas. The 80\% RPS echoes scenarios in the Renewable Electricity Futures Study (NREL 2012).

\section{A.1.8 Power Sector $\mathrm{CO}_{2}$ Cap}

The Carbon Cap scenario implements a national electric-sector cap on direct $\mathrm{CO}_{2}$ emissions based on a power-sector $\mathrm{CO}_{2}$ reduction target of $30 \%$ below 2005 levels by 2020 and $83 \%$ below 2005 levels by 2050 (Figure 33). We assume the cap to be implemented via freely allocated credits, rather than auction, so there is no direct cost associated with emitting $\mathrm{CO}_{2}$. However, complying with the cap does require the model to adjust its investment and operation decisions.

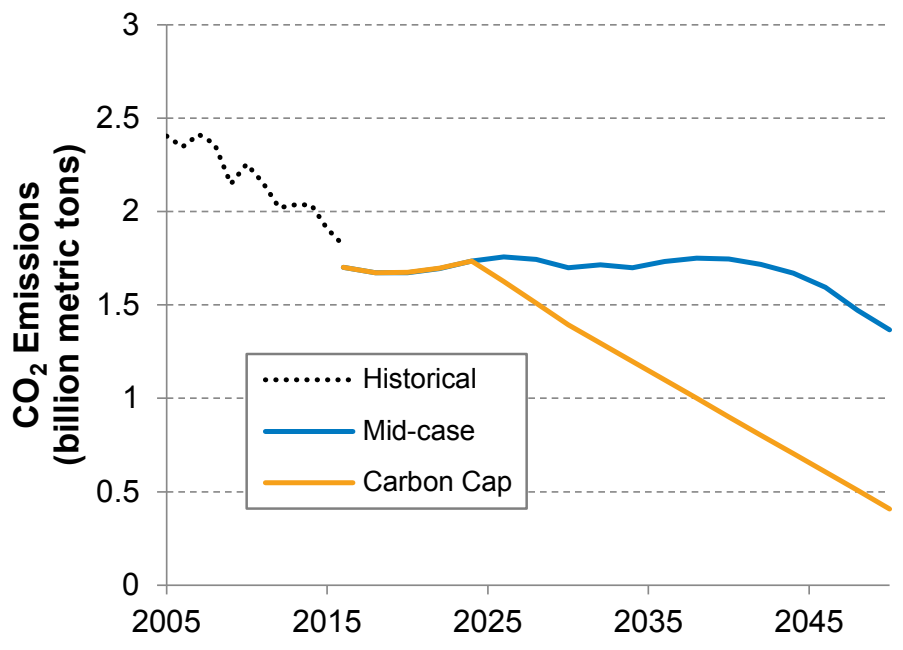

Figure 33. Comparison of prescribed electric sector $\mathrm{CO}_{2}$ cap to the $\mathrm{CO}_{2}$ emissions path in the Midcase scenario

\section{A.1.9 Impacts of Climate Change}

This impacts scenario, in contrast to the Carbon Cap scenario, applies no carbon signal, but it instead adjusts electricity demand, power system performance, cooling water availability, and hydropower energy availability in response to the shifting ambient temperature and precipitation distributions with a changing climate. Climate influences demand for electricity services directly 
through adjusted space-conditioning needs, and ambient temperature can affect both power plant operation and transmission line carrying capacities. Transmission capacity is reduced by $0.55 \%$ per $1{ }^{\circ} \mathrm{C}$ increase in summer afternoons, while thermal power plants experience a $0.5 \%-0.75 \%$ capacity reduction and a $0.1 \%-0.2 \%$ heat rate increase per $1^{\circ} \mathrm{C}$ increase in summer time slices. Precipitation data were processed by external collaborators at Industrial Economics, Inc. to determine changes to hydropower energy availability and surface water availability for thermal cooling. This scenario applies estimates for those effects based on a representative climate change scenario. The impacts scenario uses temperature and precipitation data from the HadGEM2-ES general circulation model (Collins et al. 2011) under a representative concentration pathway assuming a +4.5 watts per square meter $\left(\mathrm{W} / \mathrm{m}^{2}\right)$ radiative forcing in the year 2100 relative to pre-industrial levels (EPA 2017). Total load increases by about $145 \mathrm{TWh}$ by 2050 compared to the Mid-case scenario (primarily during the summer afternoon hours), power plant heat rates and transmission line carrying capacities are slightly derated to account for the higher ambient temperatures, and water availability for hydropower and thermal cooling have varying region- and season-specific changes.

\section{A.1.10 Reduced RE Resource}

This scenario reduces the amount of renewable energy resource available in the model for building new renewable energy generators. Specifically, the scenario reduces modeled wind, concentrating solar power, geothermal, hydropower, ${ }^{29}$ and biopower technical potential by $25 \%$. The reduction is applied uniformly across geography and resource classes (i.e., all regions and classes experience the same $25 \%$ reduction). This scenario provides a sensitivity to estimates of technical potential for renewable energy resources.

\section{A.1.11 Barriers to Transmission System Expansion}

The ReEDS model assumes new transmission lines can be constructed as needed, at costs taken from EIPC (2012) on regional transmission development and extrapolated to the contiguous United States (DOE 2015). Those cost assumptions do include regional multipliers that imply higher siting and construction costs in certain regions, notably California and the Northeast. This scenario takes the EIPC-sourced siting difficulties a step further, reflecting a concern that transmission-line siting is and will continue to be difficult and expensive (Vajjhala and Fischbeck 2007). As a proxy for explicit barriers to transmission expansion, this scenario bars any new interconnection interties, triples the capital cost of any new inter-balancing authority transmission capacity, and doubles the transmission loss rate from $1 \%$ to $2 \%$ per hundred miles. Renewable generator spur line costs are not affected. The higher rate of transmission losses is a general discouragement to relying on the transmission system to transmit power long distances.

\section{A.1.12 Restrictions on Thermoelectric Water Use}

In the Mid-case scenario, power plants can obtain cooling water from freshwater resources made available when other power plants retire, unappropriated fresh surface water, potable groundwater, appropriated freshwater, wastewater, or brackish groundwater. The restricted cooling water scenario does not allow new power plants to use any type of freshwater as cooling

\footnotetext{
${ }^{29}$ This reduction does not apply to pumped storage hydropower.
} 
water, leaving only wastewater and brackish groundwater as options. This scenario highlights the challenges of the water-energy nexus and provides insights into water availability challenges.

\section{A.1.13 Nuclear Technology Breakthrough}

This scenario explores a future in which nuclear fission-generating technologies have growing public support and see increased technological advancement. The Nuclear Breakthrough scenario implements a 50\% reduction in the overnight capital costs for new nuclear power plants. Other cost and performance assumptions for nuclear power plants remain unchanged.

\section{A.1.13 Low Financing Costs}

The Mid-case scenario assumes the weighted average cost of capital (WACC) is $8.1 \%$ nominal across all technologies. This is based on the long-term observed interest and equity rates of return observed in the utility industry (Eurek et al. 2016). However, since the economic recession in 2008, current interest rates have been much lower than their long-term values, and it is unknown whether they will return to their former levels or if there will be a period of protracted low interest rates. The Low-cost Financing scenario uses a lower constant WACC of 5.4\% nominal for all technologies, representative of recent values observed in the power sector (EIA 2017a).

\section{A.2 Changes from the 2016 Edition}

Since last year's Standard Scenarios report (Cole et al. 2016), a variety of modeling changes have occurred in the ReEDS and dGen models. Many of these key changes are summarized in Table 5 (next page). New scenarios in this year's report include the Low PV cost scenario, the Low Wind Cost scenario, and High and Low Battery Cost scenarios, the Low-cost Financing scenario, the alternate nuclear retirement scenarios (see Appendix A.1.4), and a With CPP scenario. 
Table 5. Key Differences in Model Inputs and Treatments for ReEDS Model Versions. The 2016 version was used in the 2016 Standard Scenarios report (Cole et al. 2016), and the 2017 version is used for this report.

\begin{tabular}{|c|c|c|}
\hline Key Differences & 2016 Version (May 2016) & 2017 Version (June 2017) \\
\hline Fuel prices & AEO 2016 & AEO 2017 \\
\hline Demand growth & AEO 2016 & AEO 2017 \\
\hline $\begin{array}{l}\text { Generator technology cost } \\
\text { and performance }\end{array}$ & ATB 2016 & ATB 2017 \\
\hline $\begin{array}{l}\text { Battery storage cost and } \\
\text { performance }\end{array}$ & Akhil et al. (2013) & Cole, Marcy, et al. (2016) \\
\hline Wind characterization & All wind resources using 10 TRGs & $\begin{array}{l}\text { Land-based wind uses } 10 \text { TRGs, offshore uses } \\
15 \text { TRGs }\end{array}$ \\
\hline $\begin{array}{l}\text { State renewable portfolio } \\
\text { standards }\end{array}$ & Policies as of March 2016 & Policies as of January 2017 \\
\hline California carbon policy & AB 32 & AB 398 \\
\hline Clean Power Plan (CPP) & $\begin{array}{l}\text { CPP included in Mid-case as mass-based standard } \\
\text { with national trading }\end{array}$ & CPP not included in Mid-case \\
\hline Retirements & $\begin{array}{l}\text { ABB Velocity Suite, April 2016; All nuclear plants have } \\
60 \text {-year life }\end{array}$ & $\begin{array}{l}\text { ABB Velocity Suite, May 2017; Nuclear plants have a } \\
\text { mix of } 60 \text { and } 80 \text {-year lives }\end{array}$ \\
\hline Prescribed builds & ABB Velocity Suite, April 2016 & $\begin{array}{l}\text { ABB Velocity Suite, May 2017; wind builds through } \\
2020 \text { restricted to those that have been announced, } \\
\text { permitted, or are under construction }\end{array}$ \\
\hline Electricity prices & $\begin{array}{l}\text { Rooftop PV impacts electricity prices based on AEO } \\
\text { projections of retail electricity prices }\end{array}$ & $\begin{array}{l}\text { Rooftop PV included as a negative load in electricity } \\
\text { price calculations }\end{array}$ \\
\hline $\begin{array}{l}\text { Renewable energy } \\
\text { capacity value }\end{array}$ & $\begin{array}{l}\text { Calculated using the statistics-based Z-method } \\
\text { (Dragoon and Dvortsov 2006) }\end{array}$ & $\begin{array}{l}\text { Calculated using hourly capacity factors during the top } \\
100 \text { net-load hours }\end{array}$ \\
\hline Water withdrawals & Water withdrawal limits enforced on an annual basis & Water withdrawal limits enforced on a seasonal basis \\
\hline Regional cost multipliers & Regional capital cost multipliers based on (EIA 2013) & $\begin{array}{l}\text { Regional capital cost multipliers updated to } \\
\text { (EIA 2016b) }\end{array}$ \\
\hline
\end{tabular}


The dGen model has also seen a variety of updates, which are summarized in Table 6. Rooftop PV projections are also different in that for this year's Standard Scenarios there is a unique rooftop PV projection for each scenario. Electricity prices from ReEDS were used as inputs to $\mathrm{dGen}$ for calculating the bill savings from the adoption a rooftop PV system. The full suite of rooftop PV projections used in the scenarios is shown in Figure 34.

Table 6. Key Differences in dGen Model Versions. The 2016 version was used in the 2016 Standard Scenarios report (Cole et al. 2016), and the 2017 version is used for this report.

\begin{tabular}{|l|l|l|}
\hline Key Differences & 2016 Version & 2017 Version \\
\hline Tariff set & Curated in 2014 & Curated in January 2017 \\
\hline Tariff selection & $\begin{array}{l}\text { Agents randomly select tariffs from } \\
\text { those available to their class }\end{array}$ & $\begin{array}{l}\text { Agents select the tariff with the lower } \\
\text { cost of electricity, from those available } \\
\text { to their class }\end{array}$ \\
\hline Agent rooftop area & Set to equal observed national values & $\begin{array}{l}\text { Set to equal observed state values, } \\
\text { and estimated residential/non- } \\
\text { residential breakdown }\end{array}$ \\
\hline $\begin{array}{l}\text { Electricity price } \\
\text { escalation } \\
\text { assumption }\end{array}$ & $\begin{array}{l}\text { Agents evaluate financial performance } \\
\text { of distributed generation based on } \\
\text { projections of future electricity costs }\end{array}$ & $\begin{array}{l}\text { Agents evaluate financial performance } \\
\text { of distributed generation assuming } \\
\text { electricity price changes will be the } \\
\text { same as the compound annual growth } \\
\text { rate over the past 10 years }\end{array}$ \\
\hline $\begin{array}{l}\text { Third-party owned } \\
\text { (TPO) business } \\
\text { model }\end{array}$ & TPO business model included & TPO business model not included \\
\hline $\begin{array}{l}\text { State net energy } \\
\text { metering, policies }\end{array}$ & Updated in 2014 & Updated in March 2017 \\
\hline
\end{tabular}

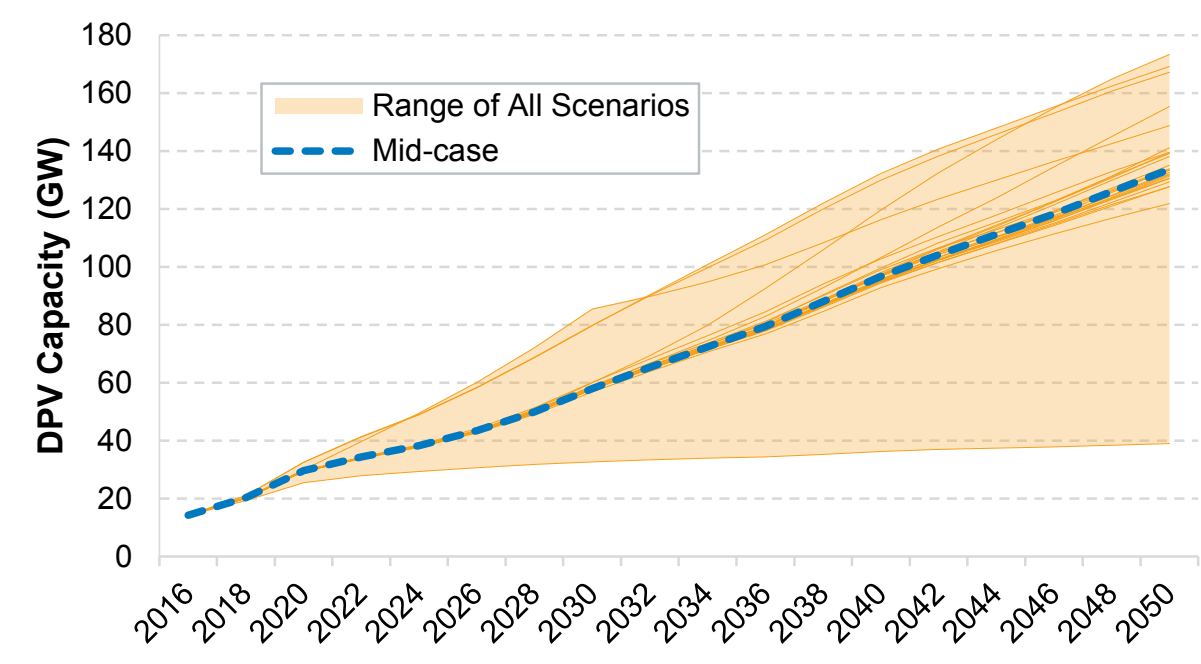

Figure 34. Distributed PV (DPV) capacity in the Standard Scenarios 
Figure 35 shows how the Mid-case projection has changed over the course of the three editions of the Standard Scenarios. The impacts of removing the Clean Power Plan from the 2017 Midcase are observed with less mid-term renewable energy and gas generation and a corresponding increase in coal generation. The impact of extending the lifetime of many nuclear units is also easily seen in the change in nuclear generation.
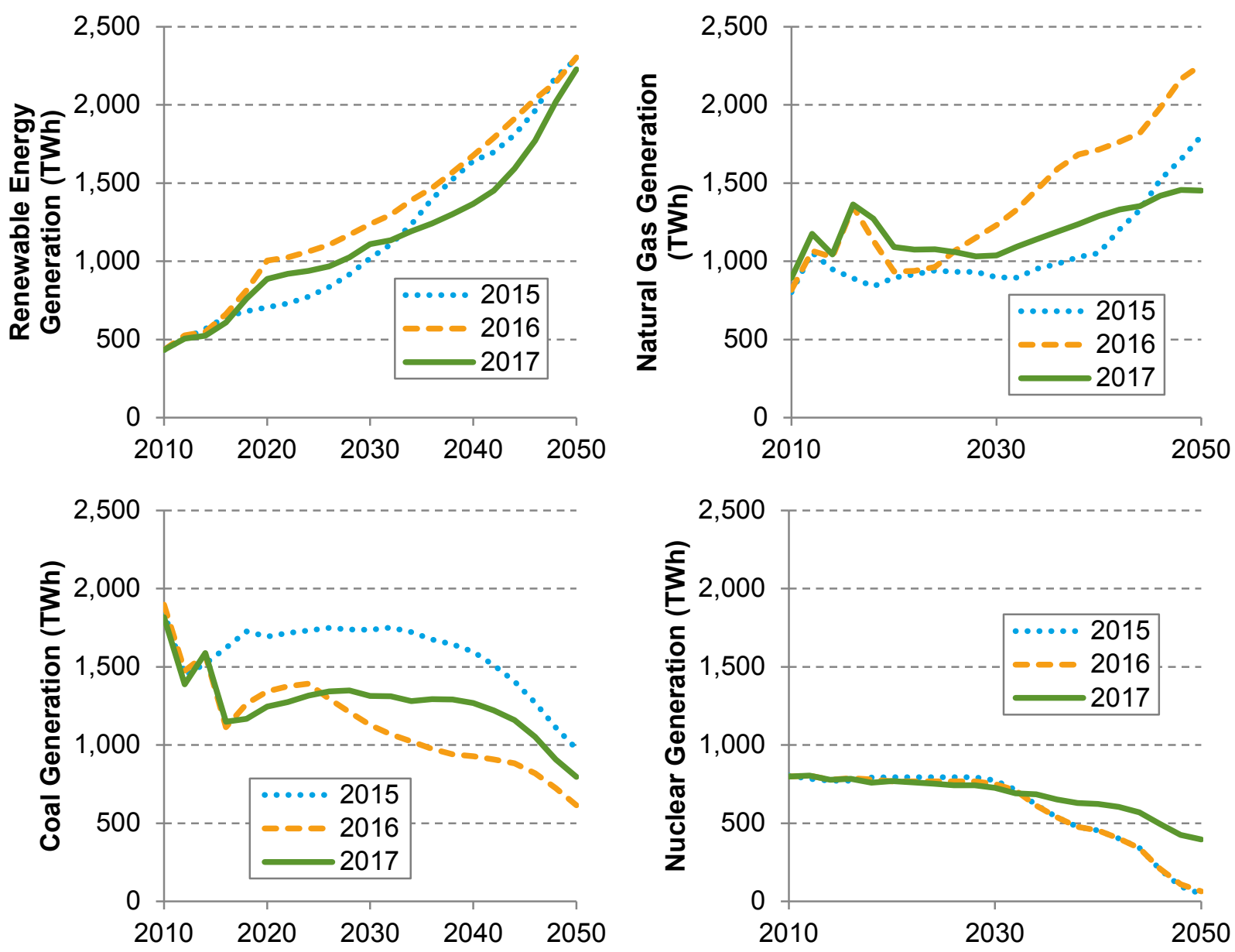

Figure 35. Mid-case projections from the 2015, 2016, and 2017 editions of the Standard Scenarios 